\title{
Women and Poverty: \\ Insights from Adult Education and \\ Pākehā Women \\ in Aotearoa New Zealand
}

\section{Lynette Cochrane}

2013

A thesis submitted to Victoria University of Wellington in partial fulfilment of requirements for the degree of Master of Development Studies

School of Geography, Environment and Earth Sciences Victoria University of Wellington 


\section{Table of Contents:}

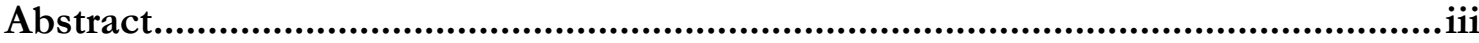

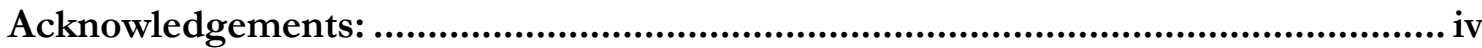

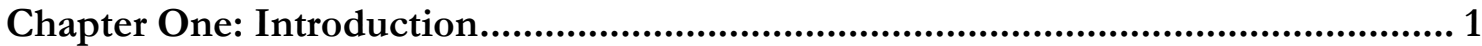

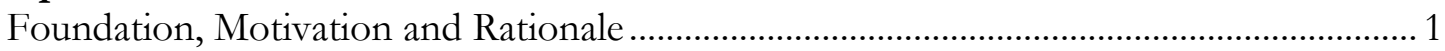

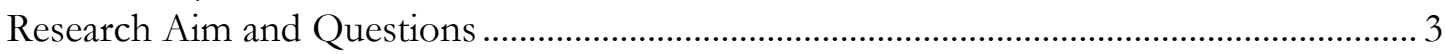

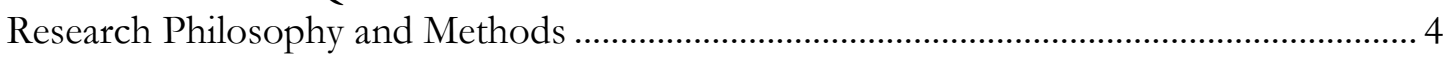

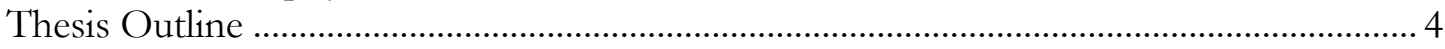

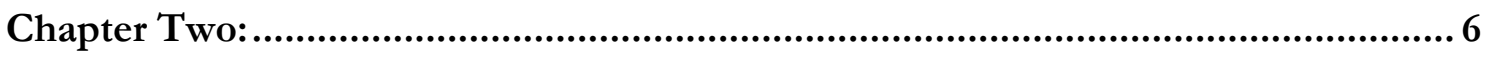

Global Overview of Women, Poverty and Education .................................................6 6

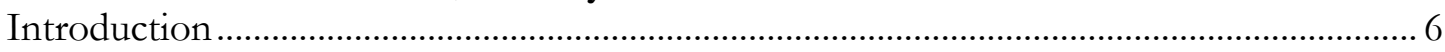

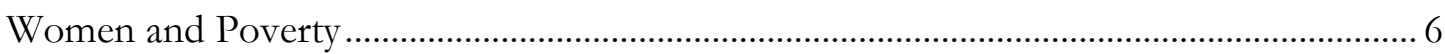

Education, Oppression and Transformation ........................................................................... 16

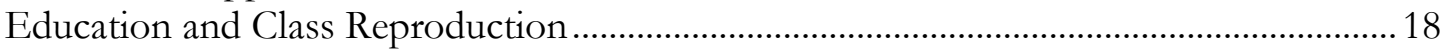

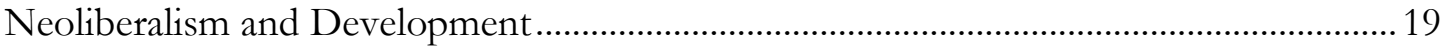

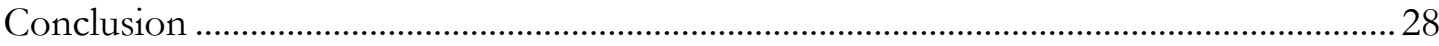

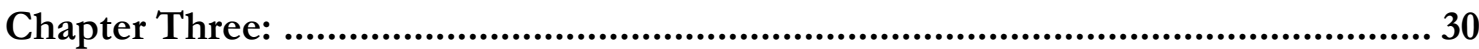

Exploring the reality of Women, Poverty and Education in a Local Context .......... 30

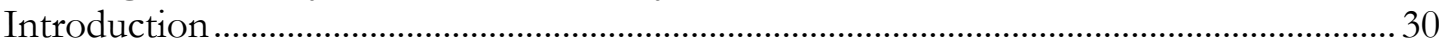

The Denial of Poverty in New Zealand ................................................................................ 31

The Recent History of Politicising of Poverty in New Zealand ............................................33

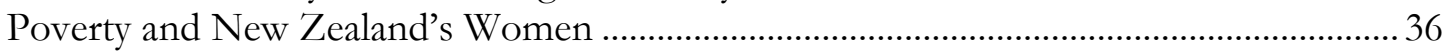

General Education Context of New Zealand ............................................................................ 41

Adult and Community Education in New Zealand............................................................. 43

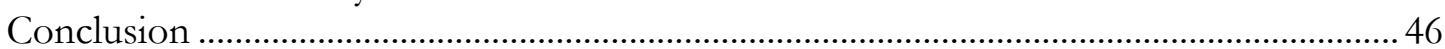

Chapter Four: Methodology and Methods ................................................... 47

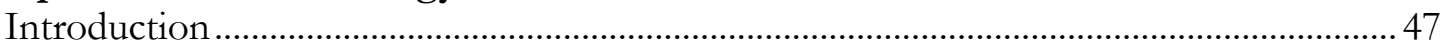

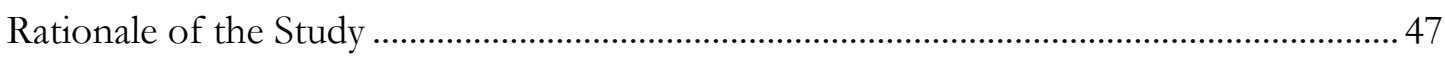

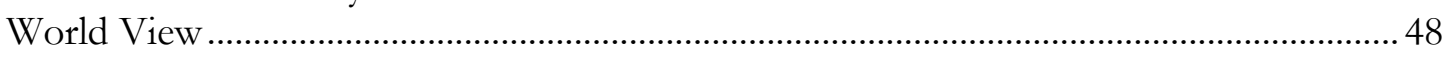

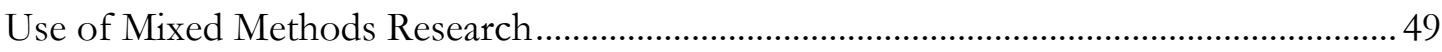

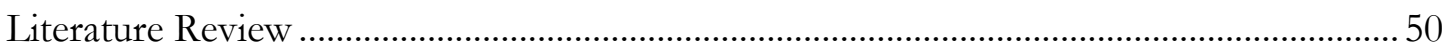

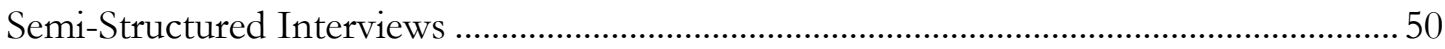

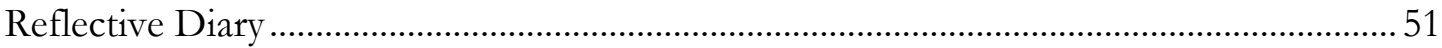

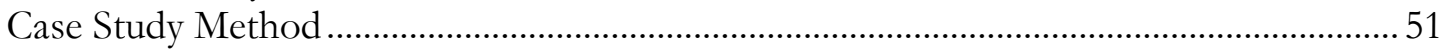

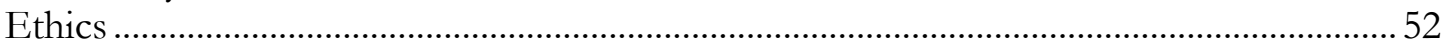

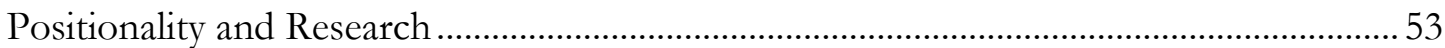

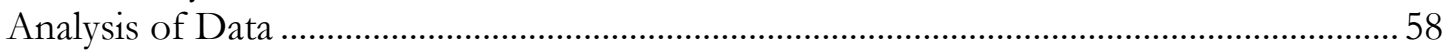

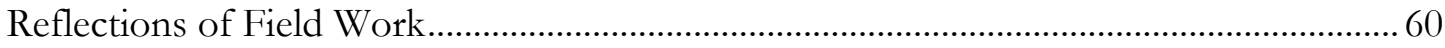

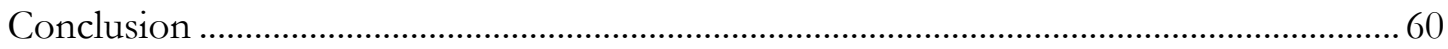

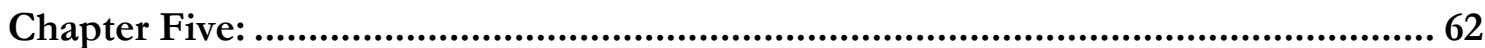

The Women's Voices - Messages from the Soul .................................................... 62

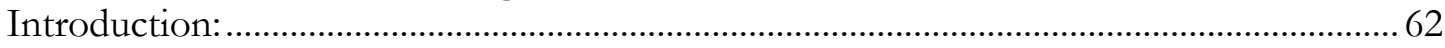

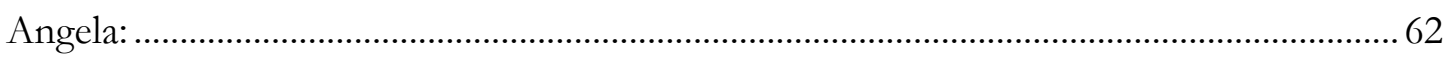

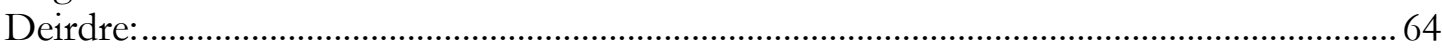

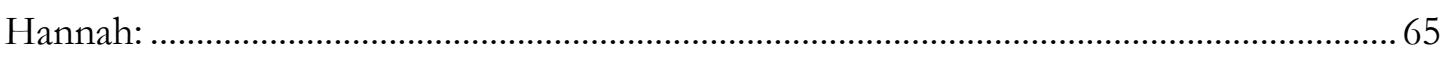

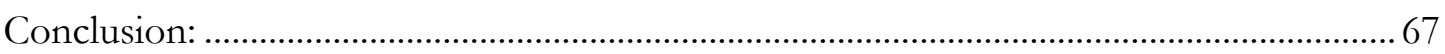




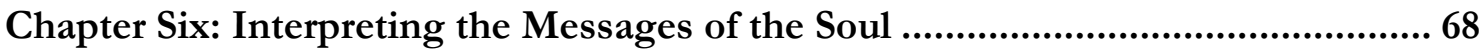

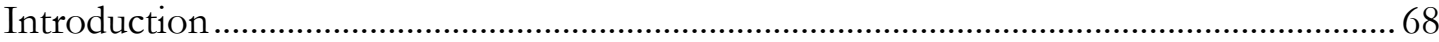

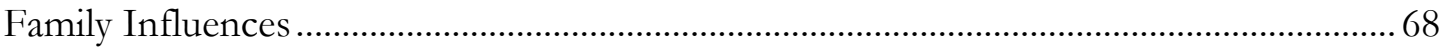

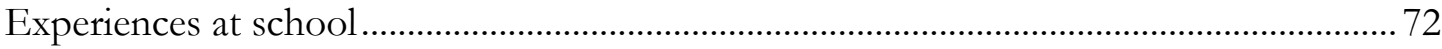

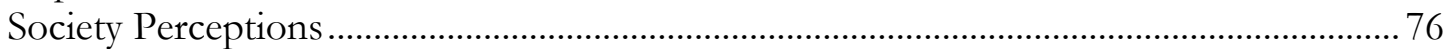

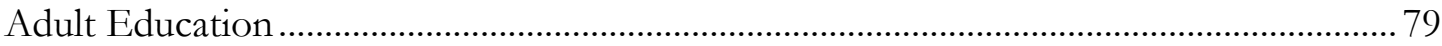

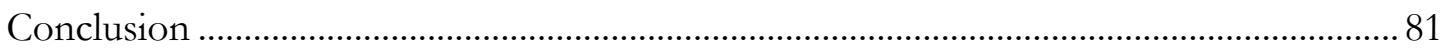

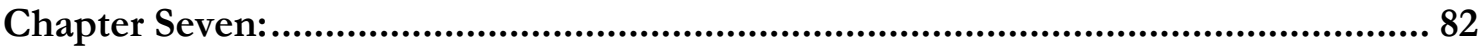

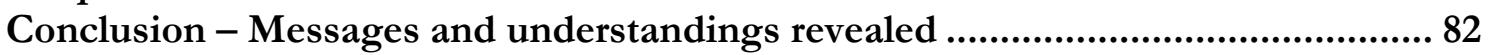

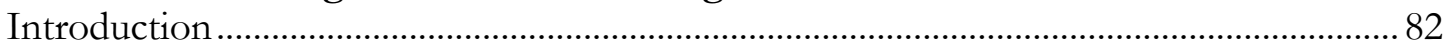

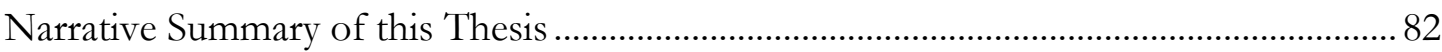

Question One: What is the relevance of the developing world literature in a developed

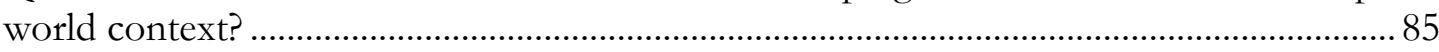

Question Two: What is the relationship between adult education and Pākehā women of

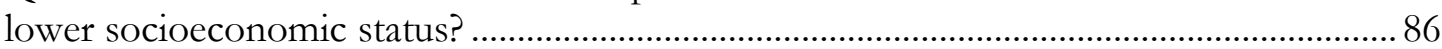

Question Three: What are the policy implications of a neoliberal approach? ....................8 87

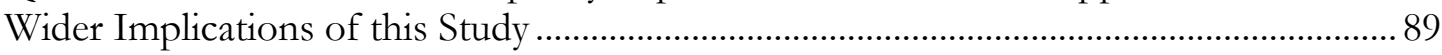

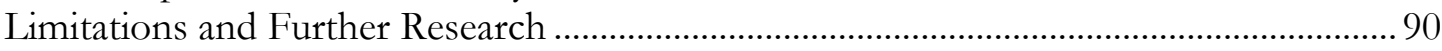

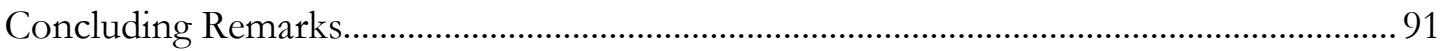

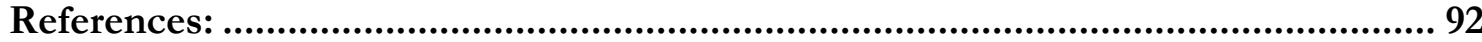

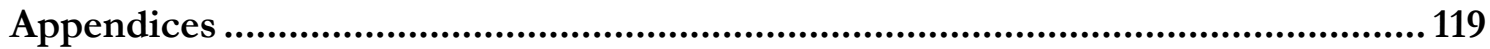




\section{Abstract}

This thesis analyses the issues of women, poverty and education. Education is viewed as a key factor enabling women to move out of poverty. This view is well established in the developing world where education plays a key role to improve life choices and opportunities for women and girls (United Nations Girls' Education Initiative, 2012). However, the influence and impact of education to improve the wellbeing of marginalised women in a developed country requires further exploration.

The interconnectedness of gendered poverty and education are explored through the stories of three Pākehā women living in Aotearoa New Zealand. Firstly, in order to understand these local experiences, the developing world literature is assessed to ascertain the global situation of women, poverty and education. Secondly, the relevant literature on women, poverty and education is examined and reflected as it relates to these concerns in Aotearoa New Zealand. Thirdly, the significance of the emergent themes is analysed as the general concerns became personal through the lived realities of three Pākehā women of low socioeconomic status.

The thesis is contained within a social constructivism framework and has been influenced by feminist methodologies. Semi structured interviews were conducted to gather knowledge and to gain insights into the reality of a marginalised Pākehā woman engaging with education to improve her self-worth and/or economic opportunities.

The research participants echoed the sentiments in the literature that their education outcomes were impacted by their family backgrounds, school experiences and there are societal perceptions concerning marginalised women with limited or no formal education. Adult education was investigated in a local context as this is the domain where women would engage with to change their education status. The arena of education including adult education in Aotearoa New Zealand is dominated by the neoliberal approach to education. Neoliberal policy in adult education does not serve the marginalised members of society nor does an education sector with a bias towards vocational outcomes. A repositioning of the adult education sector within a holistic framework which includes empowerment and improvement in the economic status of marginalised Pākehā women is required.

Keywords: Pākehā, women; poverty; adult education; social and economic status, wellbeing. 


\section{Acknowledgements:}

I would like to say a warm and heartfelt thank you to my three research partners, Angela, Deirdre and Hannah. Without these three Pākehā women there would have been no thesis. I applaud their courage and determination not only in coming forward to work with me but also making the most of their lives as they strive to be all they can be. They are inspiring role models, illustrating that a positive mind can transform lives.

To my supervisor, John Overton. Thank you for saying yes to this research and guiding me through the changing focus of the thesis. Thank you for all the 'good stuff' comments on my writing and your conviction that I would finish on time. I appreciated it when you did not run away from me when I came to tell you the latest developments in my personal life; though there may have been a fear of what I might say next. Your support through those periods assisted me in continuing this research journey and aided me in gaining the most from this academic endeavour.

To Liz O'Connor of Student Learning Support Services at Victoria University of Wellington (VUW), a large grateful figurative hug. I am so lucky to have found an advisor who I could bounce ideas off and engage with on my topic. Thank you for your 'nothing is wasted' remarks and your sensitive and constructive critiques of my work.

Thank you to Mary Redmayne, Stillwaters Community, VUW Hardship Fund, 2013 VUW Hardship Fund Equity Grant and New Zealand Federation of Women's Institutes Barbara Wood Memorial Foundation Scholarship for 2013. The financial contributions from these private individuals and public organisations are truly appreciated and lightened the financial burdens of my thesis year. Not only did I appreciate the financial assistance but the spirit and reasoning's behind the bestowing of each endowment.

To my family, I would not be the person I am today without you, so thank you for your influence in my life. To my mother and father, Jean and Jim Cochrane, I cannot tell you much I love and respect you and I am so grateful you are my parents. You have always given me positive examples of what can be achieved through hard work, commitment and resilience. The obstacles I encountered undertaking this thesis are nothing compared to the hurdles you have overcome. Your experiences have helped me gain perspective and the strength to finish this thesis and I love you both dearly.

To my first class friend Julie. Your friendship, academic insights and our putting the world to right conversations have supported me through my VUW experience. I cannot thank you enough for being such a wonderful and amazing friend. To Anna and Catherine, thank you for being beautiful intelligent women on the inside and the outside, and being supportive and understanding of all the ups and downs I experienced. To all my other friends, you know who you are, thank you so much for being there for me. To Mattie and Pete thanks for the camaraderie, mandatory coffee breaks and celebratory clapping of all achievements.

This thesis is dedicated to all women no matter their age, ethnicity, background or ability. 


\section{Chapter One: Introduction}

\section{Foundation, Motivation and Rationale}

This thesis scrutinises the intersection between women, poverty and education. Education is viewed as a key factor enabling women to move out of poverty. In the developing world education plays a key role to improve life choices and opportunities for women and girls (United Nations Girls' Education Initiative, 2012). However, the influence and impact of education to increase the wellbeing of marginalised women in a developed country requires further exploration.

Poverty is felt by indigenous women in developing countries where they experience inequality, including exclusion from education (United Nations Development Programme, 2011, p. 1). Yet this thesis challenges the common perception that poverty and limited education occurs only in the context of a developing nation and/or only to ethnic minorities. It considers and situates poverty as an issue that confronts non-indigenous women belonging to the ethnic majority in a developed country. Thus it is centred on Pākehā women as there is a need to expand the limited research and understand the effect of social and economic policies on this marginalised group (Elizabeth \& Larner, 2009). The exploration of women, poverty and education including lifelong learning within the Aotearoa New Zealand ${ }^{1}$ context is considered through the lived realities of three women. These women identify themselves as Pākehā with limited formal school educational qualifications and of low socioeconomic status.

Education is utilised as a policy to eradicate poverty for women and girls in the global south (UNESCO, 2011). As there is a high incidence of females living in poverty, there has been a feminisation of poverty (Fukuda-Parr, 1999). Gendered poverty is not restricted to scarcity of income but includes all-encompassing deprivations which permeate into other areas of women's lives for example, participating in education (Fukuda-Parr, 1999). Policies designed to mitigate inequalities encountered by marginalised women and girls in developing countries are widely accepted as relevant and appropriate. This research will broadly review the global literature on education, gender and poverty to ascertain the

\footnotetext{
1 'Aotearoa New Zealand' is often used to acknowledge the diverse and multicultural nature of the country's ethnicity. 'New Zealand' will be used hereafter as the abridged title of the country where this research is located.
} 
applicability of utilising education as an approach to combat poverty in a developed country context.

Effective gendered development approaches combine the concepts of social and economic empowerment. The twin purposes of education to improve a woman's economic status and increase her feelings of self-worth are at the core of many educational approaches (United Nations Girls' Education Initiative, 2012). Over time priorities have shifted regarding the emphasis for women as dominant development paradigms have fluctuated between equity, poverty, efficiency and empowerment approaches (Goetz, 1988). Existing data supports integrating both social and economic aspects of education to ensure women can have equity in societal and financial realms (United Nations Population Fund, 2012).

Formal education qualifications have afforded me opportunities and choices that I would have not experienced if I was uneducated. These realisations have lead to the contemplation of the power of education to improve a woman's life. Education is a vital tool in expanding a person's life and work choices and is widely used to combat poverty (Stromquist, 1990). Education for adults grew from the realisation that learning is a lifelong pursuit and hence requires resources and research (Bonal, 2004). A person's agency and capability can be increased via access to knowledge (Sen, 1999). As part of this project, an exploration of the barriers and benefits of education and the consequences of not educating women in the global south and global north was undertaken to discover the dominant issues in each locale. The themes that emerged from the local context were employed to inform the broader themes expressed in the wider literature.

This research is situated in New Zealand. As an adult Pākehā woman, it was a logical decision to examine the topics of women, poverty and education in the country of my birth. The location for this research was also influenced by my time volunteering in South America where I came to realise that while there was plenty of work to be done there eradicating or attempting to reduce poverty amongst uneducated women; it was just as true that poverty existed amongst women in New Zealand. The existence of poverty has been recognised within the indigenous and Pasifika populations of New Zealand but Pākehā women somehow miss out on being accorded similar assistance and recognition of their struggle. New Zealand is classed as a developed country under United Nation Statistics Division data (United Nations Statistics Division, 2011) . In the United Nations Human Development Index 2011 New Zealand was ranked fifth out of countries for standards of health, education and income, placing the country in the "very high human development" category (United Nations Development Programme, 2011, p. 127). The country also 
performs well in the Organisation for Economic Co-operation and Development (OECD) Programme for International Student Assessment (PISA) surveys which indicate that the country has a robust and effective education system in place (OECD, 2007). While New Zealand has positive education indicators of success, it needs to improve education for its adult population.

According to the International Adult Literacy Survey, compiled from data collected in 1998, New Zealand has an high proportion of adults who do not have the necessary 'literacy and numeracy skills to function effectively in everyday life' (Holland \& Terrell, 2007 , p. 3). Studies have also documented that adults and especially women with low numeracy and literacy levels have very limited opportunities to find employment and to change their economic circumstances (Tout, 2007).

My choice to locate my research in New Zealand and to focus centred on Pākehā women was an attempt to eliminate the concept of the 'other'. The 'other' conjures up images of poverty, ethnic minorities and those requiring assistance as residing in distance countries (Chacko, 2004). This research challenges the belief that the 'other' is only a remote entity but proposes the 'other' is also part of New Zealand society and comprises lower socioeconomic status Pākehā women seeking development through education. Consequently, this study includes Pākehā women in the discussions on poverty and how their limited income and education levels affect their lives.

\section{Research Aim and Questions}

The overarching aim of this thesis is to understand the link between Pākehā women, poverty and the influence education and in particular adult education on the wellbeing of these women. To assist in achieving this aim, I pose the following primary question which this thesis attempts to answer.

- How does education improve the wellbeing of Pākehā women?

I devised the following research questions in order to address the primary question above.

1. How applicable is the developing world literature about gender, education and poverty to the developed world? How relevant are the roles of ethnicity and gender in the way education is linked to poverty?

2. To what extent does adult education in New Zealand alleviate poverty and/or offer improved feelings of self-worth? 
3. What are the policy implications of the neoliberal approach to adult education in New Zealand?

\section{Research Philosophy and Methods}

At the heart and soul of this project are the voices and experiences narrated to me by three Pākehā women of limited economic means who live in Wellington, New Zealand. The stories of my three research partners ${ }^{2}$ were recounted and recorded in one to one semi structured interviews. This method was chosen to give privacy to each respondent as I was aware of the sensitivity of the topics under discussion and the courage it took for them to speak of their experiences. As I reflected on their stories, I considered my role as a researcher and how my own experiences and beliefs would impact on this research project. My thoughts and deliberations were noted in a reflection diary with these observations adding clarity and connectivity to this thesis. My epistemological approach is one of social constructivism and has been influenced by feminist theory. I hold the opinion that our reality is subjective and employed qualitative methods to inquire into social and cultural aspects of this study. Quantitative methods were included to examine the economic and objective topics in this project, in order to add depth and robustness to my findings.

\section{Thesis Outline}

The relevant global literature regarding women, poverty and education are presented in chapter two. The complex relationship between women and poverty is considered as are the different approaches to eradicating gendered poverty. The possibilities of education being used as a tool to oppress women and to reproduce class divisions are highlighted and analysed. The influence of the dominant theory of neoliberalism on education is evaluated as are the repercussions of this theory on poverty. The interactions between poverty and education are considered to gain insights as to why education policies designed to eradicate poverty have been not completely successful.

The global becomes local in the context provided in chapter three. This chapter chronicles the history of poverty in New Zealand and how women have been affected by this issue. Similarities and differences between Māori, Pacific Islanders and Pākehā women in poverty are noted. These comparisons are used to gauge whether policies and approaches to poverty encompass all low income women in this country, despite their ethnicity. The

\footnotetext{
2 The term 'research partner' is used throughout the thesis to acknowledge and reflect the interactions between the researcher and participant as ones of a collaborative partnership and participation in the construction of knowledge recorded in this thesis.
} 
economic and social costs of women not being educated in New Zealand are then analysed. Finally the dominant approach of neoliberalism to the adult education sector is examined, as this is the educational arena in which women engage to improve their education status.

Chapter four introduces the methodology of this research and places emphasis on the personal dimensions of research. The stimulus of this study and my world view are explained as both underpin the 'why' and 'how' I have carried out this project. Researching ethically was paramount to me as was transparency regarding the influence of my positionality as I conducted this research. In order to analyse the information generated by this inquiry, I employed qualitative and quantitative tools aligned with the mixed method approach to research to enrich and enhance my findings.

In chapter five, the personal gives way to the soul. The experiences and lived realities of three Pākehā women who identify as low socioeconomic status and left high school without formal educational qualifications are recounted in this chapter. Chapter six continues the narrative of these women as it compares and contrasts their life accounts, from which local themes with a global message emerge.

This thesis concludes by assembling the themes that materialised from this study and recounted in chapter seven. The questions posed in this project are addressed as are the wider implications of the study's findings. 


\section{Chapter Two:}

\section{Global Overview of Women, Poverty and Education}

\section{Introduction}

Education is imperative to women's social and economic wellbeing, this chapter will analyse whether education empowers and/or alleviates gendered poverty. This chapter will review the relevant literature pertaining to education for women within the context of poverty in the developing world. The advantages of educating women on an individual and societal level are considered as are the negative consequences of not educating women. In order to engage and explore how women's agency and wellbeing could be increased through education, the work of two pre-eminent education theorists, Paulo Freire and Pierre Bourdieu are discussed. Their theories challenge the social structures and inequalities in education and give insights into how education has the power to liberate, oppress and reproduce class structures in society. Lastly, the dominant and influential development theories utilised to eradicate poverty and impact positively on women's education are investigated and the benefits and limitations of each theory assessed.

\section{Women and Poverty}

The relationship between poverty and gender is clarified under a gender lens. The term gender is used to explain the institutionalised and socially and constructed identities that are used to convey the differences and inequalities between men and women (Gerson, 2004). A gender lens is used to examine how the social position of a woman influences her life choices. A gender perspective can examine how her gender impacts on her bargaining interactions and possibilities for transformative outcomes (Gerson, 2004). As Human Development Reports from the United Nations (UN) illustrate, there is a gender bias in poverty (United Nations Development Programme, 1990) with "most of the world's poor being women" (A. Scott \& Foster, 2008, p. 369). International institutions such as the World Bank have widely reported the disadvantages that women living in poverty experience. Furthermore, women are most likely to bear the majority of work done in households, they will have the least access to remunerative activities and will be less educated than men (World Bank, 1990). 
The cost of women living in poverty delays economic progress, both personally and nationally (E. M. King \& Hill, 1993). Poverty alleviation policies with a gender focus positively impact on women's economic and social position (Staudt, 2008). Strategies need to move away from treating women as dependent, subordinate social actors. Policies should see women as active agents, not passive and reliant on the state to effect change in their lives (Kabeer, 1997).

It is important to evaluate how effective poverty eradication policies are for women. Evaluation should be accompanied by the prioritisation of these policies and programmes in development interventions (T. P. Schultz, 1993). These evaluations will assist policy makers in ascertaining whether women are being further burdened as they work toward improving their economic status (Beazley \& Desai, 2008). In order for the most effective policies to be implemented, the involvement of women affected is necessary at the conception and implementation of these programmes.

\section{Gender Focus in Development}

The omission of women from development strategies was challenged in the 1970s when authors such as Boserup (1970) lobbied for equal opportunities for women, which is at the crux of the Women in Development (WID) approach to development. Liberal feminists writers viewed equality for women as economic in nature and education was used to increase a woman's earning capacity (Rathgeber, 1990). The WID movement was critiqued for emphasising economic opportunities, having limited transformative capacity, and for not addressing women's subordination nor the importance of race and class in women's lives (Razavi \& Miller, 1995).

Women and Development (WAD) grew out of the analysis of WID in the 1980s. NeoMarxist feminists used the WAD approach to investigate the power relations between men and women, where women's oppression grew out of a capitalist society. Value was solely assigned to productive work and reproductive work was excluded (Peterson \& Runyan Sisson, 1999). As reproductive work has been assigned to women and is not given a monetary value, education for women has not been a priority as the return on the investment is regarded as minimal (Rathgeber, 1990). The powerful influences of a woman's class, race and ethnicity divisions on a woman's social status were not considered under WAD approach (Young, 2008). 
Attempts to transform power relations and issues of status and power in society started to be addressed by Gender and Development (GAD) in the 1990s. Third World Feminists and Socialist Feminists in the West had a two pronged approach to these problems. They investigated firstly the material conditions and class positions and secondly the patriarchal structures and ideas that define and maintain women's subordination (Goetz, 1988). GAD philosophy called for the emancipation and empowerment of women and challenged the gender biases and institutional structures in education which perpetuates class distinctions (Cornwall, 1997).

The politics of identity are magnified when using a gender lens to reflect on development theory and using the corresponding feminism theory illuminates the ways we can deconstruct gender issues in development (Desai \& Potter, 2008b). The need to engage in fundamental 're-visioning' is essential when using a gender lens on education and development. Power relations and inequality pervade the contexts in which these visions are generated with patriarchal power structures traditions evident in developing countries. This inequality is evident in the levels of illiteracy in women.

\section{Gendered Illiteracy}

Literacy is seen as a fundamental instrument for survival and essential for advancement in an ever growing technological global community. However, UNESCO reported in 2010 that women made up 63 to 64 per cent of the 775 million adults worldwide without basic literacy skills. This ratio scarcely changed over the preceding two decades (UNESCO, 2012). Moreover, the true extent of illiteracy may be under recorded as the measurement of literacy varies from country to country.

Women's marginalisation can be manifested in the limited occupation opportunities available to oppressed women, resulting in low skilled and low paid employment. Illiteracy is not the same as ignorance nor should it be used to define a woman's ability to affect change in her life or limit her possibilities (Stromquist, 1990). The subject of adult literacy is well documented in development literature, though it does not always differentiate between genders. Authors, such as Stromquist (1989) have argued that the severity and the extent of illiteracy amongst women in developing countries has not garnered the appropriate attention it deserves from researchers. 


\section{Gender Equality in Education}

Education is being used to address the issue of inequality and is a priority in development as preserved in the third goal of the Millennium Development Goals (MDGs): to 'promote gender equality and empower women' (United Nations Development Programme, 2012). The encompassing term of gender equality refers to the outcomes for males and females to be the same and recognises the path for each may be different (Kelly, 1987). Both genders should be given the same opportunities, rights and choices with equal participation in society. This will include the transformation of power relations between the genders (Cardoso, 2011). Men and women are to be actively engaged in this transformation as equality will not occur without both parties being motivated and committed participants in the process (United Nations Population Fund, 2012).

\section{Gender Analysis in Education}

For gender equality to be realised, gender analysis is employed as a critical step in ascertaining the impact development programmes, policies and gender mainstreaming have on the existing disparity (Canadian International Development Agency, 2007). There are five main frameworks utilised in development programmes that are adapted and implemented in education projects and each has a different focus and priority. The Harvard Analytical Framework emerged in the early 1980s, and is useful in evaluating how access to educational resources can affect a woman's economic status (Leach, 2003). The Women's Empowerment Framework was developed in the early 1900s by Longwe (1991) and can be used to examine the empowerment benefits of education. The value given to productive, reproductive and community work of women can be studied in the gender division of labour under the Moser Framework (Moser, 1993). The Gender Analysis Matrix can be utilised to track gender dialogue and assessment in education (Parker, 1993). The social relations between men and women and reproduction of inequalities within institutions is investigated within the Social Relations Approach pioneered by Naila Kabeer (1994). It is evident in the literature that no universal gender analysis strategy can be implemented in every setting; instead a holistic approach is required to achieve gender equality in education (United Nations Girls' Education Initiative, 2012). There are various social benefits to education of women and girls, including impacts on population, legal access, political representation, property rights, economic participation and accessing resources to exit a violent relationship. 


\section{Connection between Population Growth and Female Education}

Research findings strongly link education achieved by women to slowing population growth, stating it has a significant influence on controlling birth rates (Nussbaum, 2004). Education has also been found to be a central determinant of child survival (Lutz \& Samir, 2011). Studies have concluded that more educated women have a stronger bargaining position within their household which leads to them have an increased say in decisions on how many children they will have. Educated women enjoy greater access to medical care which results in increased overall health; they experience higher infant survival rates and have fewer children than uneducated women. Education attainment of girls must be continued past primary education to participation in secondary education to effect a meaningful reduction in fertility (Lutz \& Samir, 2011) .

\section{Negotiating the Legal System}

Literacy is imperative to effective functioning in politics, as education is crucial to be able to navigate the complex and convoluted waters of a country's legal system (Nussbaum, 2004). In order to apply for welfare, start a business or to sign a contract, women must able to read and comprehend the legal aspects of such matters (O'Donnell, 2004). If she is knowledgeable, she is able to minimise the chances of being taken advantage of and maximises the benefits of the situation in her favour. To file a complaint including domestic violence charges, written forms must be completed and if the woman does not have the ability to traverse this legal process or support from a legal NGO, then her case will not be progressed (Nussbaum, 2004). When a woman is competently and efficiency dealing with matters of a legal nature, she is engaging with the democracy of her country and affirming her political and civil rights (Smulovitz \& Peruzzotti, 2000).

\section{Women and Political Representation}

The under-representation of women in politics has come under increasing scrutiny by scholars in the last two decades, with participation rates varying greatly between countries (Waring, 2010). Paxton, Kunovich, and Hughes (2007) report that in 2006, women made up $17 \%$ of national parliaments globally, and only 30 women were in the top echelon (Paxton \& Hughes, 2007). In many countries the dominant belief until recently was that politics were the sole domain of men. Cultural, family and illiteracy barriers prevent women from participating in the political arena (Chafetz \& Dworkin, 1986). Academics such as Burns, Schlozman, and Verba (2001) have commented on the effect that limited resources, religious beliefs and human capital of women can have on their representation in politics. 
There is a strong argument for political participation of women in politics as they bring varied interests and priorities than men to legislation. To be part of the political system and to be effective domestically and on an international stage, women need to be educated Thomas (1991).

\section{Property Rights and Women}

Economists have argued there is a correlation between a clear and defended definition of property rights and increased wellbeing of the poor (De Soto, 2000). Land ownership can be a contentious issue and is extremely problematic in developing countries with land keenly contested in rural areas. Societies that follow patriarchal traditions often see the male leaders practising the politics of exclusion to groups with less power especially women (Toulmin \& Quan, 2000).

Where a country has implemented statutory laws pertaining to property rights, women with basic education levels may find it challenging if not impossible to engage in negotiations due to a lack of education (Joireman, 2000). Lack of knowledge regarding women's rights under statutory law allows the continued exploitation of women under customary laws (Joireman, 2008). There has been an assumption by scholars that when property rights are legislated, these decisions are enforced by an efficient and effective state. This erroneous belief has led to misplaced policies initiatives which have not improved the position of the marginalised in regards to their property rights (Yngstrom, 2002).

\section{The Intangible Benefits of Women's Education}

There are the tangible advantages of education such as greater job opportunities, negotiating the legal system, political representation and greater property rights. There are intangible benefits as well. These unseen but vital outcomes of education include the ability to generate and maintain social relationships where women are equal with others, where their level of self-respect is positive and expanding (Nussbaum, 2000). Education is a powerful force in aiding a woman's mobility, be it access to jobs or access to political processes (Nussbaum, 2003). The participation in the political process is not only a step toward reducing gender disparities. It is also a positive example for their daughters of one of the benefits of being educated. Bayard de Volo (2006) has remarked on the increase of control a woman can have over her own health and nutrition as a result of being educated. This not only develops her capabilities, it intensifies her personal development and growth and connection to humanity. 


\section{The Power of Networking}

Education and literacy have been strongly linked with the ability of a woman to move outside the house to meet and work collaboratively with other women. The capacity to meet face to face with other women increases their social networks and escalates the bonds of solidarity. Education also fosters women's ability to participate in larger activities concerning women where communication is carried out via the internet, email and other forms of written correspondence (Nussbaum, 2004).

The inclusion of women in social networks assists these women in asserting their identity and rights. Successful networking does not depend on status or wealth. The benefits of these networks for women living in poverty include the ability to build capacities and the power of women to design projects of which they are the recipients (Gurumurthy, 2006). Networking increases the sense of community and contributes to women's economic security when sharing of goods takes place (Belle, 1983). Wellbeing of network members increase when social networks are fully utilised and these networks are essential strategies for coping with the difficulties women face on a day to day basis (Kebede \& Butterfield, 2009).

\section{Education and Domestic Violence}

A restricted education can limit avenues available to women who need to exit an abusive relationship. This deficiency of education results in limited options available to provide for themselves outside the relationship (Nussbaum, 2004). Studies such as that of S. L. Martin, Tsui, Maitra, and Marinshaw (1999) illustrate the link between educational attainment, poverty and family violence. The true prevalence of domestic violence of women living in poverty differs depending on whether the incidents are reported by women, men or from both parties. Researchers have noted possible bias resulting in possible over or under estimations (Moffitt et al., 1997; Schafer, Caetano, \& Clark, 1998).

Subordination of women within a patriarchal ideology is established in areas such as child bearing decisions with access and use of contraceptives linked to sexual promiscuity and the penalisation of abortion. Other social norms controlling a woman's sexuality are her condition of virginity at the time of marriage, seclusion from others and her physical mobility (Stromquist, 1990). 
There are corresponding levels of low education in countries when girls marry at a young age. Studies have noted that child marriage affects the educational aspirations of girls and the education her family views as relevant for her. As a result the girl/woman has limited bargaining power within her husband's family for resources such as food or medical treatment, thus furthering her husband's control over her. Her contribution to the family is perceived as being limited. Her life is given little value by others and herself with the real possibility of abuse against her person and mind (Jejeebhoy, 1998).

\section{Impediments to Educating Women}

Resistance to educating women is found in many developing countries. This opposition can stem from deep-rooted customs and established power relations in some communities (Gurumurthy, 2006). A woman seeking education could be construed as a threat to the existing power regime, resulting in any attempts to seek out education being thwarted by authorities via extreme or moderate means (Bagchi, 1997). The avenues available for women to explore creativity and humanity and to engage in political and economic activities increase exponentially with an increasing level of education. Her struggle to pursue and achieve the access and depth of education necessary to fulfil her potential in these domains will be immense. These efforts may in turn be met with a corresponding intensity of resistance by those in power who perceive her actions as an attack on the status quo (Nussbaum, 2004).

The status quo may not be able to be altered due to restrictive economic realities which limit a girl or woman's ability to participate in education for purely financial reasons. Parents may support the ideology of education equality for both boys and girls but can only afford to send one child to school. In many developing countries due to the higher return on education investment in boys, the male child will be assigned the economic resources available in the family for education (Agarwal, 1997).

Marglin and Marglin (1990) argue that there are nonliterate cultures in the world which should be valued, treated with respect and prized for their humanitarian achievements. The authors claim that to introduce literacy into these cultures violates them and transforms their structure, resulting in arts such as oral poetry being lost. This argument is refuted by other scholars who maintain oral poets are mostly male or highly educated wealthy women and that illiteracy may very well affect women's lives inherently as it exposes her to injustices and desolation (Nussbaum, 2004). 
The call from within a culture for women to be educated can be opposed by those with influential and powerful opinions. These voices brand this internal demand as foreign, thereby discrediting and rejecting it. As Bagchi (1997) reports, this has been a consistent theme of resistance to educating women. Traditionalists call such internal reforms as 'English' and 'Western' in nature thereby, classifying them as unwelcome and unacceptable.

Traditionalists may reject education for women but they are not the only ones resisting the opportunity to become educated. Rejection can come from women themselves (Bagchi, 1997). Women may accept theories that men are superior to women, women have been conditioned from girlhood to believe this as a truth. This conditioning is an example of 'adaptive preference' being translated as traditional and cultural norms. As Elster (1985) argued, girls may view being educated as an unattainable goal so do not reach for the possibility of being educated. Bagchi's (1997) study of girls in Bengal uncovered five other possibilities including 1) girls did not voice their wish to be educated: 2) they were not fully informed of how a lack of education would impact on their political and economic opportunities: 3) early marriage restricted opportunities to utilise education and increased the likelihood of abuse from the new family: 4) learning was difficult and not fun and finally: 5) decides education will not compose part of her life story and discounts its relevance.

\section{Combating Opposition to Women's Education}

There has been much debate in nations on the merits and pitfalls of compulsory primary education for children. International literature indicates the attainment of education positively impacts on a woman's life. Compulsory school attendance is used to combat resistance to a girl's right to educated (Mehendale, 1998). Literacy programmes carried out in rural areas which are linked to economic empowerment of women have a high success rate. Furthermore, rural women who receive education and increase their economic value to the family, thus also benefiting their husbands (Mehra, 1997).

In regions where matrilineal property inheritance and the custom of residing with the wife's family are accepted cultural norms, there is a higher value given to a woman's life (Nussbaum, 2004). The importance given to property ownership is an illustration of how critical the ability to be a property owner impacts on the empowerment and worth of a poor woman's life (Nussbaum, 2004). The financial capability of a family can restrict the chance of their female children receiving an education. Options such as the adoption of 
flexible school hours and free lunches have been lobbied as possible solutions. Flexible school hours would allow children to assist their parents at home, or lift the burden of providing a meal off parents while children would receive an education (Admassie, 2003).

As Drèze and Sen (1995) observed, the educational fortune of a nation is dramatically affected by the approach to literacy the government takes. The difference in approaches are illustrated in the diverging literacy rates as shown in 2000 between Sri Lanka 89 per cent of women were literate compared to 45.4 per cent in India (Human Development Report, 2002). The importance of basic education is borne out in a country's literacy figures, with basic education widely accepted as being an area that governments need to encourage as a basic right for citizens (United Nations, 2012). Proposals to address lack of education in a country include special funding for areas that have previously been neglected, for the removal of school fees and the requirement for children to wear uniforms. Scholars have challenged governments to identify the obstacles to female education and to put the solutions into effective and efficient educational policies. These domestic policies would in turn be supported by international NGOs who could deliver further assistance, research and experience to programmes specially designed to reduce the worldwide problem of girl's and women's education (Nussbaum, 2004).

There is general agreement that gendered poverty exists and the situation requires action to alleviate this poverty. One tool to bring about this change is through women and girls engaging in education. Not only does a woman's poverty impede her individual development but also the society, nation, and the global community in which she resides. There are far reaching consequences of educating women these include but are not restricted to addressing the inequalities in education and development. An educated woman is more likely to participate in society in political and business arenas. Maternal health is increased with the level of education a woman receives and she has more avenues to exit an abusive relationship. There are many intangible benefits of educating women, not the least of which is improving her self-worth and agency. 


\section{Education, Oppression and Transformation}

Paulo Freire (1921-1997) in his work Pedagogy of the Oppressed laid bare the connection of education, oppression and transformation. Freire's work is highly relevant in the context of this thesis as he addresses the marginalisation of people and how education can be used to enforce or dissipate this subordination. He identifies a 'culture of silence', where a person may be ignorant of her true reality. However by entering into dialogue with others, this ignorance can be transformed with her acting as her own agent in taking action that will impact on that reality. Freire identifies oppressors as those who maintain the status quo. They embrace the concept of money being the only true measurement of worth reducing all objects to their purchasing power, thus dehumanising others, these others are categorised as the oppressed. Oppression contains the identifiers of being forced to adapt to the world, reproducing what is expected of them with no input from them and the struggle to humanise themselves and the oppressors.

Education, Freire argues, is a tool of oppression where the dominant dogma is the 'banking concept', where teachers are the depositor to fill the student or empty container with knowledge that the teacher deems important. The student is in the submissive position of having to memorise information, the more passive and less analytical they are the better they perform in this education system. Freire contends that a more socially emancipatory education philosophy is the 'problem-posing education'.

Freire further argues that for true transformation to occur within education and by education, the oppressors must also be saved as they too have been dehumanised by their actions by oppressing others. He contends that the oppressed must liberate themselves and the oppressors; if they do not do this they too become part of the oppressor majority. For oppression to end, the lived experience and consciousness of each person must be valued and applied before emancipation for all can be achieved. It is understandable that in this liberation struggle the oppressed may take on some facets of the oppressor as this is the only example they have been shown. Only when learning and interpretation of reality contains critical thinking, can this false reality be challenged and discarded (1988).

This philosophy embraces the liberation of humanity, holds that people are conscious beings who want to be more than they are and challenges the dichotomy of the educated (teachers) and the uneducated (students). Education under this framework is inclusive and values the learning experiences of both the student and the teacher. Problem posing 
education is liberating as it asks the individual to be consciously involved in learning, for them to be an active participant in constructing their reality. This awareness and connection allows the humanisation of the oppressed to ensue while simultaneously encouraging the practice of education to be used as a pathway to freedom.

Dialogue between student and teacher is essential. Freire argues that people do not create in a vacuum but use words, actions and reflections to gain understanding and the ability to transform their reality. True dialogue embraces critical thinking where the individual is able to construct her or his own ideas and through praxis and communication the ability to transform them. Freire examines the opposing frameworks of antidialogicity and dialogicity in Pedagogy of the Oppressed. He views the antidialogicity framework as being oppressive with its characteristics of conquest, divide and rule, manipulation and cultural invasion which uphold the status quo. The dialogicity framework is viewed as liberating as it welcomes co-operation, union, organisation and cultural synthesis all of which are important elements in over throwing oppression.

Paulo Freire's work although accepted as influential in the foundation of critical pedagogy has also been criticised as to its usefulness in poverty alleviation and education for women. Weiler (1996) questions Freire's treatment of patriarchy and its connection to oppression, with other authors seek clarification on the connection of ethnicity, class and oppression (P. Taylor, 1993). Ladson-Billings (1997) identified a deficiency in Freire's engagement with white male privilege and its importance over education outcomes.

Pedagogy of the Oppressed may have dissenters, but they cannot dispute the reach and influence of this text on education, politics and liberation. This author has lived the experience of poverty and acknowledged the effects of this deprivation on his education. Freire stimulated debate and opened the space for educators to use education as a method of social and economic transformation. Freire's work is powerful as it challenges the belief that market forces should reign supreme over critical thinking and active social engagement of the individual in her or his reality. Education cannot be neutral; it can instead be used to address inequalities and to positively impact on a person's agency. Paulo Freire's work is relevant in the developing and developed world as it contains the love of life where the self and the other are respected, thus freeing the individual and the community from tyranny of ignorance. 


\section{Education and Class Reproduction}

Pierre Bourdieu (1930-2002), a French sociologist, was a prolific writer and is best known for his work on education and its role in the reproducing class relations. Bourdieu's philosophy is used in this thesis to investigate the interconnection between class and education. Bourdieu (1994) observed that conflict and inequality in society are present in all class types. Bourdieu viewed the construction of class, as a space of differences rather than a division between classes. Inequalities occur when one group imposes authority over another with this dominance being proclaimed physically and symbolically (1994). Societal distinctions of different social classes are turned into educational distinctions through the school structure. The distinctions of merit found in education then reproduce, legitimise and normalise existing class structures in society and further entrench class inequalities (DiMaggio, 1979).

Bourdieu (1971) developed the concept of field to explain the dynamic relationships between actors and organisations engaged in the complex production of social and cultural structures. These 'fields' are autonomous from the wider society, have their own hierarchies and rules, and are the arenas in which social actors experience conflict between each other. As actors struggle to assert their position within these fields, they must navigate a complex web of social relations to achieve their goals (DiMaggio, 1979).

In order to comprehend our social reality, Bourdieu (1989) explored the notion of habitus to "demonstrate the ways in which not only is the body in the social world, but also the ways in which the social world is in the body" (Reay, 2004, p. 432). Habitus is used as a method to relate objective structure to individual activity and acknowledges that individual agents have dispositions namely their perceptions, thoughts and actions. Social agents use these dispositions to respond to the objective conditions or fields they encounter.

"A system of lasting, transposable dispositions which, integrating past experiences, functions at every moment as a matrix of perceptions, appreciations, and actions and makes possible the achievement of infinitely diversified tasks, thanks to analogical transfers of schemes permitting the solution of similarly shaped problems" (Bourdieu, 1971, p. 83).

As Reay (2004) comments, Bourdieu utilises habitus to resolve the antagonism between subjectivism and objectivism. It is fundamental in understanding the dualisms of agency- 
structure and it explores the relationship between the micro-macro. Habitus is used to investigate how prejudices and opinions can be generational in nature and become embodied as unconscious beliefs, forming part of the internal structures within the social agent (J. Scott \& Marshall, 2005).

Bourdieu diverges from the accepted economic view of capital, as he places value on the symbolic, cultural, social and linguistic as well as the economic power it can access. As DiMaggio (1979) notes, transformation of capital is entwined with the educational system. An individual's social and economic capital are interlinked and impact both her success in the educational system and employment chances (J.-S. Lee \& Bowen, 2006). Her cultural capital is influenced by language as Bourdieu (1977) classes this as a tool with two possible facets. Firstly it can bridge social divisions by promoting communication between different groups. Secondly it is an instrument of exclusion and power to maintain the social distance between the dominant and dominated groups.

A crucial source of power is a person's symbolic capital which can be used to reproduce class divisions. Symbolic power can be gained through language and status and can construct a reality in which the dominated are unaware of their submissive position, or their complicity in its construction (Bourdieu, 1991). A holder of symbolic capital exercises symbolic violence when the power associated with the capital is used to alter the actions and perceptions of dominated social agents who have less symbolic capital. This symbolic violence is incorporated into the social structures as the subjugated agents accept their position in the social order and act accordingly (Bourdieu, 1994).

Bourdieu's sociology has been critiqued and his gendered habitus has been questioned as sex/gender and race are in danger of being secondary in importance to social class (Lovell, 2000). Bourdieu's body of work may have attracted criticism but he was a leading intellectual who sought liberation for the subordinated in society. His non-academic background has given him perceptive and insight into the social classes he spent his academic career investigating (J. Scott \& Marshall, 2005).

\section{Neoliberalism and Development}

A significant theory applied to education and development policies is neoliberalism. Neoliberalism is a political ideology that embraces and promotes economic liberalism: the state is to withdraw from the economy and leave any interventions to self-regulating market 
forces and the individual (Thorsen \& Lie, 2006). McMichael defined neoliberalism as a "philosophy positing an individual instinct for economic self-interest, justifying elevation of market principles as the organising principle of society where private interest trumps the public good” (McMichael, 2008, p. 341). As Gerald Berthoud wrote (2010, p. 78) "efficiency is preferred to social justice as a means to ends but also sometimes as an end itself'.

Under neoliberalism, development policy saw partial withdrawal of the state in the economy with this void being filled by the market alongside 'self-interested' parties making the decisions on how resources were allocated (Peet \& Hartwick, 1999). It has been argued that all states have embraced some form of neoliberal theory and that 'champions' reside throughout government and academia (Harvey, 2005).

One focus of neoliberalism is for the living standard in developing countries to be improved. Market liberalisation has been touted by neoliberals as the best course of action to improve and stimulate economic growth and reduce poverty (Kiely, 2007). Neoliberalism has also influenced education. Under neoliberalism, education is seen as a commodity within an input-out system (Olssen \& Peters, 2005). Educational institutions have been reconfigured to deal with increased competition and the requirement of meeting performance goals under the neoliberal tenure (Davies \& Bansel, 2007). To remain competitive in this environment, organisations need to attract students who are affluent enough to meet the financial costs of education and to produce graduates with increased human capital.

\section{Limitations of Neoliberalism and Poverty}

Economic cracks in the façade of neoliberalism have appeared and these cracks are equal to the level of immersion of neoliberalism a country has adopted. Huber and Solt (2004) observe developing nations experience less economic growth and suffer increased levels of inequality coupled with intensified poverty levels under neoliberal economic policies. The failings of neoliberalism are borne out in the economic costs to society. Economic costs are then magnified in the social costs of poverty as the construction of a strong social safety net is absent in neoliberalism philosophy (Huber \& Solt, 2004). Critics have called neoliberalism an enslaver of impoverished people rather than a liberator (Klak et al., 2011), with Ravallion (1995, p. 416) succinctly commenting "economic growth is clearly not all that matters to reducing poverty". 
Another fundamental tenet of neoliberalism with its supply-side economics influence is the 'trickle-down' effect. Proponents of this theory believe that a reduction in taxes for businesses and workers will result in economic growth (Bliss, 1981). Their logic expects businesses to invest while the wealthy and workers spend the extra income, hence stimulating the economy. The flaw in this logic was exposed when lower tax rates did not reduce income inequalities but rather exacerbated them. The result is an increase in absolute poverty without the benefits of the 'trickle-down' effect being realised (Toporowski, 1993). Qureshi (2008) suggested increased investment in human development via education to allow the economy to develop at a slower rate, and maintains economic growth alone is not enough and is in conflict with the trickle-down effect approach. To rectify the uneven development exaggerated under neoliberalism, the call for the state to be included in poverty reduction policies is being made. It is necessary for these states to break away from the confines of neoliberalism and take a different role that the one prescribed under this approach (Kiely, 2007).

Influential work by Kuznets (1955) suggests that initial economic growth raises the level of inequality before a distribution influence helps reduce the income gap. The classic Kuznets curve known as the 'inverted U' curve depicts inequality deepening in initial stages of development but reducing over time (Ahluwalia, 1976). Bazillier and Sirven (2008) amongst others have argued this interpretation is incorrect. Questions of inequality in the distribution of income decreasing over the course of a country's economic growth have been debated by economists. It could even be said that developing countries sit at the top of the arch of the 'inverted U' under neoliberalism with no possibility of them ever being familiar with income equality for all.

\section{Limitations of Neoliberalism and Education}

Neoliberalism has not had a positive impact on education in developing countries with Klees (1999) stating that the approach preserves educational inequalities. Investment in human capital does increase economic growth, but the value of the social good inherent in education is decreased under neoliberalism (Davies \& Bansel, 2007). The concentration of effort is on increasing labour productivity which intensifies the competition between educational institutions and the fixation of performance goals of said institutions (Davies \& Bansel, 2007). Education under neoliberalism has become another commodity or product to be traded and the only value it has is decided by the market. The responsibility of the social provision of education under neoliberalism has been devolved and duty for its 
delivery now rests with the private sector (Zajda, 2006). One of the arguments for embracing neoliberalism in education included the opportunity to diversify the curriculum, influence the pedagogy and clientele of education. Apple (1999) argues that these are inherent in neoliberalism. Rather there is a need to contest the hegemony of neoliberalism and seek alternatives to this approach.

For full participation in education to occur, the citizenry must be 'unequivocally' middle class (Davies \& Bansel, 2007). Education became user pays focused under neoliberalism, the opportunity costs to poorer families increased, resulting in their non-engagement with education. They cannot meet the cost increases of education as there are fewer resources available to them (Klees, 2008). Lower income families are unwilling to pay for education as the cost increases (Mingat \& Tan, 1986). In order to mitigate some of these issues, education vouchers were introduced in an attempt to increase consumer choice and decrease inequalities. They have not provided a solution and have instead added to the inequalities (Carnoy, 1997). The user pays reforms have failed to meet their objectives but have maintained the unequal and inefficient education status quo.

The effect of neoliberalism on the poor has been to exclude them from education as they cannot compete on an equal footing for education resources (Apple, 2001). Neoliberalism places the responsibility of education on the individual. Any failure to engage with education is therefore a personal one not an institutional failing under the neoliberal dogma. Educational institutions seek out middle class students who already have more social, economic and cultural capital than their less wealthy counterparts. The middle class students are able to manipulate the educational system to their advantage as they have been exposed to the 'unseen capital' through informal cultural rules (Apple, 2001). Standardised achievement tests are another instrument to exclude poorer children from education as they have a negative effect on the performance of schools with poor or marginalised children (Whitty, Power, \& Halpin, 1998).

As neoliberalism has been found to be lacking in spreading universal benefits to all sectors of the community, alternative theories have been sought to redress this issue. Scholars and authors have looked to human capital, human capability and quality of life theories as alternative options to the neoliberal stance. This search has opened the way to introduce humanity into development. The oppressed should be viewed as people not as numbers, 
and for definitions of poverty to be challenged and the use of neoliberalism to eradicate poverty questioned.

Neoliberal policies express a conviction that when the state withdraws from the economy all citizens can compete equally for financial and educational resources. This is incorrect as all individuals are not equal in economic status with marginalised members of society unable to access resources to the same extent as other groups. The user pays bias of neoliberalism excludes the poor and focuses on vocational/technical education for job opportunities. The critical life affirming aspects of education are ignored as they do not have a strict economic value that can be financially expressed in the market place.

\section{Human Capital Theory}

Human capital theory as identified by Sweetland (1996, p. 341) is where "individuals and society derive economic benefits from investments in people". The theory equates the value of human learning capacity as equal to any other resource utilised to produce goods and services (Lucas, 1988, 1990). The economic value given to educational outcomes in this theory is closely aligned to the neoliberal approach. The function of human capital theory is to clarify the gains of investing in education and training as they increase the value of human resources (Aliaga, 2001).

The 1960s saw human capital theory gain traction as scholars struggled to account for the economic growth in the United States using the traditional production factors of physical capital, labour, land and management (Denison, 1962; Krueger, 1968; T. W. Schultz, 1961). T. W. Schultz (1961) a prominent economist, identified this gap called the 'residual factor', as being human capital. Social returns (Becker, 1964; Bowman, 1969), profit and productivity (Psacharopoulos, 1985; Psacharopoulos \& Woodhall, 1985; Romer, 1986, 1987), economic growth (Becker, Murphy, \& Tamura, 1990; Cohn \& Geske, 1990; Romer, 1990) and employment and earnings (Becker, 1993; Bontis, 1996) are all outcomes connected with the theory.

It was not till early in the $21^{\text {st }}$ Century that scholars such as David and Lopez (2001) started to employ a wider definition in human capital theory and included socially related activities as important outcomes from education. While the definition of human capital theory may have evolved over time, the critiques remained stable. Benson (1978) noted the methodological imperfections and Mincer (1965) remarked on the theoretical inconsistencies and different interpretations of human capital theory. 
Many governments have adopted a human capital approach to education policy which is designed to produce economic outcomes. The indirect outcomes from education go far beyond economic benefits. As Colclough (2012) summarised, indirect benefits from an educated population include the reduction of social inequalities, improvement in health and nutrition, reduction in the high rate of population growth and reduced infant mortality. Further benefits include the possibility of democratic politics, war and civil strife to be reduced, for discrimination diminish and female independence to be strengthened.

Human capital theory is too economically based to fully embrace all the benefits that can be derived from education. Profit and economic growth are valued over and above the 'human' which is part of its title and is an intricate component of human development. Neoliberalism has a younger sibling and it is called human capital theory; it was born from economic parents who brought it up wanting it to have its own identity but failed to let it fly far from the capitalist nest.

\section{The Introduction of Human into Development}

The human capability approach, also known as Sen's capability approach (1979), was not born to economic parents but has a parentage linked to humanity. Sen's theories have been influential in development policy, particularly where they explored and challenged areas such as justice and freedom, social choice and agency, education, women and rural livelihoods. His humanitarian approach has contributed to work on inequality, poverty, culture and identity (Agarwal, Humphries, \& Robeyns, 2003). The capability approach brings the 'human' to the forefront of development. The approach is centred on the welfare of the individual, not their economic value as under human capital theory. Human capability is about the "ability of human beings to lead lives they have reason to value and to enhance the substantive choices they have" (Sen, 1997, p. 1959). The human capability framework is superior to neoliberalism and encompasses human capital theory, as it includes direct and indirect benefits of education and is concerned with both economic and social development (Robeyns, 2005). The core concepts of functioning (an individual's activities and state of being) and capabilities (what an individual can potentially achieve) are of importance (Kuklys, 2005). Using income as a measure of welfare is too simplistic an approach.

The human capability approach has been critiqued by scholars such as Sugden (1993) and has it been found wanting. Critics have commented that the key concepts are obscure with the approach too closely linked to economics and philosophy. It has not involved 
psychology, sociology and anthropology and gives excessive weight to choice (Qizilbash, 2011). Gasper (2002) questions what we know about 'being', as the theory of being underlines 'wellbeing', a key component of this approach. Chircusi (2009) amongst others, finds Sen's definition of utilitarian misleading and there are scholars who question the abstract nature of Sen's definition of capabilities (Mathias \& Herrera Rendon, 2006).

Criticisms of this framework have been answered by the empirical use of this approach. It is more holistic than human capital because it has embedded choice and freedom as measures of welfare in human development. The human capability approach has impacted public and development policy as it strives to empower the individual by positively increasing a person's capabilities. There are social and economic benefits in applying this approach to education. As poor uneducated women become more educated, there are greater possibilities to improve their economic status, expand their life choices and increase their involvement and inclusion in society.

\section{Including Quality of Life in Development}

A person's capability is linked to their quality of life (QOL) with QOL being succinctly defined as "what people are and able to do"(Nussbaum \& Sen, 1993, p. 2). QOL is used in different arenas and has been applied to public policy worldwide as noted by Hagerty et al. (2001) and Land (2000). QOL has also been enlisted to go beyond the narrow economic measures such as Gross National Product (GDP) in order to ascertain whether a nation's population is thriving (Reserve Bank of New Zealand, 2012).

While the definition is succinct, there is discussion between authors from diverse disciplines as to what should be measured and assessed. This debate is whether subjective indicators (psychological responses such as happiness) or objective indicators (physical quantity e.g. personal income) can be measured, with recommendations that both be included (Cummins, 1996, 1997; Cummins, Mccabe, Romeo, \& Gullone, 1994; Felce \& Perry, 1995). The objective circumstances of the individual must be considered to give meaning to her to subjective indicators (D'Iribarne, 1974). Researchers have also argued to have a complete picture of a person's life experiences, both cognitive (life satisfaction) and affective (happiness) indicators must be included in QOL measurements (Andrews \& McKennell, 1980; Brief \& Roberson, 1989; Organ \& Near, 1985).

Questions have been raised as how QOL should be assessed in different parts of the world and whether it is possible to have an agreed upon universal QOL (C. Taylor, 1993). There 
is debate on traditions, relativism and objectivity being observed and respected in this investigation of a person's QOL (Nussbaum, 1993). Measuring QOL for women in traditional societies can prove to be problematic. In developing countries, it is not uncommon to have "2 actual norms for human life" (Annas, 1993, p. 279). Women are unjustly denied access and resources of education when their actual abilities and differences in natures are not taken into account but rather the 'norm' of their gender is adhered to.

A woman's QOL can be vastly improved by access to and furthering of her education (Nussbaum, 1995). Depriving women of education is to privilege the importance of educating men and is a move away from giving women equal opportunities to develop skills and intellectual capacities. Education can be used to decrease the level of injustice of the inequalities women experience by being treated differently to men (O. O'Neill, 1993). When people have identical access to education, they are not restricted by their gender nor the 'norms' of society and can engage in education due to their actual abilities and differences in nature.

\section{Education as a Human Right}

Access and participation in education is a human right; human rights are defined as all basic rights and freedoms to which people are inherently entitled (Amnesty International Aotearoa/New Zealand, 2012). Education and its importance to developing the individual and society have been encapsulated in international binding documents, for example, Article 26 of the Universal Declaration of Human Rights adopted in 1948 (United Nations, 1948), The Convention Against Discrimination in Education 1960 (UNESCO, 1960), articles 13 and 14 of the International Covenant on Economic, Social and Cultural Rights 1966 (United Nations, 1966), the Hamburg Declaration of Adult Education 1977 (including The Agenda for the Future) (UNESCO, 1997) and The Dakar Framework for Action 2000 (UNESCO, 2000).

The recognition of education as a human right has made the contribution of education far more momentous and encompassing than a purely economic development aspect (Caetano, 2006). The significance and inclusion of human dignity is recognised under the human rights focus to education, where the space to study the interaction and impact of education on development is possible (Haddad, 2006). Having a human rights approach to education is another tool to use to eliminate the injustices of inequality, exclusion and restricted societal participation (Willmore, 2004). The concept of applying a human rights approach to education seems a non-negotiable stance for societies and governments to 
adopt. However, difficulties are encountered when the definition and application of human rights differ between countries (Halvorsen, 1990).

\section{Relationship between Education and Poverty}

The abundance of literature on the relationship between education and poverty suggests there is a straightforward and positive correlation between the two. Education allows freedom and increases choice in a person's life. There is the possibility of increasing an individual's economic status coupled with the expansion of their social networks (Shepherd, 1999). There is evidence that education is linked to better health, nutrition standards and with greater skills and knowledge flowing into the community to assist in the growth of the nation's economy (World Bank, 2008). There is debate however on whether education decreases inequality, unemployment and is effective in rural areas (Durston \& Nashire, 2001).

The interaction of poverty to education is complex and is studied and discussed in formal and informal spaces by academics and development practitioners to gain a perspective as to why education is not eradicating poverty as envisioned. The effects of poverty on individuals and the ways in which people living in poverty engage with education are pivotal pieces of the puzzle to understanding the deficiency in education outcomes (Cannon, 2012). Research indicates the experience children have at school is determined by their level of income deprivation (Horgan, 2007). Studies show the quality and outcomes these children can expect is lower than that of their more advantaged school contemporaries (Horgan, 2007).

The attitudes and behaviours of children who live in poverty also impact on their educational attainment. Scholars have called for greater attention to be paid to these perspectives when designing education programmes (Goodman, 2010). Parental beliefs have also been investigated, particularly how they influence their children's aspirations and motivations for schooling. It has been noted that children's philosophy to these aspects are closely related to the deprivation of their environment (St Clair, Kintrea, \& Houston, 2011).

A starting point in planning education policies for those living in deprivation has involved a definition and measurement of poverty. Although it is accepted that this definition can vary depending on context and circumstances, "it is wise to respect the vision of poverty articulated by poor people themselves" (Maxwell, 1999, p. 4). This is a valid sentiment for 
those living in developing countries and those in developed nations. Worldwide, there has been a focus on standardised measurements for education outcomes and for these to be accessed in terms of economic productivity. Academics such as Cardinal (2011) have suggested education should be concerned with ending the cycle of poverty rather than relying on economic outcomes as indicators of progress.

As education has been used to progress the rights of all humankind, it is also used by development agencies, international institutions and governments in an attempt to eradicate poverty worldwide (UNESCO, 2011). To achieve the United Nations Millennium Development Goal of universal primary education, there has been a concerted effort in regards to education initiatives. These include but are not limited to the following: the First UN Decade for the Eradication of Poverty 1997-2006; and outcomes from the World Education Forum 2000 and UN Secretary-General's Global Initiative on Education (Education First 2012) to make this goal a reality (United Nations, 2012). The effort to ensure all children have at least a primary education is both a reflection and facet of the human right to education. There are direct (personal incomes and accelerated economic growth) and indirect benefits to both the individual and the nation by having an educated population (Chaudhry, Malik, Hassan, \& Faridi, 2010).

For all the benefits of education to be realised, education and poverty eradication policies must analyse and consider both successful and non-successful initiatives. Implementation of holistic and relevant approaches would be beneficial to women seeking education. Authors have noted that social interactions and class affect the outcomes of education (Berstein, 1971; Bowles \& Gintis, 1976; Coleman, 2007; Halsey, Floud, \& Anderson, 1961). For education strategies to have long lasting and far reaching affects, other social sectors must be included, for if education is used in isolation as an instrument of poverty alleviation it will fail (Singal, Jeffery, Jain, \& Sood, 2009).

\section{Conclusion}

This chapter has examined how education is critical to women and their life choices, and furthermore how educating women and girls are crucial in combating poverty. Explanations of why education does not automatically transform or liberate a woman from the restrictions associated with low income have been elucidated by education theorists. Yet it is apparent that the dominant development theory that has influenced education for women and girls has been neoliberalism. Relying on neoliberal policy to eradicate poverty through education for women and girls is misguided. As well as excluding the poor from 
many educational opportunities, this approach does not allow for the accidental events in a woman's life that prevent her from engaging and benefiting from education when a neoliberal policy is in place. Thus, there is a commitment and growing acceptance that a new paradigm is required to ensure women and girls are educated in the developing world. Integral in this new paradigm is a commitment to build women's capabilities and a focus on the positives, not an emphasis on what is lacking in women's education and life.

This literature review has focused on the developing world, but what can be said or applied from these findings to a developed world setting, such as New Zealand? The complete picture is unclear from the global literature as to whether the deprivation of education would have the same societal and personal impacts on women in a developing country to those in a developed society. The effect of gender, poverty and education on women from the majority ethnicity in a developed country is investigated in the next chapter. 


\section{Chapter Three:}

\section{Exploring the reality of Women, Poverty and Education in a Local Context}

\section{Introduction}

There is no shortage of published research, academic opinion and educational policy which recognises that marginalised members of society, including girls and women, are underrepresented in early education schooling and adult education outcomes (Bishop, 2003; Findsen, 2006; McIntosh, 1988; S. B. O'Neill \& Spellman, 1983; Sissel, Hansman, \& Kasworm, 2001). The schooling experience a girl has not only influences her educational career but impacts on her post school education. If she wishes to improve her level of education, she may question whether she would engage in further education and how she could reach her educational goals. One arena where further education takes place for girls and women is adult education. There are numerous discussions of how women need to have improved access to and participation in adult education in the literature pertaining to this sector within New Zealand (Davey \& Jamieson, 2003). There are strong arguments on strategies that accommodate and facilitate girls and women in obtaining educational opportunities in New Zealand (Ministry of Women's Affairs, 2010b). Exactly which women we are talking about as being served by these strategies needs further investigation.

We need to clarify whether "women" ${ }^{3 "}$ is a descriptor to refer to Pākehā or to all women if the precursor of another ethnic marker is not noted. Women are treated as a generic homogenous group under this high level classification, which denies their individuality and specific needs. This lack of clarity as to the composition of the term women in an adult education context masks the analysis of how effective or ineffective policies are for low socioeconomic status Pākehā women. General education and adult education priorities include reaching more people with limited education, those of low socioeconomic status, unemployed and those whose culture is threatened (Findsen, 2006). It is not apparent in the literature if marginalised Pākehā women receive assistance due to their ethnic

\footnotetext{
${ }^{3}$ This thesis has used the term 'women' to describe the gender who are the subject of this thesis. The decision to use this term was one of ease of reference as it describes the socially constructed group on which this research is centred. This term is not used to limit or treat women as homogenous. I am aware that the term 'woman' or 'women' does not account for the complexities and diversities of a female's identity, behaviour and experiences. These terms are used to convey gender as it is understood in the context of male or female categories (McCall, 2005) .
} 
identification. The issues of women, poverty and education require close examination in the New Zealand context.

The intent of this chapter is to narrow the global focus of women, education and poverty to a local space. This will be accomplished by positioning Pākehā women within the context of adult education and examine adult education in connection with this group. The themes of poverty, women's status and adult education in New Zealand will be employed to scrutinise and inform this objective. The perception and solutions for poverty in New Zealand will be documented by studying how poverty has been politicalised and how poverty has impacted New Zealand women. The status of New Zealand women will be further outlined through literature pertaining to their employment, social consequences of domestic violence and their participation in leadership roles in New Zealand. The importance, acceptance and changing face of Adult and Community Education (ACE) with the implications of the use of neoliberal policies in this domain will be considered in this chapter. The subject of poverty in New Zealand will be examined first as the country's approach to this subject profoundly affects marginalised women.

\section{The Denial of Poverty in New Zealand}

The recognition of poverty in New Zealand can be linked to different historical periods as the outcomes of particular economic and political relations resulted in economic destitution at different times. The 1938 Social Security Act was established to be a buffer against the effects of economic downturns on the population. The 1938 Social Security Act is an illustration and reflection of a certain period in New Zealand's social and economic history where the welfare state was strong and those in need were "compensated when adversely affected by market forces" (Gilbert, 2012, p. 15; Sutch, 1966, 1969). A robust welfare system was manifested through the State providing state housing, free education and low cost medical care. There was a commitment from the government for social security and economic protection of its citizens (Gilbert, 2012). The historical belief that New Zealand society was egalitarian (Belich, 2001) further embedded the cultural myth of a poverty-free country. The denial of poverty can be traced to the 1970 s when the dominant belief in New Zealand was that poverty did not exist.

The prevalence of poverty has been underrated as official sources and academics considered poverty to be the domain of the unemployed without other social determinants being considered (Easton, 1976). A lack of statistical data before 1973 has contributed to the difficulty of estimating levels of poverty accurately (Easton, 1995). The 1938 Social 
Security Act laid the foundation for the poverty-free myth due to its success and reinforced the perception of equality in New Zealand, when examining government assistance and employment opportunities (Jack, 1973). The early settler history of New Zealand laid the foundation for the 'egalitarian myth' (Consedine, 1989). This myth involved the 'new country' being a haven for the working man; this 'working man' identification of course excluded Māori and undervalued women (True, 1996).

The 1970s saw the first cracks appear in the armour of the poverty-free myth, when social assistance from the Government began to offset economic hardships. The 1980s saw further erosion of the myth but not its eradication. The poor were recognised but not the phenomenon of poverty. This period saw the myth turn towards comparing levels of poverty to countries outside New Zealand, seeking to obfuscate poverty and to absolve societal responsibilities to those living in poverty (Gilbert, 2012). As illustrated in the following newspaper excerpt, poverty was viewed as occurring outside New Zealand and anyone living on a low income in this country was considered to have only themselves to blame.

“it's hard to get revved up [about domestic poverty claims] when images of real poverty abroad appear nightly on our screens. The issue is to differentiate between the moaning classes and those who simply cannot cope." (Waikato Times Sep 17, 1998: 6 as cited by Gilbert, 2012)

The 1990s saw the emergence of language differentiating people living in poverty, when the labels of 'deserving' and 'undeserving' poor were applied. The combination of equality myths and moral distinctions of poverty culminated with beneficiaries experiencing vilification in this decade (Gilbert, 2012). The decade acknowledged the presence of economic deficiency for some of the population, but was synonymous with negative representations of poverty in a political-economic period with severe welfare cuts. In contrast the 1970s lacked the acknowledgement of the 'undeserving' poor in a period of increased social assistance from the state. These two periods illustrate the correlations between the symbolic and the political-economic (Gilbert, 2012).

The labels of 'deserving' and 'undeserving' poor go deeper than being mere identification markers but are part of our cultural structures as illustrated in their persistence in our modern society (Steensland, 2006). The distinctions also form the basis to categorise larger groups which are not defined by material scarcity. The origins of 'undeserving' began with 
the development of the term 'underclass' which was originally applied to unemployed or underemployed. The term then evolved to be associated with certain ethnic groups and their neighbourhoods and assigned them certain characteristics, involving behavioural and psychological attributes (Gans, 1990, 1995). As the New Zealand Values Survey 2005 found, there is a dominant perception that the poor are lazy and lack willpower to improve their economic position (Carroll, Casswell, Huakau, Howden-Chapman, \& Perry, 2011). Poverty is no longer defined by a person's economic position but by their moral status, whether they were 'deserving' or 'undeserving' poor and belong within the confines of the accepted and legitimate reasons for poverty (Gilbert, 2012). In addition, poverty in New Zealand has ethnic associations both in the way it is presented and the experiences of poverty. Māori poverty is linked to predominately to ethnicity and Pākehā poverty associated with laziness; hence ethnicity plays a role in how poverty is perceived. As a result of this perspective, the institutional and structural aspects of poverty are ignored.

\section{The Recent History of Politicising of Poverty in New Zealand}

\section{0-1984}

The 1938 Social Security Act reflected the state's commitment to the community, "to provide, as generously as possible, for all persons who have been deprived of the power to obtain a reasonable livelihood through age, illness, unemployment, widowhood, or other misfortune" (Savage, as quoted in Gustafson, 1986, p. 223). The economic theory utilised in the post WWII welfare state was predominantly Keynesian, with the state's function "to protect citizens from the unwelcome effects of the operation of market forces, and to compensate those who have been adversely affected by market forces (the unemployed) as well as those unable or unwilling to participate in paid work" (Rudd, 1993, pp. 237-238).

The Keynesian principles followed in New Zealand were not challenged by the main political parties in the period of 1945 to 1984, though there were cumulative changes to social and economic policy (Roper, 2008). The intervention of the state in social and economic matters was given teeth in 1936 by the Reserve Bank Act. This intervention was further increased and accepted without political opposition in WWII and the post war era maintained the individual's protection from the market (Rudd 1993: 240). The foundation of the interventionist welfare state was set in the pillars of free education, state housing and mainly free medical care (Gilbert, 2012). Social equity and social cohesion were valued in this period. The acceptance of the intervention nature of the state has had resounding repercussions for society and poverty, with economic priorities given the highest value. 
Government interest lay in full employment which would limit reliance on benefits, thus restricting costs to the state (Boston, 1999). The wage freezes set in place in the late 1960s to combat inflation impacted on the lower income sector of society and especially on large families (Cuttance, 1980). Women and Māori were economically disadvantaged, significantly and negatively affected by the structural inequalities of the 'wage-earner state' (Davey \& Grey, 2009; Du Plessis, 1993; Humpage \& Craig, 2008; Rudd, 1993).

The 1969-1972 Royal Commission Inquiry into Social Security recommended increasing the accessibility and range of benefits to more sectors of society. This was to encourage these sectors to participate and increase their sense of belonging in their communities (McClure, 2003). The Domestic Purposes Benefit was introduced in 1973, accident compensation for workers in 1974 and superannuation implemented in 1977 (McClure, 2003). Any gains in economic equality through social policy were later eroded with reductions to the Domestic Purposes Benefit for single mothers. This period also saw the economic security of workers being undermined with policy moving away from full employment (Dalziel, 1999; Pearson \& Thorns, 1983),

The early 1980s also witnessed increased unemployment and lowered unemployment benefits with its associated taxation. The restructuring of poverty as synonymous with unemployment had begun (Nicholls \& Piesse, 1982). Marginalised groups experienced inclusion, and social welfare policy was used to reduce gender inequalities. Simultaneously benefit rates fell putting further economic pressure on low income groups, especially marginalised women. Poverty was acknowledged and was remedied through economic redistribution; yet this acknowledgement was selective and did not recognise workers or the unemployed. State spending on benefits was considerable with many who were not poor (middle class and wealthy senior citizens) receiving a significant portion of this budget (O’Brien \& Wilkes, 1993).

\section{4-1993}

Neoliberalism flourished in New Zealand following the election of the Lange-Douglas government in 1984, though neoliberal policy was debated with advocates seeing it as necessary and critics challenging its benefits and suitability to New Zealand. This ideology was implemented to differing degrees by successive governments (Easton, 1997; Jesson, 1999; Kelsey, 1997; Roper, 2005). 
Economic inequality in New Zealand grew more quickly than any other industrial country in the 1980s. Unemployment in the short to long term was viewed as higher than acceptable, with resulting increases in welfare expenditure (Easton, 2008). The boom and bust economic cycles became part of the New Zealand economy affecting all sectors of the community. Poverty became more pronounced and entrenched after 1987, with workers in unskilled and low skilled occupations being at higher risk of material deprivation (O'Dea, 2000; Singley \& Callister, 2002). To mitigate the effects of income inequality, the family allowance was replaced by family support in 1986. This support had conditions attached and applied to those in full time employment, excluding part time workers (Douglas, 1987). The unemployment benefit was cut and this decline carried through into the 1990s (Parliamentary Library, 2000).

Social policy changes from 1991 had dramatic effects on the severity and incidence of poverty. First, benefit entitlements were reduced and second, the labour market was deregulated (Parliamentary Library, 2000). These social and industrial relation policies resulted in hardship for many disadvantaged New Zealanders, many of whom had to reach out to voluntary organisations to meet their basic needs (Boston \& Dalziel, 1992). Benefits had greater and greater eligibility requirements, increased exclusion and different rates for different age groups. These reductions in benefits impacted on those reliant on this income the hardest (Jensen, Krishnan, Spittal, \& Sathiyandra, 2003). Low waged employees were also now being subjected to poverty as employment rates fluctuated and relief for impoverished people was inadequate especially for single parents and large families (Krishnan, 1995). State housing was not exempt from these social policy changes, as rent became market determined rather than based on tenants' income levels. Economic disparity, insecurity and poverty all increased in this period of New Zealand history. Social security also decreased and was compounded by regressive taxation including the Goods and Sales Tax (GST) which affect the poor proportionately more than those on higher income levels (Gilbert, 2012).

\section{9-2010}

The disparity between wage earners and beneficiaries continued to be reinforced through the introduction of the family benefits package in 1996. This policy aimed to address the mounting poverty in the mid 1990s (St John, 2008). The Fifth Labour Government's (1999-2002) policy changes to housing, labour relations and health care for the poor initially reduced poverty but this reduction was short lived (Stephens, 2008). The expected benefits for the economically deprived did not eventuate as expected under the neoliberal 
state, as the number of working poor had increased considerably from 1998-2004 (Stephens, 2008). In an attempt to decrease the amount of working poor in New Zealand, the Working for Families Package was introduced by the Labour Government in 2004. Again the disparity between waged and unemployed populations was reinforced (St John, 2008). Ethnic disparities in the late 1990s started to be highlighted in statistics which propelled government to implement strategies from 1998-2004 to address these issues, though they had little effect (Poata-Smith, 2008).

There is concern that any improvements in the level of poverty and decreases in income disparity linked to market conditions would revert back to higher levels if the market conditions deteriorate (St John, 2008). Recent government initiatives seem to be stepping back from eradicating poverty to a position of accepting poverty among the unemployed, irrespective of market conditions (Gilbert, 2012). Policies that step back from eradicating poverty further exclude marginalised women from society as their poverty becomes entrenched and institutionally invisible.

\section{Poverty and New Zealand's Women}

A snap shot in time of how New Zealand women are socially and economically placed in our society is seen in the Indicators for Change: Tracking the Progress of New Zealand Women: 2009 report (Ministry of Women's Affairs, 2010a). The priorties used to assertain their status include the prioritisation of skills for economic standing. There were indicators to guage levels of empowerment, costs of victimisation and society's level of care for women. These indicators reflected the wellbeing and work/life balance of women (Ministry of Women's Affairs, 2010a). This report highlights the fact that poverty does not affect each woman in the same way in New Zealand. These differences can be traced in part to her ethnic identity, being classed as 'disabled' or having mental health issues. These factors all impact on a woman's economic status and the ability to participate in society (Ministry of Social Development, 2007).

Ethnic poverty as an issue can be explored by comparing the experiences of Māori and Pākehā women who represent the two largest female ethnicities in this country. In 2006 $68.4 \%$ of women identified themselves as European and $14.7 \%$ as Māori (Ministry of Women's Affairs, 2010a). In 2008, Māori women's median hourly income was $\$ 15.00$ which was considerably less than Pākehā women who averaged \$18.22 (Ministry of Women's Affairs, 2010a). Statistics for the same year reported the likelihood of $13.7 \%$ of Pākehā women being in the highest quintile of weekly earnings as compared to $8.5 \%$ of 
Māori women. The gap between Māori women and women of all ethnic groups is wider than the income gap between men and women (Ministry of Women's Affairs, 2010a). Joblessness also has an ethnic component, with Pākehā women experiencing a considerably lower rate at 6.6\% and for Māori women 15.6\% as recorded in 2008 (Ministry of Women's Affairs, 2010a).

Research has indicated that violence against women has an ethnic component and can be influenced by stresses such as limited income (K. L. Anderson, 1997). By 2005 in New Zealand $18 \%$ of Māori women experienced confrontational offences compared to $6 \%$ of Pākehā women. The percentages rose for Māori women to $42 \%$ and 19\% for Pākehā women when recording the possibility of being a victim of sexual assault or rape (Ministry of Women's Affairs, 2010a). There are also significant differences in health outcomes when comparing Māori and European women. The life expectancy of Māori women in 2006 was only 75.1 years in comparison to 83.0 years of non Māori women. European women are more likely to report that their health is excellent (Ministry of Women's Affairs, 2010a). Some $6.8 \%$ of Pākehā women in 2006/2007 were unable to see a GP which is significantly lower than Māori women who had a rate of $14.3 \%$.

Educational attainment differs for Māori and European women, which in turn impacts their potential earnings. Post-school qualifications for Pākehā women were recorded at 49.7\% and 41.1\% for Māori women in 2008 (Ministry of Women’s Affairs, 2010a). In 2008, Māori women made up $14.6 \%$ of modern apprentices and $8 \%$ from the Pākehā ethnic group. Working hours between the two ethnic groups varied very little with Māori women recording 6.6 hours and Pākehā women at 7.1 hours in 1998-99 (Ministry of Women's Affairs, 2010a).

A New Zealand woman's ability or disability can factor in her susceptibility to live in poverty. In 2006, 18.1 percent of Pākehā women had a disability, compared with 17.0 percent of Māori (Statistics New Zealand, 2006b). As recorded by Statistics New Zealand (2006a), disabled women have an unemployment rate of $8.7 \%$ which is significantly higher than non-disabled women at $4.8 \%$. There is disproportionate representation of disabled women when examining figures of those in the population that are more likely not to work, be on low incomes and have no qualifications. Economic and social outcomes throughout a disabled woman's life can be markedly limited especially for those who are disconnected from education and employment opportunities (Ministry of Women's Affairs, 2010b). In 
2009 the Government established a Ministerial Committee on Disability Issues (Ministry of Women's Affairs, 2010b).

Poverty and mental health for New Zealand women are often interlinked and can exacerbate each other. There are a number of factors that can contribute to poor mental health, including stress, poverty, exploitation and alienation. A woman's mental health can be protected by increasing her coping skills, self-esteem and social support which can be brought about by reducing her economic disadvantage. Other strategies can include increasing her educational learning opportunities, decreasing her social exclusion and improving her personal and community life (Ministry of Health, 1997).

Government reports state that income is only part of the poverty picture as there is acknowledgment that poverty is complex and multi-faceted (Ministry of Social Development, 2012). The government's remedy is to meet this multi-dimensional, economic, social, equality and equity issue with pure straightforward economic remedies. This allows the structural and institutional ideologies to remain in place unchallenged and to be perceived as normal and righteous.

\section{New Zealand Women and Personal Income}

Quality of life is interlinked with a woman's standard of living and both are dependent on her access to income. Income therefore is an indication of availability of resources to her and thus impacts on her participation in society (P. Barber, 2011). A woman's personal income has a bearing on her personal independence and her capacity to provide for herself and others. As the New Zealand Time Use Survey 1998-1999 recorded, women in New Zealand bear the majority of unpaid and childcare work in the household which is reflected in their personal incomes (Ministry of Women's Affairs, 2010a). New Zealand women's personal incomes are lower than men's but are the lowest in the child bearing ages. In 2001 , the median income for women was $\$ 14,500$ which is $58 \%$ of the income of men who received a median income of $\$ 24,900$ (Statistics New Zealand, 2005). Pākehā women had the highest median income of women when comparing ethnic groups with the largest gap between men and women (Ministry of Women's Affairs, 2010a).

Incomes not only differ in New Zealand according to a woman's ethnicity but also her age (Ministry of Women's Affairs, 2010a). A woman's age affects her earning potential and this has been linked to a woman having a more distinct life cycle pattern than a man. As women primarily take responsibility for early childrearing, which can result in time out of 
the paid workforce, this absence influences their ability to receive income (Waring, 1988, 1997). Women's labour force status is another variable that accounts for the differing earnings, as is the variation of hours worked each week by women and men, with women less likely than men to work more than 40 hours a week (47 and 81 percent respectively) (Statistics New Zealand, 2005). Not all industries are accommodating to part time workers and do not offer flexitime. The part time and flexitime provisions are useful and appealing to those individuals who have child care responsibilities or are investing in their personal and professional value by undertaking part time study (Statistics New Zealand, 2005).

Education attainment is crucial to improve a woman's economic status. It has a strong effect on a woman's income in New Zealand with personal incomes increasing with higher levels of education. They are, however, below men at every level of educational achievement. The 2005 Focusing on Women Report (Statistics New Zealand, 2005) recorded women with no formal education as having the lowest median income. Female beneficiaries are low income earners with the aforementioned report documenting that women are more likely to receive social assistance than men (Statistics New Zealand, 2005). When comparing ethnic groups, results indicate that Māori women are more likely to be recipients of income support than others (Statistics New Zealand, 2005).

The variables of age, ethnicity, education, hours worked and occupation of women can only paint a partial picture of why women do not receive pay equity in line with men. New Zealand's gender pay gap has been stagnant for many years. While there have been some improvements and gains, there is a requirement for more affirmative action from both public and private arenas. If this is not forthcoming, the "occupational segregation" (Ministry of Women's Affairs, 2010b, p. 5) experienced in this country will never be overcome or challenged. Such segregation diminishes a woman's choice of career and the ability to influence her professional pathway that may lead to different earning possibilities. New Zealand women may have full equality guaranteed by law but in reality they are still to experience this equality in terms of their earnings. Income inequality equates to social inequality (Ministry of Women's Affairs, 2010b).

\section{Cost of Domestic Violence in New Zealand}

Social inequality is experienced by a disproportionate amount of women who are survivors of domestic violence in New Zealand society,. This inequality is expressed in economic costs and via social exclusion (Ministry of Women's Affairs, 2010b). There is an economic cost of this abuse to the individual and to government. Snively (1994) estimated the cost to 
New Zealand was between $\$ 1.2$ and $\$ 5.8$ billion per annum, which equates to approximately $\$ 8$ billion if it were calculated today. Costs arise that are met by the Government when a woman seeks assistance that may include criminal justice and legal services, medical care, refuge support, rehousing, access to social services and any further public assistance that is required. Economic costs to a woman can include loss of income and property, though these are not the only costs to the survivor of domestic abuse. The effects of domestic violence can also be seen in reduced work performance with increased days being taken off work and perhaps job loss. These factors affect both the individual, the employer and the economy by association (Yodanis, Godenzi, \& Stanko, 2000).

The social cost and exclusion of women who have dealt and are currently dealing with domestic violence are often compounded with living with a low income. One risk factor in domestic violence is a low family socioeconomic status (Fergusson, Horwood, Kershaw, \& Shannon, 1986). The link between poverty and domestic violence increases a woman's vulnerability. It increases the risk of conflict in family relationships and limits her choices of leaving the abusive association (Jewkes, 2002). Social exclusion prevents a woman from participating fully in her community and from being all she can be as a human being. This exclusion may not only affect her but also affects her children (if she has any) and it can have far reaching and long lasting effects that transcend the economic costs to New Zealand society (Statistics New Zealand, 2005).

\section{Women, Leadership and Political Participation in Society}

New Zealand is not performing well in terms of gender diversity in leadership, though this diversity has been prioritised and has social and economic benefits (Ministry of Women's Affairs, 2010b). New Zealand has just over 9\% of women board members in our top 100 NZSX companies, with only $4 \%$ of said companies having a female Chief Executive (Goldman Sachs \& Partners New Zealand Limited, 2011). Drilling down to board representation, New Zealand does not compare favourably at all with our Asia/Pacific neighbours with $65 \%$ of New Zealand's top 100 companies having no female representation (Korn/Ferry Institute, 2011).

Economic performance and governance is increased when board membership has a mixed gender composition, thus confirming the positive economic value of gender diversity (Goldman Sachs \& Partners New Zealand Limited, 2011). Leadership teams comprised of both genders are more likely to have a range of perceptions on issues, which in turn expands the variety of issues being considered and can lead to greater and more innovative 
solutions (Business New Zealand, The Institute of Directors in New Zealand, \& Ministry of Women's Affairs, 2009). Leaders are sourced using a variety of essential qualities, one of which is their education. Women completing tertiary education are able to fully capitalise and utilise their increased human capital through their further education when they are involved in leadership roles (Statistics New Zealand, 2005). Tapping into the resources and talents of women increases the probability of interests of women and children to be given greater awareness and attention. Social benefits of gender diversity in leadership roles are highlighted when women's skills are fully utilised in this arena.

Women in government is an area that deserves on-going monitoring and support to improve and ensure equality of representation in the political domain. Women in New Zealand were granted the right to vote in 1893, though it would be 1919 before they were able to stand for parliament. It would take until 1933 before the first female Member of Parliament (MP) was elected and in excess of 40 years until women MPs were in double figures in the mid-1980s. Currently the under representation of women in parliament remains as female MPs only account for 30\% of New Zealand MPs (Ministry of Women's Affairs). Female representation in Parliament not only fosters gender equality in the political sphere but has the ability to engage and increase awareness of political issues with women voters in the community.

The New Zealand Parliament has enacted the following landmark human rights legislation and adopted policies to eliminate discrimination of women. These include the Equal Pay Act 1972, the Human Rights Commission Act 1977, the establishment of the Ministry of Women's Affairs 1985, the introduction of parental leave in 1987 and the introduction of paid parental leave in 2002 (Ministry of Women's Affairs). While the above are positive steps, it is only with a stronger female presence in parliament can further progress be made for women's equity and equality. Women can gain greater participation in society when they are able to engage with education and especially lifelong learning also known as adult education.

\section{General Education Context of New Zealand}

Education for early childhood, primary and secondary schools students in New Zealand is situated in the context of a deregulated and devolved education system (Gordon \& Whitty, 1997). Core funding from the government is available to schools with financial shortfalls being met by school fees and fund raising by the school and community. The move to fund private schools and the move to Charter Schools also illustrate the state withdrawing 
from fully funding the education system. University education has also been impacted as education in this arena is becoming more privatised with student fees rising continually, thus entrenching the inequalities between those who can afford education and those who cannot.

Since 1984 New Zealand has been heavily influenced by neoliberal policy which has resulted in the commodification of education (Gordon \& Whitty, 1997). The normalising and quiet privatisation of public education as a private good is through 'quasi markets' as education is now a good to be marketed. Quasi markets embrace the increased "institutional autonomy, parental choice and competition" now established in the New Zealand education system (Gordon \& Whitty, 1997, p. 453). It is an arena where lower income and higher income groups cannot compete evenly as they do not have identical resources available to them. This results in an entrenchment of the disparity in education outcomes between low income students and those of higher incomes (O’Neill, 2011). However, the state cannot completely withdraw from the education sector due to the loss of political legitimation and the belief from society that the state should provide education for the population (Gordon \& Whitty, 1997). The government cannot leave funding of schools completely to the market and does attempt to readdress inequalities through state funding.

The state allocates funds to schools based on the decile rating system. This system is a reflection of the socioeconomic composition of students attending a particular school, the lower the decile rating, the greater the funding. Decile 1 is the lowest rating and decile 10 the highest (Ministry of Education, 2013e). The funding is to reduce inequalities of resources and to lessen the discrepancies between rich and poor schools (Ministry of Education, 2013e). Among the priorities of the Ministry of Education are attempts to increase participation, decrease educational discrepancies and improve achievement especially in the early years of a child's schooling (Ministry of Education, 2013a). The Early Childhood Education (ECE) Equity Funding policy targets the needs of the following groups, 1) Low socio-economic community, 2) Special needs and non-English speaking background, 3) Language and culture other than English and 4) Isolation (Ministry of Education, 2013a). Students of low socio-economic means are targeted to receive this funding to improve their access and participation in school. There are policies such as the equity funding to schools to address inequalities, but these are targeted for allocation of resources. There are no specific policies to target education as a tool to eradicate poverty. 
Another objective of the education system in New Zealand is to provide education that adds value to the economy, with a strong outcome bias and policy focus of equipping the population with skills that are of use to business (Ministry of Education, 2013c). The use of vocational education to impact on a person's income is aligned with the neoliberal policies underpinning the direction of education in New Zealand (O'Neill, 2011). The concerns of education in New Zealand are now ones of outcomes, returns to education investment, economic prosperity and added value (Ministry of Education, 2013b). The neoliberal education model is utilised to lift people out of poverty by working. This does not work for all members of the population (Ahluwalia, 1976).

Education policy in New Zealand acknowledges the inconsistencies of education outcomes for different ethnic groups and there are strategies in place to address these imbalances (Bishop, 2003). For example there is the Ka Hikitia - Managing for Success: The Mãori Education Strategy 2008-2012 and the Pasifika Education Plan 2013-2017 which aim to improve outcomes for students of these ethnic backgrounds (Ministry of Education, 2013d). These strategies and the focus on the deprivations experienced by ethnic minorities are essential to reduce the over representation of these groups in poor educational outcomes. However, the negative consequences of these policies are the continued racialisation of the inequality and disadvantage of the marginalised population of New Zealand. As Bishop (2003) argues, a different pedagogy is required in New Zealand to address the ethnic and class power imbalances in education. An extension of the ethnic rebalancing is the need to change the perspective and challenge the existing and dominant neoliberal discourse in New Zealand. The neoliberal philosophy embraced by the New Zealand education system neglects some members of indigenous and non-indigenous groups of society and this exclusion is keenly felt by those living in poverty. Many adults turn to the 'second chance education', the adult education sector to seek further education to improve their level of education.

\section{Adult and Community Education in New Zealand}

The definition of ACE can differ depending on what the context it operates within New Zealand: Adult and Community Education (ACE) is defined by the Adult and Community Education Association (Aotearoa New Zealand) as: 
"organised learning activities that groups or individuals undertake for their personal, community, cultural or economic development. It touches all other areas of learning but its primary focus is the adult as learner and the community as context" (Tobias, 1996, p. 42)

New Zealand society has a historical misconception that every member of society has the same opportunities to an effective education. This education myth has laid the foundations for the neglect, inconsistent attention to and importance of adult education in this country (Findsen, 2006). This complacency has proved detrimental to funding and research carried out in this sector. The disregard of this area has also adversely affected the marginalised groups that need access to ACE to improve their education and societal inclusion (Tobias, 2002). The provision of ACE in New Zealand is primarily through national community organisations, schools and tertiary institutions (Findsen, 2006).

Second chance education is synonymous with ACE. With such a powerful descriptor of this sector, it is incongruous to find that there was no official government policy and explicit commitment to ACE till the mid-1980s (Benseman, 1992). ACE had not been considered as an integral part of a learning society and as such, had not merited reliable financial support from the Government. Social equity as demonstrated in participation in education was recognised and included in the Education Act of 1990 (Benseman, 1992). The objectives of lifelong education opportunities being open to all have not always been met as ACE has not always been effective in attracting those of most need. Participation studies observe that adult education is a predominately a Pākehā middle class domain with participants who are 'socially, economically and educationally privileged' (Benseman, 1980). Many community programmes draw a predominately middle class clientele as the subjects offered, timings of these courses and their costs often exclude those in most need of second chance education (Findsen \& Lomas, 1993). As illustrated in the AECLWP 2001 report on ACE in New Zealand, there is under representation by a number of groups including older adults, household mothers and lower socioeconomic women (Adult Education and Community Learning Working Party, 2001).

The increased attention from the state towards ACE has had repercussions for the ACE sector. In 2003 the Tertiary Education Commission (TEC) became the umbrella organisation for all government funded and accredited post compulsory education. This included ACE and it was integrated into tertiary education. ACE is seen by its advocates as dynamic and diverse and therefore is difficult to define or categorise (Harrè Hindmarsh, 
1996). The sector's critics applauded the convergence of ACE into TEC as it can be directed and contained as desired by the state (Slater, 2009). Supporters of ACE acknowledge the benefit of such amalgamation as it recognises the sector and assigns its credibility that may have been lacking previously (Slater, 2009). There are concerns that ACE will lose the very essence of its identity, be unable to respond to the community as required and lose the community focus that would make it effective in responding to the educational needs of marginalised members of society (Slater, 2009).

\section{Government and Adult Education}

In 1999, the Government of the day began to enact tertiary education reforms which was espoused by reports issued by the Tertiary Education Advisory Commission (TEAC) between 2000 and 2001 outlining proposed strategies for a 'more managed approach' (TEAC, 2001). This new governance direction had an economic rational and 'user pays' focus (Avis, 2005; Olssen \& Peters, 2005). ACE which had been immune from market-led forces was now caught up in the maelstrom of policies that were now focused on outcome based achievements for funding (TEC, 2005).

The foundations for the neoliberal approach to tertiary education are found in the Learning for Life 2 report, with the emphasis on funding relationships between providers and the government. Learning, teaching and how they were to be achieved was not the focus of this document (New Zealand Government, 1989). This neoliberal ethos has been honed and deepened in the subsequent decades as noted in the strategic direction of the Ministry of Education in 2006. Educational priorities and success were measured in economic, then social outcomes (Ministry of Education, 2006). The tertiary education environment in New Zealand has embraced the 'learning for earning' discourse, which has subsequently become institutionalised and dominated policy in this sector (Zepke, 2009).

The consequences of accepting the pedagogy of 'learning for earning' and placing responsibility of student success on the individual dismisses the social purpose in education (Freire, 1988). Adult education has been argued as a crucial resource to bring about social change. This resource has been stifled and faces major battles to be effective against the dominant discourse which values productivity and is outcome bias (I. Martin, 2006). These tensions do little to improve social cohesion through utilising ACE and do little to encourage the social aspirations of marginalised groups through education (Zepke, 2009). The challenges of lower socioeconomic women to connect with ACE opportunities were further increased in 2009 when funding for ACE was reduced by $\$ 13$ million to just $\$ 3$ 
million. In 2009 subsidised night classes numbered 200,000, a year later these subsided places were reduced to just 25,000. Schools offering adult courses in 2009 in the Greater Wellington region reduced in number from 20 to 5 (C. Harris, 2010). The ramifications of the reduced funding is witnessed in the corresponding reduction in courses offered and impacts on the ability of the disenfranchised to improve their social and economic status (Findsen, 2006).

\section{Conclusion}

The context of this chapter has explored the issues of poverty, women's status and the treatment of the adult education sector. There are strategies directed to women and ethnic groups that improve a woman's participation in education. The consequences of these polices can be immense on girls as well as their life as women. There are educational policies that have priorities to involve and reach more Māori women, Pacific Island women and low socioeconomic members of society. With ethnicity being the main focus of poverty in New Zealand, deprivation has been ethicised in this country. Education is considered vital to address women's deprivation but under the neoliberal approach in New Zealand, the outcomes are concerned with accumulation of skills and financial gain. Empowerment, increased self-esteem and self-worth are not valued. Marginalised women wish to engage with adult education as it is promoted and viewed as a 'second chance' arena. However, this domain has been used primarily by middle class Pākehā female clients.

Women engaging in education is critical in overcoming women's material and social deprivation in developing countries and those of ethnic minorities in developed countries. However, it is a trial for marginalised women who are deemed to be in the ethnic majority of a developed country to gain the same access as other groups to adult education. There is an assumption that they are served under the standardised and general education system, as it is the structure transplanted from our colonial forbearer. Pākehā women who do not have a high level of education and are of limited income are not accommodated in the neoliberal structure that is in place in New Zealand. These findings were uncovered due to the utilisation of a methodology and selection of methods which allowed insights, themes and meanings to emerge from the research. The methodology and methods involved in this thesis are outlined in chapter four. 


\section{Chapter Four: Methodology and Methods}

\section{Introduction}

This chapter reviews the tools that were used to answer the research aims and questions of this study. The chapter begins with the motivations behind the study and the underpinning epistemological framework in which the methodology is situated. Secondly, there is an examination of the methods employed which include qualitative and quantitative forms of inquiry. The positionality and ethics of the researcher are discussed, as are the experiences and realities of fieldwork which is carried out at 'home'. Lastly, the chapter outlines how the data was analysed and concludes with the researcher's reflections of her research journey.

\section{Rationale of the Study}

The rationale underpinning this research has been to situate development in a New Zealand context. Development historically has dealt with those in need of assistance as residing in the 'developing world' (Desai \& Potter, 2008a). Those living in poverty have been defined as the 'other' (Smith, 2008) positioned away from developed countries, out of sight and deemed to be in need of Western development (Smith, 2008). The motivation behind this research has been to situate the 'other' close to home and in direct line of sight. In doing so I question the process of 'othering' as there are no others, no them and us, just a diverse group of people living together in a community. This research highlights the plight of poorly educated, Pākehā women of low socioeconomic status, who struggle to improve their lives through education.

A further impetus to undertake this research was to investigate the reality of how Pākehā women living in poverty fare under the New Zealand education system. Pākehā women belong to the ethnic majority are assumed to be accommodated under the dominant Pākehā education system (Papuni \& Bartlett, 2006a). Education has been used to eradicate poverty for women and girls in developing countries and has a focus on ethnic minorities in developed countries (United Nations Population Fund, 2012). This thesis is investigating whether the approaches and knowledge gained from the developing world context is applicable in the local context of New Zealand. This research was motivated by the quest to establish whether education is and can be used as a tool to eradicate poverty in New Zealand. This thesis is driven by the question of what happens to poor Pākehā women who have fallen through the cracks of the education system that purports to serve them. 
'Pākehā' has been privileged to describe my ethnicity and that of the women I am researching with. M. King (1985) defines 'Pākehā' as "an indigenous New Zealand expression that denotes things that belong to New Zealand via one major stream of its heritage: people, manners, values and customs that are not exclusively Polynesian", but also "no longer European" (M. King, 1991, p. 16). The term Pākehā recognises the unique second indigenous culture in New Zealand and the symbiotic relationship with Māori (K. Barber, 1999). 'Pākehā' instead of 'European' is used to convey the sense of belonging to this part of the world and the distinctive culture that has evolved and developed as the country has matured (M. King, 1991).

\section{World View}

The desire to undertake this research was born from a deep-seated aspiration to understand how women negotiate their life choices. I am interested in looking at the experiences, attitudes and motivations of women themselves. By my very nature and moral compass, I wish to see social justice being applied to every person. Women are entitled to engage, develop and participate in their own life and in their community to the fullest degree. To enable me to gain the knowledge that I am seeking with these women, I was conscious that I needed to adopt an appropriate epistemological approach, which is social constructivism.

Social constructivism is embedded in my methodology; through it I gain and interpret knowledge (Crotty, 1998). My epistemological stance ensures that I approach the production of information in a coherent and consistent manner to produce valuable knowledge. Social constructivism embraces the relationship between culture and context and their importance in understanding what transpires in society (Derry, 1999). This approach follows the philosophy that reality is a construct of human activity with knowledge produced both socially and culturally (Kukla, 2000). I align with social constructivism in the belief that 'learning is a social process'. Social constructivism is appropriate to this study as this is how women create and give meaning to their experiences and lives. Learning can be shaped by external factors and is where individuals gain meaning through social activities such as education (Au, 1998).

There are different approaches that I could have chosen (Kitchen \& Tate, 2000), the perspective I have adopted is not without its critics and I am aware of these critiques (C.-J. G. Lee, 2012). On balance, this approach reflects my philosophy, that our reality cannot be purely objective, that it is subjective and socially constructed. Social constructivism embraces the use of quantitative methods, with such tools being used in concert with 
qualitative approaches. I do not believe that my world view and values are independent of my study. They have influenced my choice of topic, my methods and how I have written up my research. Social constructivism is therefore consciously and subconscious woven into the very essence of this thesis.

\section{Use of Mixed Methods Research}

Mixed method research is a useful tool to employ when investigating social, cultural and economic phenomena in an inherently interdisciplinary field such as development studies (Gamlen, 2012). There has been a long tradition of utilising a variety of methodologies, with the multiple method widely used in this discipline (McKendrick, 1999). The mixed method was chosen for this research as it provides a 'breadth of understanding' (McKendrick, 1999), simultaneously overcoming the limitations of having no single ideal approach (Gamlen, 2012). Advocates of the purist approach do not believe qualitative and quantitative methods are compatible, arguing that capturing objective reality is impossible (Onwuegbuzie, 2000). It is my belief that for the purposes of research a positive and open attitude to all techniques should be held. The combination of empirical exactitude with descriptive precision enhances the depth and adds validity to my findings (Johnson \& Onwuegbuzie, 2004).

I was mindful that my methodological perspective would guide my research inquiries and connect theory to my research question. I believe the inclusion of quantitative methods as part of this inquiry would complement the qualitative methods employed (Hesse-Biber, 2010). Quantitative methods were employed to set a context for the qualitative methods as the thesis and analysis are strongly qualitative. Secondary quantitative data was analysed from development literature, government policies and statistical data. The statistics of current poverty data and education were used to determine how New Zealand is performing in regards to poverty levels, inclusion of women and issues of low socioeconomic status Pākehā women and education. Government policy and guidelines were studied with a particular focus on adult education, noting the impact of government attitude to this sector and policy ramifications.

The women's voices and stories that constitute the soul of this research could only be authentically obtained using qualitative methods. The use of semi structured interviews enabled the lived experience of these women to be investigated and recorded. Qualitative methods are deemed to be subjective, context based, with reality perceived by the individual's own experiences (Gamlen, 2012; McKendrick, 1999). The adoption of the 
qualitative paradigm in concert with quantitative methods of enquiry enables a more thorough exploration of educational and social phenomena (Onwuegbuzie, 2000).

\section{Literature Review}

The literature review was undertaken to information which was used to inform my future research directions and methods. The review of development literature included analysis of journal articles, scholarly books, policy documents, online newspaper articles and relevant academic theses. It was essential to have a solid understanding of how education has been used to eradicate poverty in the developing world, including the challenges and successes of this sector for these women. The analysis of the developing world literature assisted me in evaluating poverty, gender and adult education in a developed country context. The examination of information allowed me to discover the gap within the literature of how adult education is located in the alleviation of poverty by education and establishes that my study would contribute to filling this knowledge vacuum.

\section{Semi-Structured Interviews}

Semi-structured interviews were the principal method applied to gather qualitative data regarding how education or lack of it has impacted the lives of lower socioeconomic status Pākehā women. The one-on-one approach was selected as one that would be less intimidating for women to come forward to discuss the sensitive topics of poverty and limited education. It has been my experience that in group work there may be one strong voice that wants to be heard and this can intimidate or stifle contributions from other participants and thus focus groups were not used. Interviews enabled in-depth discussions and explored the personal experiences and opinions of each woman being interviewed (Brockington \& Sullivan, 2003). The interviews were audio recorded with only the participant and interviewer present to ensure confidentiality and to encourage the participant to speak freely. The interviews varied from 60 to 90 minutes in duration and were conducted in quiet locations familiar to the interviewees. Two of the participants wished to have their own identities used in the research findings, with one participant choosing to remain anonymous. 


\section{Reflective Diary}

This thesis was not only a journey of discovery of academic knowledge but of personal discoveries. Being new to research and how to conduct it, I found it cathartic to keep a record of my actions and emotions as I undertook the research. By noting my immediate thoughts and feelings as I encountered each issue, I was able to reflect honestly and candidly on the research experience. The raw analysis of my actions aided me in revealing another dimension to my data and I gained perspectives which would have been lost if I had not utilised this diary. By reflecting on each interview in the journal, I was reminded of my emotional connection to each participant. This connection continued when I was deciding how best to send the requested copies of transcripts to the participants. I chose to personally take the transcript to the organisation which one participant gave as a contact address. I was hoping to see her and give her the transcript in person but unfortunately she was unavailable. I followed up the visit with a phone call later in the week to make sure she received the document. By being reflective it ensured that I acted appropriately and respectfully to each participant and responded to their individuality. The reflective diary was of assistance to me in both professionally and personally in this research journey.

\section{Case Study Method}

The participants in the study have been viewed as individual case studies, as this research is not a representation of Pākehā women of low socioeconomic status in New Zealand. The case study approach is extremely useful in untangling social complexities (Eisenhardt, 1989). This research strategy can involve a small or large number of participants and allows for analysis on many levels (Yin, 1981a, 1981b). Case studies combine both qualitative and quantitative data collection methods and have incorporated the validity and reliability inherent in experimental research design (Eisenhardt, 1989). Case studies are a useful tool to test theory (P. A. Anderson, 1983; Pinfield, 1986) or generate theory (Gersick, 1988; S. G. Harris \& Sutton, 1986) and to provide description (Kidder, 1982), all of which are relevant to this study.

The acceptance of the case study as a valid research strategy has not been without its dissenters, who have called it a 'non rational and scientific venture', with deep seated problems (Miles, 1979). These claims have been counted by authors such as Yin (1981b) who state case study research is a systematic and legitimate method of inquiry. The case study strategy is warranted when a pragmatic inquiry into a contemporary phenomenon in its real life context is being undertaken, especially when this boundary can be blurred (Yin, 
1981a). Adopting the case study method was invaluable to unearthing the connections between theory and reality in this research.

\section{Ethics}

The ethical concerns of undertaking this study were at the forefront of my mind before and were present throughout the research process (Hesse-Biber, 2010). The ethical questions included but were not restricted to the following: whether I was a suitable researcher for this topic; how I would ethically recruit respondents with whom to research; will my research benefit my participants; how can I respect and be sensitive to these contributors beyond the required law; and have I been true to my own ethical code (Hesse-Biber, 2010)? These questions and ethical dilemmas were partly appeased by attending an ethics seminar held by the chair of the Victoria University of Wellington Human Ethics Committee in July 2012.

This seminar grappled with these predicaments and highlighted possible ethical conflicts that may occur in the research journey. The discussions that took place demystified the ethics approval procedure from a university perspective and made it more than a 'tick the box' section of my research. I was aware that my research would not proceed without voluntary 'research partners'. It was important to make the connection that ethical research is a living thing, with my participants connecting reality and theory (Guillemin \& Gillam, 2004). The issues of the participant's right to say no or withdraw, the location where the research would take place and the power relationship of the interviewer and interviewee were highlighted during my communication with an organisation, such as the Suzanne Aubert Compassion Centre that deals with vulnerable people (Houghton, Casey, Shaw, \& Murphy, 2010). This conversation was invaluable as it brought to life that ethics is not one sided and can be perceived differently (Clark, 2002). The welfare of the guests of Suzanne Aubert Compassion Centre is the organisation's main priority. They required a complaint procedure in the event that the participant was unhappy with me as interviewer, or with the interview itself. The Suzanne Aubert Compassion Centre wanted a process that allowed the participant to bring any concerns she had directly to them if the interviewee felt that was the safer and more comfortable option for her (Reflective Diary, 2012, $18^{\text {th }}$ October) .

Consent must be given by research participants and I had the requisite consent and information forms for my research partners, with written consent the preferred method by Victoria University of Wellington. The more appropriate form of consent might be verbal 
(Houghton et al., 2010) when dealing with participants who have limited literacy. The participants in my study left school without formal education qualifications and I was mindful that participants may have restricted reading abilities. This recognition brought awareness that each participant's individual needs must be accommodated, making the research process supportive and not burdensome (Rosenthal, 2003). It is also imperative that a researcher is not patronising and treats all respondents equally and ethically. I was mindful of potential harm to my participants as an ethical issue as the research participants were vulnerable in different ways. They may suffer humiliation or censure when the thesis is published and I attempted to mitigate this possibility by giving participants the choice between anonymity or using their real name (Reflective Diary, 2012, 23 ${ }^{\text {rd }}$ August).

The appropriateness of using incentives by gifting a supermarket voucher to my participants for their time was another ethical consideration for me to ponder and reconcile. There are differing opinions on whether incentives are a system of coercion and undue influence, or are harmless and merely a tactic to recruit and maintain research participants (Grant \& Sugarman, 2004). I did not wish to be condescending nor imply that my research partner was in need of the voucher. I did not intend that the incentive degrade or impose power discrepancies between the researcher and the researched name (Reflective Diary, 2012, 23 $3^{\text {rd }}$ August). My deliberations led to offering the supermarket voucher to my participants in a gesture of reciprocity, born of good will and appreciation of having the privilege of hearing their experiences (Harrison, MacGibbon, \& Morton, 2001).

\section{Positionality and Research}

Positionality is a lens that can be applied to magnify and interrogate power relations in research, both explicit and implicit. It can be utilised to investigate the relationships of the researcher and the researched and the transfer of knowledge between the two agents (Chacko, 2004). Chacko defines 'positionality' within a feminist theory framework, referring to "aspects of identity in terms of race, class, gender, caste, sexuality and other attributes that are markers of relational positions in society" (2004, p. 52). My positionality is inherent in my research design; it flows through this thesis without conscious thought and it is integral to this thesis. It was imperative that I objectively scrutinised and reflected on how I undertook this research project. I was able to achieve this by understanding my positionality, accepting its influence and actively engaging with 'being me' throughout my research journey (Sultana, 2007). 
My decision to embark on this research experience began in South America where I had travelled to volunteer on a women's empowerment project established in Huanchaco in Peru and run by a local Non-Government Organisation (NGO). After my volunteering I was able to travel with other like-minded travellers and our exploration of the continent took us through different countries, with differing levels of poverty that were visible and not so visible. I began to think of home as the contrast of countries with different levels of development illustrated to me that populations living in poverty become more invisible with the development of their economies. I live in a 'developed country', we have a compulsory education system and social welfare is available to members of our community in need (O'Brien, Bradford, Stevens, Walters, \& Wicks, 2010). New Zealand is not without poverty, there are high levels of adult illiteracy and the profile of female Pākehā/European New Zealanders living with low education and limited incomes is low (Holland \& Terrell, 2007). The limited debate on these subjects compelled me to undertake this research. The social injustice of the situation should not be normalised and accepted; marginalised Pākehā women deserve more, are worth more and are greater than the labels used to categorise them. I not only identified with these women as a low income Pākehā woman but I also wanted to highlight their lived realities and experiences.

Contributing to the awareness of the plight of these women was not the only motivation behind my wish to work with Pākehā women. My motivation was also to carry out research with women of my own ethnic group. Important and essential research is being carried out with Māori and Pacific Island women, with researchers not necessarily belonging to these ethnic groups. I do not believe that I am the appropriate person to carry out research with such women. I was born in Dunedin of European parents; attended schools that were mainly Pākehā and only knew one friend of Māori descent growing up, and I do not speak te reo Māori. To be able to fully engage, to be culturally respectful and to hear all the nuances in my interviews, I would want to converse with my participants in their native language. Travelling around South America with a limited grasp of Spanish highlighted how limited my interaction with local inhabitants was, due to a language barrier.

Carrying out fieldwork at home has challenges. The advantage of not having to 'enter', 'leave' and 'return' to the field (Till, 2001) enabled me to extend my research period when personal matters took priority over my study and afforded me extra time to recruit participants. There are disadvantages of living in my research domain, for instance separating the research and personal selves and how the boundaries of the field and home 
can blur (Till, 2001). I used my shifting physical, personal and professional locations to explore the fluidity of my research spaces and acknowledged that they are complex social spaces (Rose, 1997). By virtue of moving back and forth between these domains, I was being changed as a researcher, influenced by the research process and influencing the research in return. The fluidity of the settings did lead to some discomfort, but afforded me the opportunity to gain new insights, challenge assumptions and provide a more empathetic account of my participants' experiences (Nast, 1994).

My fieldwork presented me with an outsider/insider position which I had to negotiate throughout the research process (McDowell, 1992). I did have some similarities in common with my participants which included being an adult Pākehā female born in New Zealand. My education level is quite different to one participant but is similar to my other research partners. I simultaneously felt an insider and outsider while conducting my research and experienced the conflict and confusion of not belonging to one group (Chacko, 2004). This 'in-between' position brought feelings of being adrift and of uneasiness (Entrikin, 1991). This space, though uncomfortable, was an opportunity to balance out the subjective and objective components of this study and to modify the dominant methods of acquiring and producing knowledge (Katz, 1994; Nast, 1994).

Reflexivity was an ever present companion and conscience on my research journey and has close links to feminist methodology (Rose, 1997). I do not espouse a particular feminist position but embrace the feminist philosophy and theoretical perspective that all people should have full social, political and economic equality (Offen, 1988). The alignment of reflexivity and the feminist framework encourages the continuation of self-discovery, continues to challenge power relations and situates the researched at the core of knowledge production (Rose, 1997; Sultana, 2007). The adoption of a reflective tone was used to moderate the exploitation and extractive nature of research through the continual questioning of my intentions, actions and prejudices (Chacko, 2004).

\section{The Reality of Recruiting Participants and Interviewing}

The recruitment process of voluntary participants was restrained by a combination of institutional ethical regulations, respect for these women and an acknowledgement of the sensitivity of the subject we would be discussing (Halse \& Honey, 2007). My primary recruitment strategy was one of approaching organisations that work and support people in need. I did not have an established network of contacts who work with the women I wished to approach and the method of personally approaching organisations was adopted 
to overcome this obstacle (Reflective Diary, 2012, 23d August). As I had no previous dealings with these organisations, I made personal visits with a letter introducing myself, copies of the information and consent forms for the participant plus a poster for their notice boards. Due to financial constraints, visitations were carried out by foot and were restricted to the Wellington inner city and Newtown areas.

Organisations visited included Citizens Advice Bureaus, Work and Income (WINZ), Community Probation Service, Women's Refuge, church groups with city missions for people in need and second hand stores. The motivation behind the choice of organisations was to connect with women in different sectors of the community, who may use a variety of different resources to support them. The reaction I received when I explained my intent and the reason for the study was initially one of caution then assistance. Many of the organisations deal with vulnerable clients. I believe their initial reluctance to engage with me was to protect their guests/clients and to alleviate the 'project saturation' many of them experience.

My request to have the poster displayed was met with varying degrees of success. If an organisation did not think it was an appropriate study for them to be associated with and did not meet their mission, I was politely informed my poster would not be displayed. Other groups were happy to display my poster and receive my information, though I had no control over where the posters were displayed or for how long. The community centre that connected me with my first participant was incredibly interested in my research and the focus on Pākehā women. The same organisation warned me that it could be difficult to recruit my particular demographic. In their experience lower socioeconomic status Pākehā women are not as visible in accessing assistance as other groups in need (Personal comms 2012).

The impersonal recruitment strategy of using intermediaries has been commented on and has not been overly successful in recruiting women of low socioeconomic status especially those of colour (Madriz, 1998). The concerns of this recruitment method for women of colour (Madriz, 1998) may also be of concern for marginalised Pākehā women as demonstrated by the lack of response to my posters. There are uncertainties and problems associated with using posters as a source of recruitment. Respondents may take details but not call, they may notice the poster but not take any details, and or they may telephone but not leave a message if I am not present to take the call. Relying on the participant to get in touch with the researcher may add another barrier for the respondent to overcome, be it financial or emotional (Reflective Diary, 2012, $5^{\text {th }}$ October). Participant reluctance has 
been recorded when conducting research on sensitive subjects (Morse, 2001; Renzetti \& Lee, 1993). The reasons for this reluctance could be connected to the type of research or the desire for privacy (Renzetti \& Lee, 1993). The characteristics of the potential participants may also make a respondent reluctant; this category can include being advantaged, disadvantaged or sensitive and secretive (Adler \& Adler, 2001). Gender has not been specified as a particular problem in recruiting participants but has been addressed in respect to power sharing (Butera, 2006).

Personal networks proved to be invaluable as the recruitment of my second participant was through a mutual friend and by informally discussing my research in relaxed social gatherings. This personal relationship led to my second respondent volunteering her time and agreeing to collaborate with me on this research project. The fact that I had a relationship with this participant before the interview made some aspects of the interview easier but also made it challenging. I had to remind myself to be impartial interviewer and not let my friendship interfere with how I conducted the interview or our relationship after the research (Reflective Diary, 2013, $14^{\text {th }}$ March) .

The recruitment of my third research partner was through a 'gatekeeper', who introduced my research and presented the opportunity for the potential respondent to contribute to my project by participating in an interview. This gatekeeper or sponsor approach is widely used in social science (Adler \& Adler, 2001) and, as I can attest, it is an efficient and effective recruitment method.

The willingness of the participants to engage in this study was enhanced by both the interviewer and interviewee being of the same gender and ethnicity (Madriz, 1998). The empathy and the ability to relate to each other were raised due to the commonality of gender and ethnicity. Rapport was increased and differences between us minimised by conducting the interviews in informal, comfortable and familiar settings to the participants (Jarrett, 1993). I took into consideration the emotional and physical safety of both parties before the interview location was agreed. This reflection was taken to limit or eliminate any potential harm to either party as a result of taking part in the interview (Corbin \& Morse, 2003).

Conducting semi-structured interviews are more than gathering information; they are spaces where both parties construct meaning through conversation (Mishler, 1986). The narratives of our culture and lived reality was brought to life through the experiences shared with me by my informants (Gudmundsdottir, 1996). This reality was exposed by 
each interview having the same list of questions but each interview was as unique and different as the women interviewed.

I am not an experienced researcher or interviewer and was nervous before my first interview. My first respondent has experienced mental health issues and could be categorised as being vulnerable. I found her to be courageous, giving and full of compassion for others. I acknowledged my prejudices and assumptions when first meeting her and focused on being empathetic but not patronising in our interaction. My impartially was tested with my second interview as I have an existing relationship with this participant and have a similar educational background. This neutrality slipped when the conversation ventured into different territories and interrogated issues more deeply than would have occurred without the commonalties between us.

The interview experience with my third informant was again distinctive. I had grown more comfortable with interviewing and was excited to hear the views from a participant of differing background and age to my other research partners. My conversation with this participant also took new directions though not for the same reasons existing in the second interview. It resulted from the desire of both of us to engage and add to the knowledge surrounding the topic I was investigating. The articulation and understanding of me as a researcher, the elucidation of each interview interaction and interpretation of the meanings constructed in these interviews (Gudmundsdottir, 1996) were essential in the 'writing in' phase of this project (Reflective Diary, 2013, 14 ${ }^{\text {th }}$ March).

\section{Analysis of Data}

Literature was used to interrogate and illuminate the core themes and to broaden understanding (Knopf, 2006). These topics were explored to discover further linkages and interconnectedness of themes. I categorised literature into which theme it pertained to, sub themes were then discovered and outlined in lists which were used to investigate and flesh out the main themes.

Data on poverty, Pākehā women and adult education were reviewed to determine New Zealand's performance in these areas and to provide a context for this research project. Government policies were reviewed to ascertain their impacts and influence and to inform the main themes.

The semi-structured interviews were transcribed soon after the interviews, with my initial thoughts on themes and feelings recorded in my reflective journal immediately after each 
meeting. These feelings and contemplations were extremely powerful and allowed the themes uncovered in the interview to be first noticed and documented. I did not transcribe every 'um' and 'ah' in order to retain the clarity of the information pertinent to this study and to ensure the smooth flow of the transcribed interview. This speaks to the power of the researcher to decide what is appropriate and could be viewed as an attack on the integrity of the reported conversation (DeVault, 1990). It is inevitable that the researcher will control the transcription process. I accept this position and would prefer to be honest and explicitly state I have taken this action than deny or remain silent as to my actions (Malkki, 1995).

Once the interviews had been transcribed and collated with material gathered from the other qualitative methods, I began the task of deciphering the themes manually. There is a growing popularity within the social sciences to employ computer based programmes to decode themes (Pope, Ziebland, \& Mays, 2000). This method is particularly appropriate for a large number of participants. However, as my group of participants only numbered three, I employed a more organic approach. I preferred to print off my transcripts and used highlighter pens to note themes. This allowed me to ruminate on a more intimate level with the information gleamed from my participants to assemble my core ideas. I replayed the taped interviews, placed myself emotionally and mentally back in the interview to connect with my research partners and their stories.

I found the next stage the 'writing up', both daunting and exhilarating as this was the stage that I had to do justice to my participants experiences. The 'writing up' process has been presented at the final point where a singular truth is produced from the collected data and is part of a linear progression (Coffey \& Atkinson, 1996). My philosophical stance rejects this statement and embraces the notion of subjective or 'situated truths'. To make sense of qualitative data, I accept 'writing in' as a more appropriate and fitting term as it includes the researcher and the embraces the importance of self-reflexivity (Mansvelt \& Berg, 2010).

Academics have raised concerns of a dilution of the argument and decreased accountability with the passing of time from the interview stage to when the 'writing in' phase takes place (Cupples \& Kindon, 2003; Mikkelson, 1995; Stevens, 2001). To counteract these possibilities, I recorded my thoughts in my reflective diary and transcribed the interviews while the conversation was still fresh in my memory. My dedication to these tasks wavered due to dealing with unforeseen personal circumstances which occurred while I was undertaking my research. 


\section{Reflections of Field Work}

My research journey incorporated personal matters that financially, emotionally, physically and psychologically were not expected and I had to find ways to deal with and work through them. I acknowledge that these events have impacted my thesis and I can honestly say I do not know if these have been positive or negative. I decided to take time off when two separate events were acute and with hindsight admit the periods leading up to and after were also traumatic. This affected the schedule of when I undertook certain research tasks, as I didn't have the energy to deal with anything over and above the personal issues that were my priority at that time. I postponed one interview as I recognised that I would not be present emotionally, mentally and spiritually for that person and that was not acceptable to me. Each participant was laying bare a sensitive and personal life experience and she deserved my full attention and mental presence; anything less than that I could not ethnically and morally tolerate.

The emotional roller coaster that I went through provoked me to constantly question my decision to undertake this research and whether it was the appropriate time to proceed with it. The psychological struggle I went through before asking for financial assistance made me question how other Pākehā women deal with this dilemma. What medical issues do these women also have to overcome and still carry on with their education dreams or do they have to set aside these aspirations for the reality of earning a wage in a low paid job? I had my own hurdles to overcome and process what the most appropriate options were. I was fortunate as I had options and a support system. I appreciate that not all Pākehā women of low socioeconomic status are as fortunate and have greater obstacles to surmount than the ones I had to contend with.

\section{Conclusion}

This chapter has explored the epistemological framework of the thesis and the qualitative and quantitative methods applied to answer my research questions. Research is not carried out in a vacuum and can be influenced and affected by issues both expected and unexpected. It is essential for the researcher to be flexible and open to change. The research design must be robust yet malleable, reflect the researcher's ethics and positionality, embody and present a true representation of the research participant(s) involved. This study and methods used are not without restrictions. There are limitations in regards to the contribution this research may add to academia knowledge and benefit it may bring to the participants. The impact of a single master's thesis may be limited but 
joined with other academic and scholarly voices its ability to effect change can be far reaching. 


\section{Chapter Five:}

\section{The Women's Voices - Messages from the Soul}

\section{Introduction:}

This chapter chronicles my research partners' stories and memories pertaining to their education experience. The intention of this chapter is to give the reader a snapshot into the lives of three unique women, as it narrates how their education has helped shape the women they are today. These interviews constitute the soul of this thesis and it has been a privilege for me to be able to record and share their experiences in this document. These narratives depart from the theoretical and only deal with reality as the truths of three marginalised Pākehā women lives are documented in this chapter. The themes and insights gathered from the conversations recounted below will be discussed further in chapter six.

\section{Angela:}

Angela contacted me after seeing one of my posters asking for participants. Her determination to have her voice heard was exhibited by her perseverance to get hold of me. Due to a change in office, my contact details required updating and in the interim Angela had tried to get hold of me but to no avail. I then received an email from the organisation that had the poster displayed asking me to call Angela and after our phone call we agreed a time to meet. Both of us were early to the meeting and when I first met Angela as she was having a calming cup of tea to relax her as she was experiencing an episode of anxiety. She had pushed through this feeling to meet me. I learnt that this interview was so important that it was the impetus for her to leave the house that day and that she would have been very disappointed if I had cancelled. The informal nature of our first interaction was wonderful and I think it relaxed both of us. It allowed us to chat about nonsense things and provided a gentle path to wander down before embarking onto the interview proper.

I had a glimpse of Angela's day to day obstacles she has to overcome and was humbled by her comment that taking part in this research had increased her feeling of well-being. This sentiment and awareness remained with me throughout the interview. Her reasons for meeting me were also remarkable. She wanted her story heard not just for herself but to publish the plight of people with mental illness and to let the public know there are poor people living in New Zealand. Angela did not wish to remain anonymous as she wanted her name to be associated with her contribution to this research. I believe this stance empowered her and strengthened her commitment and connection to her community. 
Angela is fifty four and through the years saved enough money to be able to purchase her own home. This has not come without sacrifices. Angela regularly goes without healthy food and doesn't use her heating as paying the power bill is a financial difficulty for her. She has an impression that people think she is wealthy as she owns her own house, though she finds it hard to find the money to buy food. Her empathy for others is vast as, though she may struggle financially, she is aware that others are also in need and gives away food even if that means she goes without.

There is a history of mental illness in Angela's family and her life has been affected by abuse she experienced from a close family member. Angela did not stipulate the type of abuse she suffered and as it was up to her to share what she wished to with me I did not inquire as to its nature. She found some solace in children's homes where she spent some of her childhood, but they were also distressing for her as she was not always safe in them. Her schooling was troubled partly due to her having learning difficulties and from the lack of support she felt from the school and teachers. A further disruption and eventual reason for her leaving school early was being removed numerous times by her mother often in a traumatic fashion. This stress coupled with her struggling at school proved too much and she left at age fifteen.

Much of Angela's education has been through informal means including her kindergarten teacher (who she called her "saviour"), neighbours, church members and even her father who taught her "when you have no education you do it yourself". She accepts but does not like her level of reading and writing and endeavours to make the best of her situation. Angela has experienced the derision of others in connection to her education and the unrealistic expectations of government welfare departments for the type of job she can aspire to and fulfil. One such encounter with a WINZ office placed her in a vacancy that she was not qualified to hold and resulted in her feeling despondent and acutely aware of her literacy limitations. Angela put renewed effort in to meet the requirements of the job but in the end admitted it was beyond her reading skills. The attitude of the welfare office was one of censure as they had formed an opinion that she did not want the job and stopped her welfare payments. This misinterpretation and lack of understanding of Angela's circumstances at WINZ resulted in distress for Angela and had financial consequences for her.

Angela has not given up on education but is realistic about what she can achieve within the present adult education structure. She is concerned that she takes longer to pick things up than others, and worries that she is being selfish as she requires more support than other 
students. Her adult education experience has not been an overly positive one with the subjects, cost and class structure proving difficult for her to engage with. The impression I had of Angela from our interview of one of resilience; a survivor who wishes to better herself and others through acceptance, understanding and support.

\section{Deirdre:}

Deirdre's involvement in this research came about through our friendship and informal chats we had about my project. She self-identified as a potential research partner as she met the criteria of women I wished to work with. After some discussion of the negatives and positives of using her real name, it was agreed that we use an assumed name to protect her privacy. We met at her home and our pre interview conversation was sprinkled with material that we then went on to investigate and put on the record in our interview. Interviewing a friend brought a different dynamic to our meeting. I was conscious that having an existing relationship with a participant could impact on how I conducted the interview and how it was possible that the role of researcher and friend can be blurred. I endeavoured to be vigilant about this possibility, consciously separating my researcher and friend selves in this setting.

Currently Deirdre is completing a master's degree, having navigated family crises and post graduate study the previous year. Deirdre had enrolled in university part time in the late 1980s while she was married. She decided not pursue her degree when her marriage broke up, instead concentrating on being the sole bread winner for herself and two children. Her first venture into university was a "feeling her way" period with her subjects not directly linking to a job and she did not feel that she could justify continuing at that time.

Deirdre's parents were of the generation where hard work and perseverance counted and education was not deemed essential to secure a job. Her father's determination to do well at school by overcoming a learning difficulty has instilled in Deirdre a desire to reach her educational goals. Deirdre remembered stories of how teachers were not interested in her dad, except for one teacher who showed interest and this improved her father's achievements exponentially as a result.

School was a haven from a tumultuous home life for Deirdre. Deirdre did not dwell on this subject but it was apparent that her relationship with her mother and how her mother treated Deirdre and her siblings was cruel. She was enrolled for the school certificate qualification when her mother decided that she had to leave school to get a job to help out the family financially. Both Deirdre and the principal of her school were unhappy with this 
decision as both wanted her to continue with her education. Deirdre was fifteen when she left school and began working. Her plans to go back to school were put on hold when she met her future husband and married at nineteen years of age. Her experience of school was not a completely satisfactory one as she felt neglected for being of average intelligence and felt that for a girl to gain a teacher's attention she had to be exceptional.

Deirdre has experienced the trials of living on a low income as a child and as an adult. Her decision to undertake her current study that has practical and theoretical components has been motivated from a desire to be more employable. The higher education she has been involved in has afforded her new knowledge and tools to function in an ever evolving world. Deirdre may be fifty eight years old but she has no wish to remain static. While feeling out of her comfort zone by continuing her education, this decision has allowed her to continue to develop both emotionally and intellectually. Her access and possibilities to connect with people have been expanded by her engaging in formal education activities.

The expectations of what are acceptable for a woman to do career or family wise has been felt by Deirdre. She has lived with the implicit and explicit restrictions and constructed her own freedoms in this space. Deirdre has experienced exclusion as an older student and also felt the admiration of others for undertaking study as a mature student. Deirdre is an intelligent, humorous, motivated woman who has made her own way utilising her engagement with education to flourish personally and professionally.

\section{Hannah:}

I contacted Hannah after receiving her details from a friend and fellow development studies student. Hannah and my friend's mother work together and the topic of my research and search for volunteers had come up in conversation resulting in Hannah giving permission for me to contact her. I called Hannah and after a very lively exchange, we agreed to meet at her house later that week. Hannah's neighbourhood is not overly affluent but I noticed as I walked to her house from the train station that her neighbourhood was well kept and had a great welcoming feel to it. Hannah had finished her job for the day at the day-care centre where she works and was fitting the interview around errands she had to take care of that afternoon.

Hannah is twenty seven years of age and was born and lives in the same area as her mother and step-father. She has a partner and a six year old daughter. She remembers loving her primary and intermediate schooling but tragedy struck at the beginning of third form when her father died. She was thirteen years old. This event coupled with the onset of puberty 
and starting high school led to a period of depression. She was bullied and with all these issues to deal with started to be truant from school. The habit of being absent was well embedded by her fifth form year when she would have been sitting school certificate. Hannah's school year was the first to come under the assessment system of National Certificate in Educational Achievement (NCEA) scheme, which replaced School Certificate.

The high school Hannah attended is a decile two school with many students coming from low socioeconomic communities in the area. There was a suggestion from her sister to move schools due to the bullying she was experiencing but she had friends at her old school and didn't want to move. Hannah mentioned that with hindsight, it may have been a good thing to move, but as a child she just wanted to be around her friends. Hannah managed to get the minimum credits to keep moving ahead though she had to repeat one subject and had to take the class with the year behind her.

Teacher support and interest in Hannah as an individual was crucial to her choices of subject and the attention of teaching staff was reflected in her attendance and performance in particular topics. The choices of subjects were not always to Hannah's liking and those that she liked had to be passed in the previous year before continuing. Due to Hannah's lack of attendance she could not achieve higher NCEA levels in the subjects she liked as her truancy was now affecting her school record and she was not achieving the requisite level. Hannah's parents did not leave school with any qualifications but she had their support as they both believe education is valuable. Hannah's engagement in different subjects would have been assisted by further support from teachers but she believes this was limited as she was "not an amazing student". She recollected that her cousin who attended a higher decile school and has similar education talents to herself received assistance, and believes this assistance made a difference to her cousin's academic outcomes.

Hannah left school at seventeen when she was expelled due to her poor attendance and she started a part time job at a supermarket. She did contemplate going to another school as an adult student to achieve a university entrance qualification but decided to remain at work when she was given full time hours. The desire to attend university was with Hannah with achieving a university degree as the goal, but at seventeen she was not sure of what her major would have been. After changing jobs as she wanted to do more than work in a supermarket, she continued to seek out courses that would assist her in gaining a university 
entrance qualification. After many frustrating years, a colleague told her about an organisation that operated NCEA level five certificate courses where attendance could be part time and this was her step to her degree course. Other courses were full time and Hannah for financial reasons could not afford to take time off work, so financial support from the government was not sufficient to have allowed her to attend such courses.

Hannah wished to continue her education as validation of her belief that she had the ability to achieve an advanced level of education and deserved to succeed in the educational arena. She wishes to improve her job opportunities and more importantly for Hannah, she wants to be a positive role model for her daughter. She does not wish to be viewed as "uneducated' if society associates lack of education with a deficiency in a person's intelligence. The unveiling of the appropriate course that met Hannah's needs and interest has coincided with the timing being right in Hannah's life for her to be able to take up this opportunity. She has never given up on wanting to learn and has used this motivation to overcome the invisible and visible barriers to achieve her education goal. Hannah has had a rocky relationship with childhood and adult education but remains upbeat on what can be achieved when you put your mind to it. I found Hannah to be a charming, engaging and insightful person and I appreciated her candour and openness that was present in our discussion together.

\section{Conclusion:}

This chapter has introduced my three research partners and communicated their thoughts and memories in regards to their education experiences. Their stories have illustrated that there can be areas of similarity and of difference between women with lower socioeconomic backgrounds. A woman may experience abuse or mental illness or neither. She may have a loving supportive family environment where education is valued or she may not. Education may be something she wishes to engage with as she enjoys it or she may find the interaction highly challenging and therefore not a pleasurable experience to continue. These three narratives illustrate women are not homogeneous and neither are their upbringings and educational experiences. The themes and points of discussion that have touched upon in this chapter will be investigated and discussed in the following chapter. 


\section{Chapter Six: Interpreting the Messages of the Soul}

\section{Introduction}

The previous chapter introduced the life stories and histories of three Pākehā women of lower socioeconomic status in connection to their education journey in New Zealand. This chapter serves as an extension of their stories, as it delves deeper into their narratives to explore the themes that arose. The themes that are discussed in this chapter have been informed by the literature and include the analysis of the commonalities and the areas of divergence between each woman. Four themes emerged from their accounts. These include family influences, experiences at school, society perceptions and adult education. Exploration of these four areas is essential to understand how challenging it is for a girl and then as a woman to engage and flourish in the education arena. Thematic analysis has been employed to shed light and gain meaning from these topics. In order inform on sociocultural and structural conditions (Braun \& Clarke, 2006) thematic analysis was conducted within a social constructivist framework, this analysis tool is widely utilised to analyse qualitative data (Roulston, 2001).

\section{Family Influences}

\section{Instability in the Household}

The childhood of each of the research partners was affected by varying degrees of uncertainty and insecurity within their family units. Angela's childhood began in Tauranga where her parents had a business which was given up when they moved south to Wellington, with only $£, 50$ in their pockets. The impetus for the family move was her mother's health, which was deteriorating due to schizophrenia and cancer. The effects of mental health and the stigma attached to mental illness can have a substantial and long lasting influence on a young girl's life (Jewkes, 2002). The relocation south accompanied with a down turn in the family finances, not only put stress on Angela father's health but also on Angela's health.

Deirdre's predominant instability factor was the marriage break up of her parents, but the preceding years saw the family business fail and relocation from the North Island to the South Island. Although Hannah's family had been more stable financially and locality-wise her trauma traced from the death of her father which occurred in her formative years. Hannah did not mention any abuse in her family though both Angela and Deirdre 
experienced different forms of it from a close family member, with Angela enduring the upheaval and trauma of being removed from the family home.

Each participant had to deal with traumatic events as a young person. These events would have been challenging for an adult who has a higher level of maturity to cope with and overcome, let alone a child. Angela and Deirdre experienced the changing financial status of their families due to the loss of family businesses. Loss of family income would be compounded for Deirdre when her parent's income became split between households due to her parents' divorce. Hannah's family income would also be affected as the possibility of two adults earning an income was reduced to one when her father passed away.

Both Angela and Deirdre had the challenge of fitting into a new place and schools and Hannah had the trial of starting high school at the time of her father's passing. The death or absence of a parent as a result of divorce changes the dynamics and structure of a family. This upheaval can impact negatively on a child's cognitive ability and sense of self in her developmental years (Brooks-Gunn, Duncan, \& Maritato, 1997). The disruptions in Angela, Deirdre and Hannah lives were out of their control and illustrate the unpredictability of a child's life. All three participants have demonstrated the influence of particular life cycle events on their levels of poverty and wellbeing. The significance of life events on children such as mental health, poverty and abuse have been captured and reflected in the wider literature (Jewkes, 2002). All of these factors impacted on how each woman engaged and enjoyed her early experiences with education. The seeds of this engagement were not solely sowed by themselves, but were propagated by their parents' memories of school and the parent's level of education.

\section{Parent's Education}

The level of education attained by the parents of my three research participants was limited, with only Angela's mother's profession as a nurse indicating a higher level of education. Angela's father was an immigrant from Romania and whilst he owned a takeaway shop, Angela recounted that he could hardly read or write. Education was valued in her household and to get ahead you might have to help yourself. She had a very strong memory and connection to the advice given to her by her father years ago.

"Ah, my father tanght me one thing, when you have no education you do it yourself. You do word sounding and that's what helps you to make word sounds" (Angela interview 2012). 
Deirdre's mother had limited education having left school at twelve years of age to help her own mother look after her father who received a brain injury after an accident and couldn't work. Deirdre's father suffered from a learning difficulty which impeded his progress at school, but this did not diminish his thirst for knowledge. Deirdre mentioned that her stubbornness to finish her degree could be traced to the commitment she sees in her father to see things through. She concedes that:

"if you talk. to my father about some subjects, he is an extremely knowledgeable man and he loves learning new stuff and he is always learning new stuff. But if you say anything to bim about formal education, then that would put the fear of god into him" (Deirdre interview 2012).

Deirdre's father suffered from the pressure to keep up with the other students and lacked support from teachers. Her father wanted his children to do well in school but found assisting his children with homework extremely taxing and frustrating if they did not get things right straightaway.

"Part of that is obviously Dad having memories of his own time at school, but also I think you know, that was the way it was tanght then, if you didn't pick it up straight away you were stupid or dumb and everything else and people got angry with you" (Deirdre interview 2012).

Deirdre made mention of one teacher that taught her father well and this change in style and attention made a massive difference to her father's educational outcomes in that year. The impact of this one teacher was far reaching, resulting in Deirdre being given the teacher's first name as her middle name.

There was also an acknowledgement that Deirdre's father would have loved to further his learning, but he felt he had too much against him for this to happen. Her mother did not have this same opinion, as she did not particularly enjoy school and if she had continued, it would have been solely as a means to an end to earn more financially. Deirdre admitted that her mother was content to be able to have a basic level of education that afforded her a decent level of reading and writing and "school for girls in those days wasn't something that was encouraged".

Hannah's parents both left school early with her mother leaving at the age of seventeen and her father when he was fifteen. Her father came from a large family where he numbered thirteen out of fourteen children, his mother was very relaxed in how far he took his schooling, "The Mum was like, if you want to do schooling you do schooling kind of thing, I think". Both of her parents did not obtain formal education qualifications, "though they think 
education is great'. There was no pressure on Hannah to go on to university, but there was support for however far she wanted to take her education.

The limited scope of education of the research partners' parents does not seem to have dampened their parent's belief in the value of education. The basic level of education appears to be readily accepted with further education being entirely optional and perhaps out of reach depending on the individual's abilities. There were different levels of engagement in education at home with each family. This may be a reflection of each parents' education level or expectations for their children. These observations are in accord with the broader themes in this thesis concerning poverty and education. There are connections between the low education of a parent and limited educational attainments of the child though this outcome is not a certainty (Goodman, 2010). Lack of education in the parent does not necessarily reproduce low education in the child. The education levels attained by Deirdre and Hannah are witness to that statement.

The purpose of education and its use has differed slightly between the three women's families. Angela did not mention her extended family but Hannah's is very excited that she is gaining a degree and Deirdre's children are also very proud that she has continued on to further education. Education may be valued but the reasons to remain in schooling or to leave can be complex as demonstrated by the experiences of the three women.

\section{The Choice between Working and Education}

There are different reasons behind Angela, Deirdre and Hannah leaving school when they did. Firstly, Angela was not able to perform well in the mainstream education system due to her learning difficulties, lack of relevant support at school and her anxiety. Her post school years have also been affected by her anxiety and she has found it difficult to find appropriate employment due to her illness and her level of literacy.

Deirdre's choice would have been to remain at school, "as school was a haven for me anyway compared to home, it was, yeah it was". The decision to remain was taken away from her, when her mother decided that she needed to leave school to get a job as the family had fallen into financial hardship.

Hannah on the other hand left school as she was not excelling in education. She had been offered part time then full time employment and decided this was where her energies would lie in her post school years. 
The motivations for leaving the education arena differed for each participant but all of them wished to build on their earlier education. Angela was very open and candid in regards to the possibility of this occurring for her as she says "there is no support out there, there is no support for mental health". Hannah remained positive that she would eventually get back into education, as the job that was open to her when she left school was not fulfilling. She wanted to have a higher income while working in a job that she felt connected with and found meaningful. Deirdre's love of learning had not diminished since she left school and led her to post graduate education in a field that interests her and has solid job prospects. The conflict between the financial consequences of a reduction in income to return to education and the desire to continue education has been noted in the existing literature ( $T$. P. Schultz, 2002) .

\section{Experiences at school}

\section{Early Experiences}

Angela did not allude to her preschool, primary or intermediate schooling. She did not differentiate her school years as being enjoyable or difficult. She pronounced them as nonproductive and that she had been failed by the school system. The hurt and frustration of this experience came through in her words and tone: "But they didn't teach me anything and I'm not lying, the way they teach you is bad". Angela continued: "They gave me direction but not proper direction, it wasn't really proper" (Angela interview 2012).

Hannah and Deirdre did not mention any preschooling but both seemed quietly animated when recounting that their primary and intermediate school years were enjoyable. Hannah revealed:

"Yeah, school was good, umm, loved primary school, loved intermediate, start of third form my fatherpassed away, so third form was the hardest year of my life" (Hannah interview 2013).

Deirdre commented "I enjoyed school for the most part. Primary school was kind of ... pretty stable, gradually moved through the ranks as I was meant to be, I wasn't brilliant or anything. Again, I was a girl, it was like 'whatever', you are a girl”' (Deirdre interview 2012).

All of my research partners found their school years at one time or another challenging, with all of them being affected by different issues. Angela experienced the disapproval of teachers who felt she should not be in a special class and that her statements of abuse were just efforts to seek out attention. 
Deirdre felt the gender bias in the classroom where boys received greater support than girls; she felt that her level of intelligence had to be greater than the boys to garner a teacher's attention. Deirdre also had to participate in IQ Tests when she was in standard four. She hated these tests "with a passion" and viewed them as a "prestige thing". Deirdre received average scores on these tests which reinforced her 'averageness' and their influence on how she performs in education is still felt:

"Of course I was average so with IQ tests, I hate them and it would stress me out doing those things, I remember that then and I think I carry that over when I do exams as well" (Deirdre interview 2012).

Being classed of average intelligence is not a thing to be proud of in Deirdre's eyes as it did not single her out as an individual or someone that mattered, she stated that 'it wasn't necessarily a thing that people went yahoo, you are average, lol". When asked if she wanted a 'yahoo', Deirdre responded with "yes I wanted a yahoo or didn't you do well". Deirdre did receive a rare 'didn't you do well' when her parents attended a prize giving when she won a book prize. Her education achievement received validation when her parents took time out to be there for her, illustrating the importance of parent involvement in their child's education can be enormous.

Hannah felt her life stressors impacted on her education from the third form when her father died. With the onset of puberty, beginning high school at a new and larger institution and experiencing clinical depression, Hannah's connection with education began its separation. She was bullied and started to become absent so she did not endure this intimidation. She did change classes but this was not a permanent fix. The continued pressure of meeting internal assessments in her fifth form year resulted in her truancy, with this behaviour being embedded for her remaining school years.

\section{To Stay or not to Stay at School}

When asked if Angela could turn back time and stay at school, she was adamant in her decision and succinct in her reply that she would not.

"No, no because my circumstances were too bad, it was it was too traumatising too sickening, too too ob how can I put it? Too down, too, I said I need one to one" (Angela interview 2012).

Deirdre having had a more positive experience at school as this environment was her haven, said that she would have stayed at school if it was her decision. 
"I would definitely stayed in school. Yeah, because I loved it, I really liked being, I liked learning, I love learning" (Deirdre interview 2012).

Hannah did not have the option of choosing to stay longer at school as she had reached the final year and could not go any further. She acknowledged that if she had received greater assistance from the teachers she may have had different educational outcomes, as that assistance would have influenced her grades and motivation. As Hannah had started to earn an income, that activity took priority over any education possibilities.

The decision or choice to remain at school was different for each woman. Angela left school barely being able to read and write. She did not believe there were any possibilities of her receiving extra support that she needed to improve her education. She was not supported and encouraged by her teachers but felt "dumb" and did not want to prolong the feeling of inadequacy experienced in the school environment.

Deirdre did not have the option to remain longer as her mother removed her from school in her school certificate qualification year.

"Yeah, well at fifteen I was actually signed up, but Mum and Dad had a business in the North Island that had a restaurant that had gone bankrupt, and we had moved back down south, so money was quite tight for them. So Mum told me that I had to leave school and get a job, so that I could help pay for things. Yeah, so I did that and I always, I still have very vivid memories of going into the Principal's office because, and he wasn't very happy at all. He said to me 'do you really want to do this [Deirdre]?' and he could tell by my face that I didn't but Mum was there and Mum was basically getting slightly aggressive - it's nothing to do with her', its - 'yeah. I'm a child and she will do what she is told', so yeab I left and got a job. Yeah, and my pay was $\$ 15$ a week" (Deirdre interview 2012).

The experiences of Angela, Deirdre and Hannah at school and whether they wished to remain longer in that environment varied. As research carried out in Great Britain highlighted, a child's schooling career was affected by their aspirations and motivations and their poverty. The quality of education and outcomes are affected by a child's level of disadvantage with the attitudes of the teachers being highly influential on their progress (Horgan, 2007). The negative effect of a disparaging teacher on the educational experience of a child was chronicled by Angela in this chapter. 


\section{Views on the Meanings of Educated and Uneducated}

The definition of 'educated' and 'uneducated' differed between the participants, with the emphasis being placed on different priorities. Angela viewed educated as meaning -

"Educated means to me, not putting people down, if you can't read it, support them if you can, don't just look at them and say they're dumb" (Angela interview 2012).

Hannah's understanding of educated was linked to the type of school a child attended and the grades that each individual gained.

"I'd say, someone that has done well at school, gone to a private school or umm been really high achiever at a public school, got $A+$ or got really good qualifications continued at university. Yeah and now working in their degree, would be educated to me yeab" (Hannab interview 2013).

Deirdre's definition has changed as she remarked: "bmmm, my goodness. What does educated look like? I might have answered that quite differently a while ago". Deirdre views herself as "partly educated" as she has does not think she has had time to retain all the knowledge she has acquired. Deirdre views being educated as a constant process and that to be educated access to other educated people via formal education is vital.

"Ah, and I think educated looks like a constant process, or a constant stream of learning things, that is what educated is. One of my lecturers, I look at him and think what a mind he has, he is educated. He can argue something in a logical intelligent manner, I don't think I can do that necessarily, sometimes I can but other times I get lost in fluff. I think educated is being able to cut through that fluff to get to the core of something and then articulate it" (Deirdre interview 2012).

When the description of 'uneducated' was examined, Angela and Deirdre sensed the term to mean, that a person was missing out and is limited in life choices. Angela noted "Uneducated is unhealthy, it's really really unhealthy but it's not people's fault". When asked to expand on that remark, Angela stated "It means you is limited to what job, you're limited". The concept of 'uneducated' also made Deirdre sad as illustrated by her comment below.

"Oh, see now I feel sad. Uneducated, I feel it is sad, it is missing out somewhere. It is not being able to even become part way to reaching your full potential as a human" (Deirdre interview 2012).

"I feel an uneducated person is missing out and I feel bad about being uneducated, but then I don't, again it depends on what sort of education you are talking about. Because, what I recall that is an uneducated person is someone who is not taught to think, someone who can't think or 
stands stuck in a certain place. It gives you a chance on having a better life possibly that you might have had" (Deirdre interview 2012).

Hannah took a more academic view.

"Umm would be, didn't do well in school, found it ,finds it hard to, yeah, to get into anything, umm that, just works any job" (Hannah interview 2013).

The concept of what educated looked like for two participants involved a strong sense of how we treat fellow human beings. This recognition appeared to be based on personal experience and philosophical convictions. Educated for one research partner, who identified this as having a strong academic meaning, may stem from her current education journey, and that 'educated' is illustrated in the grades you obtain at school. Academic attainment can be used to represent the sum of a girl's abilities although it is only one part of her life and is only one of the arenas in which she can excel.

Uneducated, for all participants referred to limitations in job opportunities and for one participant, it conjured up images of how restricted an individual's potential can be, if they are uneducated. The opinions of the three participants echo the sentiments in the developing world literature which embraces the economic and social benefits women gain through engaging with education (Freire, 1988).

\section{Society Perceptions}

Each participant has interacted with society as a woman without formal education qualifications and each has been affected by this interaction. Angela has felt the lack of compassion from people, including her peers. This lack of empathy has resulted in distress for her and has added to her day to day challenges that need to be overcome and conquered.

"You know, society is rude" (Angela interview 2012).

"I can't read, one man said, he made fun of it and I was really down about it and it stopped me walking, it stopped me walking. And I said, why did I listen to that person, why did I take a chance to listen to bim?" (Angela interview 2012).

Angela has also been the recipient of the inclusive and accepting nature of members of her community. These actions have touched her life on practical and emotional levels. 
"The people here are so good to me, one day I got so anxious at home that I couldn't, I didn't know what I was doing going up and down and they calmed me down" (Angela interview 2012).

"And I got good neighbours and I am very very lucky" (Angela interview 2012).

Deirdre touched on interpretations of class aspirations when discussing societal perceptions.

"You know New Zealand has always prided itself on its classless society, which is a load of crap because we definitely bave classes it's just not as overt as some other countries" (Deirdre interview 2012).

Generational perceptions impacted on Deirdre's life as she remarked:

"I think as a woman of my generation, we were never expected to obtain that much anyway, not of my generation and family background and my class if you will. You know, I was meant to get married and have children and become a grandmother and die quietly, without causing too many problems" (Deirdre interview 2012).

Resistance to education by family members was felt by Deirdre by her then husband who "was quite supportive at first, as long as it didn't interfere with anything else". She recounted that her return to education had no connection to the marriage breakup, but this was not a belief held by a male tutor at her university who knew her husband.

"One of his friends happened to be a tutor at the university and he said to bim, ob this happens a lot with women that go back to university, you know" (Deirdre interview 2012).

Deirdre's confidence was affected by others' opinions and what is deemed to be acceptable behaviour.

'That was, again, it was a slap back down that you shouldn't be doing this because, you are being selfish, yes it was definitely that, you are being selfish by wanting to do this and look what has happened, you have broken up the marriage because you are doing this. It has made you think about things that you shouldn't!" (Deirdre interview 2012).

Society's ability to embrace and not judge a woman going back to education as a mature student, according to Deirdre's experience is an area that needs improvement.

"I get funny looks sometimes but now it is more of an age thing, because I am an older person at university studying" (Deirdre interview 2012). 
"Yes, there is a reaction every time and that is an age thing as well I think, the surprise of what you are doing. And then a lot of them go 'oh good on you' and 'why I don't know how you do it, I couldn't do that' and when they keep going on like that, sometimes is it like 'what the fuck are you doing that for?'. It is their code for, 'what the bell would you want to be doing that for, it's just bloody stupid'. You know bludging off us the rest of us taxpayers." (Deirdre interview 2012).

Hannah sees the lack of formal education qualifications as a barrier to fully participating in society and that society narrowly defines people without formal qualifications as 'thick'. Hannah observed that practical abilities and work experience are down played and ranked below an individual obtaining a qualification.

"Actually some people are practical and some people are theory people, you know" (Hannah interview 2013).

'I think if you don't have formal education qualifications, you can't do things in society that you want to. Like, you can't achieve as much as you want to in society, so they kind of look at you being down."(Hannah interview 2013).

Hannah has felt the limitations with regard to job opportunities as she has been judged on her school academic career. She feels that education qualifications are being held up as a measure of a person's intelligence which is too limiting; it does not take into account how a person may have changed since her school days. Angela has borne the brunt of people's ignorance but this has not dampened her compassion and positive action on behalf of others. She is aware that she is not the only person who has suffered these injustices and wishes others to have more support than she did. Deirdre has battled herself and others beliefs to maintain her resolve in continuing her education.

The societal prejudices and limitations of women without education qualifications experienced by the research participants of this study exist in the developing world literature. Women living in poverty with low education are excluded from many aspects of society and are limited in their participation (Rahnema, 1997). The obstacles to education can be as diverse as the belief that women shouldn't be educated, to the distance required to travel to nearest the educational institution from a woman's home. As highlighted by the experiences of the three research respondents, the amount of time and effort to overcome the different prejudices held by society vary, as do the restrictions experienced by each woman. The complexities and the influence of society's perceptions on uneducated women are evident in the developing world and the developed world context. 


\section{Adult Education}

There have been differing degrees of success and engagement with adult education amongst the three research partners. Angela remarked that there weren't enough classes, and stating the structure of group classes and levels were not conducive for her learning style.

"I think I am selfish wanting one to one, I am just thinking about myself and it's very hard it's a debatable thing, are you being selfish?, are you worrying about the next person that needs it as well?" (Angela interview 2012).

"Because I wouldn't be able to understand what they were saying and people would get bored with me, because a lot of people do, because my level is like a 5 year old" (Angela interview 2012).

She has tried to get involved in adult education, but does not feel the government respects and values this type education, especially for those living in poverty and with mental health issues.

'I don't like this government, he doesn't support the poor and he doesn't respect people with mental illness, be's got no respect"(Angela interview 2012).

Deirdre has had a far more positive relationship with adult education than Angela, having achieved a university degree as a mature student. Deirdre observed that the most negative aspect would be financial, and, to a lesser degree, having time to undertake adult education.

"Financial aspects, it takes money to do it and I am getting to a stage in life where I am freaking out about how I am going to support myself once retirement age comes along... Financial aspect is the biggest negative and sometimes I think the time as well, because I haven't had time to do other things" (Deirdre interview 2012).

For Deirdre, the positive aspects of adult education are far greater than just increasing your job prospects.

"Positives, it's changed, well, it has just changed me, I think" (Deirdre interview 2012).

"So the positives are that I am continuing to learn, I am engaged and engaged in learning as well, that is the other thing that education has done. Education has made me engaged and made me realise there is a lot more out there that I don't know and there is so much to learn and you will die learning it. And I fully intend doing that, I need another life time" (Deirdre interview 2012). 
Hannah is now experiencing a positive relationship with adult education and made mention of how important it was for an adult to achieve a qualification as validation of your efforts.

"The positive was, for once I felt supported. Yeah, I found it really really supportive, umm because you knew you were going to get a certificate in something, as an adult you are like, especially an uneducated adult. I cried when I found out that I got into that course because, for once I am actually going to have a qualification. So that is what I found positive is that I got lot of support" (Hannah interview 2013).

Hannah stated that she found it extremely difficult to find out about relevant adult education classes and is only on her present course due to her personal networks, who gave her information on the existence of the course. Hannah observed that there was funding from the government go back to study.

"The government does give you money but it's not enough to survive these days" (Hannah interview 2013).

Hannah feels much more comfortable and ready to take on the challenge of her university degree as a result of the earlier adult education class that she took part in. She and the other students on the earlier course, were given tools and skills to achieve in an university environment and as she observed,

"It was at the right time, I was ready, because I would keep trying and trying to get into doing a degree and then I did that and it got me ready" (Hannah interview 2013).

Another positive aspect of partaking in adult education for Hannah is being a role model for her young daughter. By increasing her education level and her self-confidence, Hannah is now engaging more in her daughter's education.

'Even my daughter is excited; 'my Mummy is going to university'. And I go to her 'you can go to university one day', you need to work hard. And I have learnt from my mistakes at school to send her to a good school and to invest in it, every day she comes home from school, I help her with her homework, help her do this so that she knows that I am interested in her, and she has got a good teacher that is interested in her. Because me and her father are both uneducated and we've both agreed with each other we want [daughter's name] to do the best" (Hannah interview 2013).

Adult education in New Zealand and elsewhere has been the domain where women are able to tap into their second chance at education, in a bid to address their educational and social inequalities. There are differing experiences and levels of success from women 
engaging in adult education as there has been varying degrees of success of educational policies for women. The three research respondent's sentiments towards the criteria of funding, support and relevance of courses to low income women reflect those in adult education literature (Tobias, 2002).

\section{Conclusion}

This chapter has utilised thematic analysis to investigate the four themes that emerged from the research interviews undertaken as part of this research project. These themes were interrogated to gain an understanding as to what influences and obstacles, a woman may have to negotiate to engage in education. The topics under discussion in this chapter included family influences, experience at school, society perceptions and adult education. These subjects of interest are not only present in the New Zealand education context but also in the wider literature, each informing the other. This chapter has uncovered four lines of enquiry, as it documented the lived education experience of three women who identified, as being of low socioeconomic means, residing in a developed country. It is a natural progression to weave these lines back into the global literature and the developing country context, to investigate whether these themes transcend location, and are applicable in both spaces (developing and developed country contexts). The subsequent chapter will illustrate how taken together, the themes identified in this chapter, the themes in the wider literature and education policy illustrate how poverty, gender and education outcomes are connected. 


\section{Chapter Seven:}

\section{Conclusion - Messages and understandings revealed}

\section{Introduction}

The purpose of this chapter is to assemble the different layers of knowledge to illuminate the emerging themes and to answer the research questions posed in this thesis. The exploration of the global situation concerning education, poverty and women enabled the local context to be explored from a developed country perspective. The local became individual through the experiences of Pākehā women living in poverty and their interactions with education. The soul of this thesis was laid bare through the examination of the relationship between marginalised Pākehā women, poverty and education. A synopsis of the thesis is detailed below to reacquaint the reader with the story of this study and the rationale behind the research being carried out. The research questions are stated and answered as are the wider implications of this research project. The chapter concludes with the study's limitations and reflection that these limitations are not negative but are an opportunity for further research into the area of women, poverty and education.

\section{Narrative Summary of this Thesis}

The desire to undertake research into how Pākehā women of low socioeconomic status interacted with adult education was personal in origin. My access and engagement with education was not obscured by my income or ethnicity, but through my level of intelligence and self-belief in my abilities. My aspiration underpinning this study was to undercover how a woman's income impacted on her interaction with education and whether being part of the ethnic majority affected her involvement. There is clear evidence that women in New Zealand in particular of Māori and Pacific Island ethnicity, who live on limited incomes, do not fare well in our education system and there is on-going research searching for solutions to their issues. My goal in this research was to ensure the voices of Pākehā women living in poverty were given the same consideration and to uncover possible solutions suited to these women and their particular problems.

The search to gain understanding for Pākehā women in New Zealand began with an appreciation of the situation of marginalised women and education in a developing country context. My research journey began with me delving into the development literature, as it pertains to women in the developing world. It has been documented that to eradicate poverty, women and girls must be included and education is an important tool to be 
utilised in improving their social and economic status. This investigation of literature unearthed the complex and complicated relationship between women and education. The literature laid bare the strong rhetoric of the importance of education for this group, whilst exposing the continuing struggle to educate women and girls in developing countries.

The natural progression of investigating the situation of educating women in a developing country was to examine this endeavour in a developed country context. The New Zealand perspective gave insights into the issues that were applicable in both contexts but also brought to light topics unique to the New Zealand setting. The issue of poverty in New Zealand and the treatment of this subject have been contentious, as has the question of women living in poverty and what part their ethnicity plays in their situation. As women strive to continue or begin their education, they turn to the adult education sector in order to achieve their educational goals. This sector has not been without its problems of identity, funding and purpose. This fact however does not extinguish the impact such conflicts can have on the possibilities and opportunities for marginalised women to engage with adult education.

In order that I could understand the complexities, conflicts and barriers to educating women, I employed a social constructivism epistemology and utilised a methodology that was relevant and appropriate for this study. This research was borne from a personal wish to highlight the plight of low income and limited educated Pākehā women.

The voices and experiences of my three research partners were recorded in this thesis and are the cornerstone of this study. Without these women, their lived reality and personal histories, this study would be bereft of depth and meaning. There were similarities and differences between the women, illustrating how each woman's experience with education is unique and that women are not a homogeneous group. My research participants wanted to take part in this study for their own reasons. This individual consciousness became part of the wider social consciousness, as each woman recognised that they were also speaking out on behalf of other low income Pākehā women.

It was through the process of analysing the data from the literature review and my interviews that my thesis started to shift and morph from my initial area of investigation to one that was wider and more encompassing in nature. My research began with a goal of understanding of the barriers to adult education amongst lower socioeconomic Pākehā women in Wellington. The global literature includes evidence that barriers to education exist for women in developing countries, as does the literature pertaining to the women at 
the centre of my thesis. The more I read and the deeper into the subject of education and poverty I investigated, I realised that focusing on barriers to education for Pākehā women was negative, superficial and one dimensional in nature. This realisation resulted in my questioning where my research was taking me. At first this state of affairs was unsettling but I recognised this was part of my research journey and I let this uncertainty guide me and the direction of my thesis.

It was undeniable that each of my research respondents had obstacles to overcome to access education not only in their childhood but as adults. In the initial stages of analysing the data from the three research respondents, the breadth and range of these barriers stood out. The contemplation of the barriers to education for women was required and this scrutiny was necessary, as it furthered my understanding of the issues hindering the education of marginalised women in the world.

The quest of a more inclusive thesis topic allowed the prominent beliefs from each participant on education and poverty to emerge naturally. Each research respondent had a strong and positive attitude towards education and saw it as an essential component of improving their social and economic wellbeing. Education as tool to alleviate poverty is well established in the global literature and in development policies for women and girls. My research partners' beliefs mirror those existing in the development literature. By expanding the purview of this study I was able to recognise and document the importance of how random and accidental episodes can impact on a woman's level of education and income as illustrated in my research partners' life stories.

The randomised nature of a woman's life leads to individualised life pathways. The inclusion of these accidental events in strategies is essential to reduce poverty for marginalised Pākehā women. The omission of the unpredictable nature of a woman's life in approaches to address poverty would result in exclusion from education and from society as a whole. An inclusive approach incorporates the social and economic components of education to empower a woman and its complementary aspect of improving her economic status. The holistic methodology allows the positive attributes of empowerment and economic improvement to interact culminating in increased self-worth and economic status. A holistic approach does not privilege economics over empowerment but treats both with equal importance and accepts both as crucial to improving a woman's life. It is my conviction that a holistic encompassing stance regarding education for lower socioeconomic status Pākehā women is required. My 
opinion of the importance of a holistic approach to women, poverty and education has influenced how I approached and answered my research questions.

The principal aim of this thesis is to understand the link between Pākehā women, poverty and the influence of adult education on the wellbeing of these women. An overarching central question was posed of how education might improve the wellbeing of Pākehā women. The aim and the primary question were answered through the separate areas of inquiry which came under the purview of the secondary research questions.

\section{Question One: What is the relevance of the developing world literature in a developed world context?}

The first question to be answered by this research was whether literature concerning development in a developing country was relevant in a developed world setting. This study has documented the applicability of global literature to a developed country context and how the global and local are intrinsically linked. The literature has enabled insights and understanding of the plight of marginalised women and the use of education to combat poverty in both global and New Zealand contexts. The importance of understanding whether education can eradicate poverty in a 'poor' country or a 'rich' country is essential, as there are women in both spheres requiring improvement of their social and economic wellbeing.

The issue of a gender focus in education policies and initiatives is as important in the global south as it is in New Zealand (E. M. King \& Hill, 1993). There are barriers to education for women in each setting, some are unique to each locale but others are universal and know no country boundaries. There are social and economic costs to each woman, to their community and nation if they are living without education and on low incomes (Staudt, 2008). The opportunities to feel empowered and participate in their community are limited by an inadequate education. This is true for all marginalised women. The awareness of how education can be used to transform or oppress a woman's life and how it can be used to reproduce existing class divisions is much debated in the literature (Bourdieu, 1994; Freire, 1988).

This debate and the requirement to be conscious of the possible role of education are critical in all countries. Education will not liberate and improve a woman's life if it maintains the status quo; women will remain adrift from reaching true equality and equity if this is the case. In order for women to gain and reduce the inequalities they experience, the priorities and direction of education policies have changed over the years. The literature is 
rich with scholars and development practitioners questioning the lack of progress in educating women and girls. The dominant approach to education has been biased towards economic considerations, especially training for employment (Freire, 1988). There has however been a movement away from a pure economic education attitude to education, but there is still resistance to fully engaging with a holistic approach. A holistic approach embraces the dual purposes of education, one being to improve work opportunities and the other to increase levels of empowerment (Sen, 1999). This struggle of direction and focus of education is felt in developing countries and developed countries such as New Zealand. The juxtaposition of education and poverty is also seen in adult education and marginalised Pākehā women in New Zealand.

\section{Question Two: What is the relationship between adult education and Pākehā women of lower socioeconomic status?}

The second question of this research addressed was whether the role of adult education in New Zealand was one of alleviating poverty or one of increasing a woman's feelings of self-worth, or a combination of both. Answering this research question the two halves of what constitute the education benefits as a whole for women are combined. One half is economic, with personal income levels positively improved through interaction with education. To complete the individual, the same woman will increase her conscientization of her status and enact change in her life. This is achieved through her liberation from oppression and increased wellbeing through her engagement with education. As such the adult education sector has a major part to play in enabling positive change in marginalised women's lives in New Zealand.

The Adult and Community Education sector in New Zealand has experienced periods of neglect, indifference and confusion in terms of direction and identity (Findsen, 2006). Adult education has been promoted as the sector of second chance education. The marginalised clientele originally targeted by this sector, and who would have benefitted from its resources are amongst those that are now being neglected (Zepke, 2009). The majority of ACE's clientele are mostly middle class Pākehā who have an education. The reality of the ACE sector is that it is available to middle income or higher income earners to increase their feelings of wellbeing and is recreational in nature (Findsen \& Lomas, 1993). This 'hobby' perception is furthered compounded by the government reducing its funding to this sector, resulting in the reduction and breath of classes offered and the increase in fees to attend courses (Galloway-Lees, 2009). 
The social purpose of adult education is in conflict and juxtaposed against the economic 'learning for earning' mantra of the government in New Zealand (New Zealand Government, 1989; Zepke, 2009). This philosophy introduced the key beliefs of the neoliberal approach to the ACE sector, where productivity and individual responsibility are paramount (Ministry of Education, 2006; New Zealand Government, 1989). The government approach since the 1990s has been one of using education as a tool to improve New Zealand's competitive edge globally and nationally for educational outcomes to be of benefit to the economy (Zepke, 2009). To aid in this goal, adult education was incorporated into the tertiary education sector which had already adopted the outcome based practice (TEC, 2005). There appears to be a disconnection between the government requiring its adult members of society to be economically efficient and resourcing an educational sector that would make this possible. This disconnection does not allow the lower socioeconomic status population to increase their economic potential.

ACE and lifelong learning are being embraced by New Zealand society. There is however a mixed message with this sector in New Zealand as to whether its purpose and outcomes are to be social or economic. The current neoliberal policy embedded in the education system does work for some but not for all marginalised Pākehā women, as witnessed by my three research partners. This research concludes that the ACE sector should adopt a holistic approach and embrace both the social and economic aspects of its nature. For ACE to be effective there is a requirement for it to be a medium for the oppressed in society to become conscious of their position, and be actively involved in transforming this oppression into freedom and equality. This consciousness must be accompanied by realisation that there is a connection between education and the reproduction of class divisions. Value needs to be placed on the symbolic, cultural, social and linguistic capital of a woman as well as her economic capital in adult education and this is essential in deconstructing class barriers. The importance of self-worth and the benefits of improved levels of empowerment on the outcomes of a woman's life must not be discounted. The concept of value is at the core of answering the third question of this study and involved the interaction of neoliberal policies, education and poverty in New Zealand.

\section{Question Three: What are the policy implications of a neoliberal approach?}

The third question sought to uncover the repercussions of the neoliberal approach to education and poverty for lower socioeconomic status Pākehā women. The influence of neoliberal policy is felt in the school education system and its effect is compounded in 
other education arenas. It is evident from the research findings that there is a neoliberal approach to poverty in New Zealand and it has an ethnic component to it. There is striking and indisputable evidence that women of Māori and Pacific Island descent are marginalised in terms of income and education attainment (Ministry of Women's Affairs, 2010a). There are necessary and essential policies in place to address these inequalities. There is on-going research to further understand and seek solutions to overcome the obstacles that prevent them fully participating in their community (Papuni \& Bartlett, 2006b; Poata-Smith, 2008). This focus on the deprivations experienced in the personal and societal aspects of women who are members of ethnic minorities in New Zealand is a two edged sword. The positive aspect concerns the effort under the neoliberal vision is to make these women more economically productive. The negative trait of neoliberalism in New Zealand is the 'blaming' of the individual and assigning the woman's ethnicity responsibility for her level of deprivation.

A further and less visible issue of these ethnic focused priorities is that by blaming the ethnicity of a woman for her level of poverty, there is no examination of the neoliberal approach. New Zealand governments have a duty under the Treaty of Waitangi accord with Māori to seek remedies for unequal treatment and to address these inequalities (Orange, 2011). This relationship has led to poverty in New Zealand being racialised, with certain ethnic groups targeted in preference over other groups. The inequalities between Māori and Pākehā women cannot be denied and there is a clear mandate to eliminate any imbalances. However, there are inequalities between lower socioeconomic Pākehā women and other Pākehā women not living in poverty. Under neoliberalism in New Zealand, the deprivation that low income Pākehā women experience is not targeted.

The neoliberal approach has had a major role in development, influencing how poverty is categorised and addressed and how education to combat poverty is utilised (Zepke, 2009). This dominant theory has been applied in the developing world and in the New Zealand context, with far reaching consequences (Findsen, 2006; Ravallion, 1995). The belief that a woman living in poverty can use the neoliberal environment to her advantage is erroneous. It is not a system where all members of society are created equal but reinforces the divisions between income classes. The benefits of this system go to people who have economic and educational stability, namely the middle class (Davies \& Bansel, 2007). The findings to my three research questions have informed my opinion on the wider implications of this study. 


\section{Wider Implications of this Study}

Throughout this research, women, poverty and education have been the three areas of examination. Under close interrogation the relationship between these three areas has yielded an understanding and highlighted the repercussions of a positive and negative interaction between the three topics. The first implication from this study concerns women either in developing or developed countries, who all require and deserve to have their voices and lived realities heard. Education for these women to be meaningful must include them as part of the solution, which will enable them to engage in education. My research findings indicate that women interpret and make sense of their own experiences in order to understand their reality. Each woman's reality is subjective and informs her opinion on wider societal issues. It is imperative that the epistemological stance of women be included in education policies, as these beliefs will impact the success or failure of approaches designed for marginalised women. Further examination of marginalised women in developing and developed countries is appropriate as each setting would inform on the other, allowing each context to learn and benefit from their similarities and differences. The exchange of ideas, approaches and methods to improve their social and economic situations would be of value to each woman, no matter the context of her country.

Importantly, this research project has illustrated that poverty reproduces itself and transcends its location. The implication from this study is that poverty is indeed entrenched in New Zealand society and the government and society need to move away from giving this issue an ethnic appearance. If policies continue to have a racial bias, poverty for Pākehā women will continue to be overlooked and discounted as an issue that must be rectified. This study has established that poverty for Pākehā women is influenced by their family situation, their experiences at school and their perceptions of inclusion or exclusion in society. The thesis has also highlighted that women are not only excluded from education due to their deprivation level or ethnicity. Women can be barred from education due to cultural and power relations in her society, they may be experiencing abuse that keeps them secluded or they are excluded as only males are educated in their family. These issues must be addressed in a holistic approach as remedying a woman's level of poverty is not garnered by economic means alone. Empowerment leads to economic opportunities as economic solutions alone do not necessarily bring about increases in a woman's agency.

A further implication of this research is in regards to the neoliberal approach adopted by New Zealand in its education sector, including adult education. The neoliberal attitude 
neglects the marginalised members of our society who cannot fully engage or gain access to its resources. This neglect begins in a girl's school years and then flows into adult education. This has led to low income Pākehā women's exclusion as there is no attention on their group. There is a weak focus on the second chance education sector, a limited emphasis on poverty and a restricted effort to address women's issues. The government's priorities are primarily centred on building the economy which includes reducing welfare dependency. The economic priorities of the New Zealand government are hampered by their neoliberal stance and require revising. A human capability approach should replace neoliberalism in New Zealand as this is an inclusive and positive framework for all New Zealanders to operate with. The implications of this would result in a woman's capabilities being concentrated on and not on her deficiencies. This change of attitude would be of benefit to the individual and society as a whole and I believe translates into a prosperous economy.

\section{Limitations and Further Research}

The first limitation of this thesis concerns the positionality of the researcher herself. The objectives of this study were set and answered in a particular manner, certain methods were employed and the findings influenced by the epistemological stance held by myself. The position of being an insider/outsider has impacted on how the research was carried out and how the respondents engaged with the researcher. My biases have been evident in this study, and while I have been vigilant about mitigating the effect these biases would have on my research, I cannot attest to subduing them completely. If another researcher undertook this study with a different background, gender, ethnicity and epistemology, the findings may yield different conclusions. My positionality has also been a strength as it has allowed an openness of mind to the research findings. My empathy with the women at the heart of this thesis has enabled a respectful retelling and analysis of their experiences.

An additional restraint of this research would be one of the limited breadth of participants. My research partners numbered three and were based in Wellington. The findings from this study would have been enhanced with an increased number of participants. It would have benefited from the inclusion of women with more varied backgrounds and a greater number of locations being involved. The experiences of women in urban and rural areas differ as do their access to adult education resources. A greater divergence of ages would also have useful in order to compare and contrast the influences and experiences of lower socioeconomic status Pākehā women. 
These limitations suggest opportunities to investigate the relationship between adult education and marginalised Pākehā women in more detail. A comparison study between the situation in New Zealand and another developed country would give invaluable data on the condition of other ethnic majorities living in poverty. A further research project which included the views of women in a developing country on poverty and education alongside Pākehā women in New Zealand is merited. This study would add further depth to the academic literature on women, poverty and education.

\section{Concluding Remarks}

Undertaking this research has been a personal and professional journey, which included a prerequisite of being open and welcoming to wherever the knowledge generated by my research will lead this thesis. The evolution of this study has taken it down exciting and on occasion unforeseen paths. These included changing the main concern of the thesis from barriers to education to encompassing a more holistic approach which accounted for the random life events and their impacts on education. The fluidity of this research has allowed the themes to emerge organically. This flexibility was a great strength of this thesis as the research process evolved, so did the direction of the study and the depth of the findings that emerged. The theme of how applicable developing world literature on women and poverty in a developed country has been grappled with as have the notions of ethnic poverty.

The concepts of education as an oppressor or liberator and as a vehicle to reproduce class relations have been debated. The neoliberal philosophy has been found to be limiting in nature and does not service the marginalised members of society at any stage of their education journey. The growing literature that embraces a move away from the neoliberal approach is becoming larger and is gaining more support. If a more holistic approach was enacted into education polices this would benefit all members of society as equality and equity would be embraced in full measure. The interaction between women, poverty and education is complex and requires due diligence in all three areas. This is necessary to ensure education for every woman is available and that it can lead to meaningful improvements in both the social and economic aspects of her life. 


\section{References:}

Adler, P. A., \& Adler, P. (2001). The reluctant respondent. In J. F. Gubrium \& J. A. Holstein (Eds.), Handbook of Interview Research: Context and Method (pp. 515-536). Thousand Oaks, CA: Sage.

Admassie, A. (2003). Child labour and schooling in the context of a subsistence rural economy: can they be compatible? International Journal of Educational Development, 23(2), 167-185.

Adult Education and Community Learning Working Party. (2001). Koia! Koia! Towards a Learning Society: The Role of Adult and Community Education. Wellington: Ministry of Education

Agarwal, B. (1997). "Bargaining" and gender relations: within and beyond the household. Feminist Economics, 3(1), 1-51.

Agarwal, B., Humphries, J., \& Robeyns, I. (2003). Exploring the challenges of Amartya Sen's work and ideas: An introduction. Feminist Economics, 9(2-3), 3-12.

Ahluwalia, M. S. (1976). Inequality, poverty and development. Journal of Development Economics, 3(4), 307-342.

Aliaga, A. O. (2001). Human capital, HRD and the knowledge organization. In A. O. Aliaga (Ed.), Academy of Human Resource Development 2001: Conference Proceedings (pp. 427-434). Baton Rouge, LA.

Amnesty International Aotearoa/New Zealand. (2012). What are Human Rights? Retrieved 10 October 2012, from http://www.amnesty.org.nz/who-weare/universal-declaration-human-rights

Anderson, K. L. (1997). Gender, status, and domestic violence: An integration of feminist and family violence approaches. Journal of Marriage and Family, 59(3), 655-669.

Anderson, P. A. (1983). Decision making by objection and the Cuban missile crisis. Administrative Science Quarterly, 28(2), 201-222.

Andrews, F. M., \& McKennell, A. C. (1980). Measures of self-reported well-being: their affective, cognitive, and other components. Social Indicators Research, 8(2), 127-155.

Annas, J. (1993). Women and the quality of life: Two norms or one? In M. Nussbaum \& A. Sen (Eds.), The Quality of Life (pp. 279). Oxford: Clarendon Press. 
Apple, M. (1999). Rhetorical reforms: Markets, standards and inequality. Current Issues in Comparative Education, 1(2), 6-18.

Apple, M. (2001). Comparing neo-liberal projects and inequality in education. Comparative Education, 37(4), 409-423.

Au, K. H. (1998). Social constructivism and the school literacy learning of students of diverse backgrounds. Journal of Literacy Research, 30(2), 297-319.

Avis, J. (2005). Beyond performativity: Reflections on activist professionalism and the labour process in further education. Journal of Education Policy, 20 (2), 209-222.

Bagchi, J. (1997). Loved and Unloved: The Girl Child in the Family. Calcutta: Stree.

Barber, K. (1999). Pakeha ethnicity and indigeneity. Backwaters run deep: locating New Zealand social anthropology. Social Analysis, 43(2), 33-40.

Barber, P. (2011). How to get closer together: Impacts of income inequality and policy responses. Policy Quarterly, 7(4), 62-68.

Bayard de Volo, L. (2006). The nonmaterial long-term benefits of collective action: Empowerment and social capital in a Nicaraguan women's organization. Comparative Politics, 38(2), 149-167.

Bazillier, R., \& Sirven, N. (2008). Is there a social Kuznets curve? TheiInfluence of labour standards on inequality. The Journal of Development Studies, 44(7), 913-934.

Beazley, H., \& Desai, V. (2008). Gender and globalization. In V. Desai \& R. Potter (Eds.), The Companion to Development Studies (2nd ed., pp. 359-364). London: Hodder Education.

Becker, G. S. (1964). Human Capital: A Theoretical and Empirical Analysis with Special Reference to Education New York: Columbia University Press.

Becker, G. S. (1993). Nobel lecture: The economic way of looking at behavior. Journal of Political Economy, 101(3), 385-409.

Becker, G. S., Murphy, K. M., \& Tamura, R. (1990). Human capital, fertility, and economic growth. Journal of Political Economy, 98(5), S12-S37.

Belich, J. (2001). Paradise Reforged: A history of New Zealanders from the 1880s to the year 2000. Auckland: Penguin. 
Belle, D. E. (1983). The impact of poverty on social networks and supports. Marriage \& Family Review, 5(4), 89-103.

Benseman, J. (1980). The Community College as an extension of educational provision. Continuing Education in New Zealand, 12(2), 49-68.

Benseman, J. (1992). Participation revisited: who gets to adult/community education 19701990? The New Zealand Journal of Adult Learning, 20(1), 11-20.

Benson, C. S. (1978). The Economics of Public Education. Boston: Houghton Mifflin.

Berstein, B. (1971). Class, codes and control (Vol. 1). London: Routledge \& Kegan Paul.

Berthoud, G. (2010). Market. In W. Sachs (Ed.), The Development Dictionary: A Guide to Knowledge as Power (pp. 78). London: Zed Books.

Bishop, R. (2003). Changing power relations in education: Kaupapa Māori messages for "mainstream" education in Aotearoa/New Zealand. Comparative Education, 39(2), 221-238.

Bliss, M. (1981). 'Supply side' economics explained: the true believer writes a loving hymn, a new theology of capitalism WEALTH AND POVERTY. The Globe and Mail Retrieved 11 June 2013, from http://search.proquest.com/docview/386830867?accountid=14782

Bonal, X. (2004). Is the World Bank education policy adequate for fighting poverty? Some evidence from Latin America. International Journal of Educational Development, 24(6), 649-666.

Bontis, N. (1996). There's a price on your head: Managing intellectual capital strategically. Business Quarterly, 60(4), 40-47.

Boserup, E. (1970). Woman's Role in Economic Development. London: Allen \& Unwin.

Boston, J. (1999). New Zealand's welfare state in transition. In J. Boston, P. Dalziel \& S. St John (Eds.), In Redesigning the Welfare State in New Zealand: Problems, Policies, Prospects. Auckland: Oxford University Press.

Boston, J., \& Dalziel, P. (1992). The Decent Society? Essays in Response to National's Economic and Social Policies. Auckland: Oxford University Press. 
Bourdieu, P. (1971). Intellectual field and creative project. In M. K. D. Young. (Ed.), Knowledge and Control: New Directions for the Sociology of Education (pp. 161-188). London: Collier Macmillan.

Bourdieu, P. (1977). Outline of a Theory of Practice. Cambridge: Cambridge University Press.

Bourdieu, P. (1989). Social space and symbolic power. Sociological Theory, 7(1), 14-25.

Bourdieu, P. (1991). On symbolic power. In J. B. Thompson (Ed.), Language and Symbolic Power. Cambridge, Massachussetts: Harvard University Press.

Bourdieu, P. (1994). Language and Symbolic Power. Oxford: Polity Press.

Bowles, S., \& Gintis, H. (1976). Schooling in Capitalist America. New York: Basic Books.

Bowman, M. J. (1969). Economics of education. Review of Educational Research, 39(5), 641670.

Braun, V., \& Clarke, V. (2006). Using thematic analysis in psychology. Qualitative Research in Psychology, 3(2), 77-101.

Brief, A. P., \& Roberson, L. (1989). Job attitude organization: An exploratory study. Journal of Applied Social Psychology, 19(9), 717-727.

Brockington, D., \& Sullivan, S. (2003). Qualitative research. In R. Scheyvens \& D. Storey (Eds.), Development Fieldwork: A practical guide (pp. 57-72). London: Sage Publications.

Brooks-Gunn, J., Duncan, G. J., \& Maritato, N. (1997). Poor families, poor outcomes: The well-being of children and youth. Consequences of growing up poor (pp. 1-17). New York: Russell Sage Foundation.

Burns, N., Schlozman, K., \& Verba, S. (2001). The Private Roots of Public Action. Cambridge, MA: Harvard University Press.

Business New Zealand, The Institute of Directors in New Zealand, \& Ministry of Women's Affairs. (2009). Women on Boards: Why Women on Company Boards are Good for Business (2009). Wellington: Ministry of Women's Affairs.

Butera, K. J. (2006). Manhunt: The challenge of enticing men to participate in a study on friendship. Qualitative Inquiry, 12(6), 1262-1282. 
Caetano, P. (2006). The human right to education: Freedom and empowerment. Multicultural Education, 13(4), 2-10.

Canadian International Development Agency. (2007). Gender Analysis Retrieved 08 October 2012, from http://www.acdi-cida.gc.ca/acdi-cida/ACDICIDA.nsf/eng/JUD-31194519-KBD

Cannon, R. (2012). Are we neglecting children's participation in school? Development Policy Blog Retrieved 24 August 2012, from http://devpolicy.org/

Cardinal, T. (2011). Using education to reduce poverty. Alberta Counsellor, 31(2), 25-30.

Cardoso, F. H. (2011). Foreword, 'Because I am a Girl: The state of the world's girls 2011 - So what about boys? (pp. 9). Surrey, United Kingdom: Plan International.

Carnoy, M. (1997). Is privatization through education vouchers really the answer? A comment on West. The World Bank Research Observer, 12(1), 105-116.

Carroll, P., Casswell, S., Huakau, J., Howden-Chapman, P., \& Perry, P. (2011). The widening gap: Perceptions of poverty and income inequalities and implications for health and social outcomes. Social Policy Journal of New Zealand(37), 111-122.

Chacko, E. (2004). Positionality and praxis: Fieldwork experiences in rural India. Singapore Journal of Tropical Geography, 25(1), 51-53.

Chafetz, J., \& Dworkin, A. (1986). Female Revolt: Women's Movements in World and Historical Perspective. Totowa, NJ: Rowman \& Allanheld.

Chaudhry, I. S., Malik, S., Hassan, A. u., \& Faridi, M. Z. (2010). Does education alleviate poverty? Empirical evidence from Pakistan. International Research Journal of Finance \& Economics(52), 134-141.

Chircusi, M. (2009). Sen's conception of the "capability approach" to assessing deprivation and well-being. Contemporary Readings in Law and Social Justice, 1(2), 126-130.

Clark, D. A. (2002). Development ethics: A research agenda. International Journal of Social Economics, 29(11/12), 830-848.

Coffey, A., \& Atkinson, P. (1996). Making Sense of Qualitative Data: Complementary Research Strategies. Thousand Oaks, CA: Sage Publications.

Cohn, E., \& Geske, T. E. (1990). The Economics of Education. New York: Pergamon Press. 
Colclough, C. (2012). Education, poverty and development - mapping their interconnections. Comparative Education, 48(2), 135-148.

Coleman, J. S. (2007). Equality of Educational Opportunity (COLEMAN) Study (EEOS), 1966: Inter-university Consortium for Political and Social Research (ICPSR).

Consedine, B. (1989). 'Inequality and the egalitarian myth'. In D. Novitz \& B. Willmott (Eds.), Culture and Identity in New Zealand. Wellington: GP Books.

Corbin, J., \& Morse, J. M. (2003). The unstructured interactive interview: Issues of reciprocity and risks when dealing with sensitive topics. Qualitative Inquiry, 9(3), 335354.

Cornwall, A. (1997). Men, masculinity and 'gender in development'. Gender and Development, 5(2), 8-13.

Crotty, M. (1998). The Foundations of Social Research: Meaning and Perspective in the Research Process. St. Leonards, Australia: Allen \& Unwin Pty Ltd.

Cummins, R. A. (1996). The domains of life satisfaction: An attempt to order chaos. Social Indicators Research, 38(3), 303-328.

Cummins, R. A. (1997). The Comprehensive Quality of Life Scale (ComQol) (Fifth ed.). Melbourne: School of Psychology, Deakin University.

Cummins, R. A., Mccabe, M. P., Romeo, Y., \& Gullone, E. (1994). Validity studies the Comprehensive Quality of Life Scale (Comqol): Instrument development and psychometric evaluation on college staff and students. Educational and Psychological Measurement, 54(2), 372-382.

Cupples, J., \& Kindon, S. (2003). Returning to University and writing the field. In R. Scheyvens \& D. Storey (Eds.), Development Fieldwork: A Practical Guide (pp. 217-232). London: Sage.

Cuttance, P. (1980). The extent of poverty among large families in Hamilton, New Zealand. Journal of Sociology, 16(3), 96-103.

D'Iribarne, P. (1974). The relationship between subjective and objective well being. In B. Strumpel (Ed.), Subjective Elements of Well Being. Paris: OECD.

Dalziel, P. (1999). Macroeconomic constraints. In J. Boston, P. Dalziel \& S. St John (Eds.), Redesigning the welfare state in New Zealand: Problems, policies, prospects. Auckland: Oxford University Press. 
Davey, J., \& Grey, S. (2009). New Zealand: From early intervention to humanizing the market. In P. Alcock \& G. Craig (Eds.), International Social Policy: Welfare regimes in the developed world. New York: Palgrave MacMillan.

Davey, J., \& Jamieson, A. (2003). Against the odds: pathways of early school leavers into university education: evidence from England and New Zealand. International Journal of Lifelong Education, 22(3), 266-280.

David, P. A., \& Lopez, J. K. (2001). Knowledge, Capabilities and Human Capital Formation in Economic Growth. Treasury Working Paper 01/13 Retrieved 10 October 2012, from http://www.treasury.govt.nz/publications/research-policy/wp/2001/01-13/

Davies, B., \& Bansel, P. (2007). Neoliberalism and education. International Journal of Qualitative Studies in Education, 20(3), 247-259.

De Soto, H. (2000). The Mystery of Capital. New York: Basic Books.

Denison, E. F. (1962). The Sources of Economic Growth in the United States and the Alternatives Before Us. New York: Committee for Economic Development.

Derry, S. J. (1999). A fish called peer learning: Searching for common themes. In A. M. O'Donnell \& A. King (Eds.), Cognitive Perspectives on Peer Learning. Mahwah, USA: Lawrence Erlbaum Associates Publishers.

Desai, V., \& Potter, R. (2008a). Editorial introduction. Part 1,The nature of development and development Studies. In V. Desai \& R. Potter (Eds.), The Companion to Development Studies (2nd ed., pp. 1-3). London: Hodder Education.

Desai, V., \& Potter, R. (2008b). Editorial introduction. Part 7, Gender, population and development. In V. Desai \& R. Potter (Eds.), The Companion to Development Studies (2nd ed., pp. 319-320). London: Hodder Education.

DeVault, M. (1990). Talking and listening from women's standpoint: Feminist strategies for interviewing and analysis. Social Problems, 37(1), 96-114.

DiMaggio, P. (1979). On Pierre Bourdieu. American Journal of Sociology, 84(6), 1460-1474.

Douglas, R. (1987). 1985 Budget. Wellington: Government Printer.

Drèze, J., \& Sen, A. (1995). India: Economic Development and Social Opportunity. Delhi: Oxford University Press. 
Du Plessis, R. (1993). Women, politics and the state. In B. Roper \& C. Rudd (Eds.), State and Economy in New Zealand. Auckland Oxford University Press.

Durston, S., \& Nashire, N. (2001). Rethinking poverty and education: an attempt by an education programme in Malawi to have an impact on poverty. Compare: A Journal of Comparative Education, 31(1), 75-91.

Easton, B. (1976). 'Poverty in New Zealand: Estimates and reflections'. Political Science, 28(2), 127-140.

Easton, B. (1995). 'Poverty in New Zealand: 1981-1993'. New Zealand Sociology, 10(2), 182214.

Easton, B. (1997). In Stormy Seas: The Post-War New Zealand Economy. Dunedin: University of Otago Press.

Easton, B. (2008). The globalisation of a welfare state. In B. N. Lunt, M. O’Brien \& R. Stephens (Eds.), New Zealand, New Welfare. Melbourne: Cengage.

Eisenhardt, K. M. (1989). Building theories from case study research. The Academy of Management Review, 14(4), 532-550.

Elizabeth, V., \& Larner, W. (2009). Racializing the "social development" state: Investing in children in Aotearoa/New Zealand. Social Politics: International Studies in Gender, State \& Society, 16(1), 132-158.

Elster, J. (1985). Sour Grapes: Studies in the Subversion of Rationality. Cambridge: Cambridge University Press.

Entrikin, J. N. (1991). The Betweeness of Place: Towards a Geography of Modernity. Baltimore: John Hopkins University Press.

Felce, D., \& Perry, J. (1995). Quality of life: Its definition and measurement. Research in Developmental Disabilities, 16(1), 51-74.

Fergusson, D. M., Horwood, L. J., Kershaw, K. L., \& Shannon, F. T. (1986). Factors associated with reports of wife assault in New Zealand. Journal of Marriage and Family, 48(2), 407-412.

Findsen, B. (2006). Access and participation issues in New Zealand adult, community, and tertiary education. In A. Oduaran \& H. Bhola (Eds.), Widening Access to Education as Social Justice (pp. 208-226): Springer Netherlands. 
Findsen, B., \& Lomas, G. (1993). Programming issues in a community learning centre: The case of Rutherford High School. The New Zealand Journal of Adult Learning, 21(2), 4373.

Freire, P. (1988). Pedagogy of the Oppressed; translated by Myra Bergman Ramos. New York: Continuum.

Fukuda-Parr, S. (1999). What does feminization of poverty mean? It isn't just lack of income. Feminist Economics, 5(2), 99-103.

Galloway-Lees, I. (2009). Adult education vital for community Retrieved 10 May 2013, from http://www.stuff.co.nz/manawatu-standard/opinion/eye-on-theelectorate/2549398/Adult-education-vital-for-community

Gamlen, A. (2012). Mixed methods in research on diaspora policies. In C. Vargas-Silva (Ed.), Handbook of Research Methods in Migration. Edward Elgar Publishing: Cheltenham.

Gans, H. (1990). Deconstructing the underclass. Journal of American Planning Association, 56(3), 271-278.

Gans, H. (1995). War against the Poor: The Underclass and Antipoverty Policy. New York: Basic Books.

Gasper, D. (2002). Is Sen's capability approach an adequate basis for considering human development? Review of Political Economy, 14(4), 435-461.

Gersick, C. J. G. (1988). Time and transition in work teams: Toward a new model of group development. The Academy of Management Journal, 31(1), 9-41.

Gerson, K. (2004). Understanding work and family through a gender lens. Community, Work \& Family, 7(2), 163-178.

Gilbert, G. (2012). Mediation, Regulation, Critique: Mapping the Relationship between Cultural Meanings and Political Responses to Poverty, 1970-2010. phD thesis, Victoria University of Wellington, Wellington.

Goetz, A. M. (1988). Feminism and the limits of the claim to know: Contradictions in the feminist approach to women in development. Millennium - Journal of International Studies, 17(3), 477-496.

Goldman Sachs \& Partners New Zealand Limited. (2011). Closing The Gendar Gap: Plenty of Potential Economic Upside (pp. 1-22). Wellington. 
Goodman, A. (2010). The Importance of Attitudes and Behaviour for Poorer Children's Educational Attainment. York, United Kingdom: Joseph Rowntree Foundation.

Gordon, L., \& Whitty, G. (1997). Giving the 'hidden hand' a helping hand? The rhetoric and reality of neoliberal education reform in England and New Zealand. Comparative Education, 33(3), 453-467.

Grant, R. W., \& Sugarman, J. (2004). Ethics in human subjects research: Do incentives matter? Journal of Medicine \& Philosophy, 29(6), 717-738.

Gudmundsdottir, S. (1996). The teller, the tale, and the one being told: The narrative nature of the research interview. Curriculum Inquiry, 26(3), 293-306.

Guillemin, M., \& Gillam, L. (2004). Ethics, reflexivity, and "ethically important moments" in research. Qualitative Inquiry, 10(2), 261-280.

Gurumurthy, A. (2006). Promoting gender equality? Some development-related uses of ICTs by women. Development in Practice, 16(6), 611-616.

Gustafson, B. (1986). From the Cradle to the Grave: A biography of Michael Joseph Savage. Auckland: Reed Methuen.

Haddad, S. (2006). Education of youth, human rights and human development. Convergence, 39(2/3), 131-145.

Hagerty, M. R., Cummins, R. A., Ferriss, A. L., Land, K., Michalos, A. C., Peterson, M., .. . Vogel, J. (2001). Quality of life indexes for national policy: Review and agenda for research. Social Indicators Research, 55(1), 1-96.

Halse, C., \& Honey, A. (2007). Rethinking ethics review as institutional discourse. Qualitative Inquiry, 13(3), 336-352.

Halsey, A. H., Floud, J. E., \& Anderson, C. A. (1961). Education, Economy and Society. London: Collier-Macmillan.

Halvorsen, K. (1990). Notes on the realization of the human right to education. Human Rights Quarterly, 12(3), 341-364.

Harrè Hindmarsh, J. (1996). Mapping the field in the 1990s. In J. Benseman, B. Findsen \& M. Scott (Eds.), The Fourth Sector: Adult and Community Education in Aotearoa/New Zealand. Palmerston North: Dunmore Press. 
Harris, C. (2010). Cuts end popular night classes Retrieved 03 April 2013, from http://www.stuff.co.nz/national/education/3323417/Cuts-end-popular-night$\underline{\text { classes }}$

Harris, S. G., \& Sutton, R. I. (1986). Functions of parting ceremonies in dying organizations. The Academy of Management Journal, 29(1), 5-30.

Harrison, J., MacGibbon, L., \& Morton, M. (2001). Regimes of trustworthiness in qualitative research: The rigors of reciprocity. Qualitative Inquiry, 7(3), 323-345.

Harvey, D. (2005). A Brief History of Neoliberalism. Oxford: Oxford University Press.

Hesse-Biber, S. N. (2010). Mixed Methods Research: Merging Theory with Practice. New York: The Guilford Press.

Holland, C., \& Terrell, J. (2007). The Learning for Living project: New directions in training support for foundation learning. Literary Link Retrieved 03 October 2012, from http://www.acal.edu.au/publications/newsletters/LL2007/0707v27n4LL.pdf

Horgan, G. (2007). The Impact of Poverty on Young Children's Experience of School. York, United Kingdom: Joseph Rowntree Foundation.

Houghton, C., Casey, D., Shaw, D., \& Murphy, K. (2010). Ethical challenges in qualitative research: examples from practice. Nurse Researcher, 18(1), 15-25.

Huber, E., \& Solt, F. (2004). Successes and failures of neoliberalism. Latin American Research Review, 39(3), 150-164.

Human Development Report. (2002). Deepening Democracy in a Fragmented World. Oxford: Oxford University Press.

Humpage, L., \& Craig, D. (2008). From welfare to welfare-to-work. In B. N. Lunt, M. O'Brien \& R. Stephens (Eds.), New Zealand, new welfare. Melbourne Cengage.

Jack, A. J. (1973). 'Poverty and social security'. In S. Webb \& J. Collette (Eds.), New Zealand Society: Contemporary Perspectives. Sydney: John Wiley \& Sons.

Jarrett, R. L. (1993). Focus group interviewing with low-income minority populations: A research experience. In D. L. Morgan (Ed.), Successful Focus Group: Advancing the State of the Art (pp. 184-201). Newbury Park: Sage. 
Jejeebhoy, S. J. (1998). Associations between wife-beating and fetal and infant death: Impressions from a survey in rural India. Studies in Family Planning, 29(3), 300-308.

Jensen, J., Krishnan, V., Spittal, M., \& Sathiyandra, S. (2003). New Zealand living standards: Their measurement and variation, with an application to policy. Social Policy Journal of New Zealand, 20, 72-97.

Jesson, B. (1999). Only Their Purpose is Mad. Palmerston North, NZ: Dunmore Press.

Jewkes, R. (2002). Preventing domestic violence. BMJ, 324(7332), 253-254.

Johnson, R. B., \& Onwuegbuzie, A. J. (2004). Mixed methods research: A research paradigm whose time has come. Educational Researcher, 33(7), 14-26.

Joireman, S. F. (2000). Property Rights and Political Development in Ethiopia and Eritrea: The State and Land 1941-1974. Athens, OH: Ohio University Press.

Joireman, S. F. (2008). The mystery of capital formation in sub-sharan Africa: Women, property rights and customary law. World Development, 36(7), 1233-1246.

Kabeer, N. (1994). Reversed Realities: Gender Hierarchies in Development Thought. London: Verso.

Kabeer, N. (1997). Editorial: Tactics and trade-offs: Revisiting the links between gender and poverty. IDS Bulletin, 28(3), 1-13.

Katz, C. (1994). Playing the field: Questions of fieldwork in geography. The Professional Geographer, 46(1), 67-72.

Kebede, W., \& Butterfield, A. K. (2009). Social networks among poor women in Ethiopia. International Social Work, 52(3), 357-373.

Kelly, G. P. (1987). Setting state policy on women's education in the Third World: Perspectives from comparative research. Comparative Education, 23(1), 95-102.

Kelsey, J. (1997). The New Zealand Experiment: A World Model for Structural Adjustment? Auckland: Auckland University Press.

Kidder, T. (1982). Soul of a New Macbine. New York: Avon.

Kiely, R. (2007). Poverty reduction through liberalisation? Neoliberalism and the myth of global convergence. Review of International Studies, 33(03), 415-434. 
King, E. M., \& Hill, M. A. (1993). Women's education in feveloping countries: An overview. In E. M. King \& M. A. Hill (Eds.), Women's Education in Developing Countries: Barriers, Benefits and Policies (pp. 1-50). Washington: World Bank.

King, M. (1985). Being Pakeha: An encounter with New Zealand and the Maori Renaissance Auckland: Hodder and Stoughton.

King, M. (1991). Pakeha: The Quest for Identity in New Zealand. Auckland: Penguin Books.

Kitchen, R., \& Tate, N. (2000). Thinking about research: what choices have you got? Conducting Research into Human Geography: Theory, Methodology and Practice (pp. 1-27). Harlow: Prentice Hall.

Klak, T., Wiley, J., Mullaney, E. G., Peteru, S., Regan, S., \& Merilus, J.-Y. (2011). Inclusive neoliberalism? Progress in Development Studies, 11(1), 33-61.

Klees, S. J. (1999). Rhetorical reforms: Markets, standards and inequality. Current Issues in Comparative Education, 1(2), 19-26.

Klees, S. J. (2008). Neoliberalism and education revisited. Globalisation, Societies and Education, 6(4), 409-414.

Knopf, J. W. (2006). Doing a literature review. PS: Political Science and Politics, 39(1), 127-132.

Korn/Ferry Institute. (2011). Mind the Gap: Half of Asia's boards have no women, a risky position for goverance and growth (pp. 1-8). Singapore: Korn/Ferry Institute.

Krishnan, V. (1995). Modest but adequate: An appraisal of changing household income circumstances in New Zealand. Social Policy Journal of New Zealand, 4, 1-20.

Krueger, A. O. (1968). Factor endowments and per capita income Differences among countries. The Economic Journal, 78(311), 641-659.

Kukla, A. (2000). Social Constructivism and the Philosophy of Science. New York: Routledge.

Kuklys, W. (2005). Amartya Sen's Capability Approach: Theoretical Insights and Empirical Applications. Berlin: Springer.

Kuznets, S. (1955). Economic growth and income inequality. The American Economic Review, 45(1), 1-28. 
Ladson-Billings, G. (1997). I know why this doesn't feel empowering: A critical race analysis of critical pedagogy. In P. Freire, J. W. Fraser, D. Macedo, T. McKinnon \& W. T. Stokes (Eds.), Mentoring the Mentor. New York: Peter Lang Publishers.

Land, K. (2000). Social indicators. In E. F. Borgatta \& R. V. Montgomery (Eds.), Encyclopedia of Sociology. New York: Macmillan.

Leach, F. (2003). Practising Gender Analysis in Education. Oxford, United Kingdom: Oxfam.

Lee, C.-J. G. (2012). Reconsidering constructivism in qualitative research. Educational Philosophy and Theory, 44(4), 403-412.

Lee, J.-S., \& Bowen, N. K. (2006). Parent involvement, cultural capital, and the achievement gap among elementary school children. American Educational Research Journal, 43(2), 193-218.

Longwe, S. (1991). "Gender awareness: The missing element in the Third World development program". In C. March \& T. Wallace (Eds.), Changing Perception: New Writings on Gender and Development (pp. 149-157). Oxford, United Kingdom: Oxfam.

Lovell, T. (2000). Thinking feminism with and against Bourdieu. Feminist Theory, 1(1), 11-32.

Lucas, R. (1988). On the mechanics of economic development. Journal of Monetary Economics, 22(1), 3-42.

Lucas, R. (1990). Why doesn't capital flow from rich to poor countries? The American Economic Review, 80(2), 92-96.

Lutz, W., \& Samir, K. C. (2011). Global human capital: Integrating education and population. Science, 333(6042), 587-592.

Madriz, E. I. (1998). Using focus groups with lower socioeconomic status Latina women. Qualitative Inquiry, 4(1), 114-128.

Malkki, L. (1995). Purity and Exile: Violence, Memory and National Cosmology among Hutu Refugees in Tanzania. Chicago: University of Chicago Press.

Mansvelt, J., \& Berg, L. (2010). Writing qualitative geographies, constructing meaningful geographical knowledges. In I. Hay (Ed.), Qualitative Research Methods in Human Geography (pp. 333-355). Ontario: Oxford University Press.

Marglin, F. A., \& Marglin, S. A. (1990). Dominating Knowledge:Development, Culture and Resistance. Oxford: Clarendon. 
Martin, I. (2006). Where have all the flowers gone? Adults Learning 18(2), 15-18.

Martin, S. L., Tsui, A. O., Maitra, K., \& Marinshaw, R. (1999). Domestic violence in northern India. American Journal of Epidemiology, 150(4), 417-426.

Mathias, N., \& Herrera Rendon, T. (2006). A hermeneutic of Amartya Sen's concept of capability. International Journal of Social Economics, 33(10), 710-710.

Maxwell, S. (1999). The meaning and measurement of poverty. ODI Briefing Paper Retrieved 03 February 2013, from http://www.odi.org.uk/resources/docs/3095.pdf

McCall, L. (2005). The complexity of intersectionality. Signs, 30(3), 1771-1800.

McClure, M. (2003). A decade of confusion: The differing directions of social security and accident compensation 1969-1979. Victoria University of Wellington Law Review(34), 269-277.

McDowell, L. (1992). Doing gender: Feminism, feminists and research methods in human geography. Transactions of the Institute of British Geographers, 17(4), 399-416.

McIntosh, P. (1988). White Privilege and Male Privilege: A Personal Account of Coming to See Correspondences Through Work in Women's Studies. Wellesley: Center for Research on Women, Wellesley College.

McKendrick, J. H. (1999). Multi-method research: An introduction to its application in population geography. The Professional Geographer, 51(1), 40-50.

McMichael, P. (2008). Development and Social Change: A Global Perspective. Los Angeles: Pine Forge Press.

Mehendale, A. (1998). "Compulsory primary education in India: The legal framework". From the Lanyers Collective, 13(4), 4-12.

Mehra, R. (1997). Women, empowerment, and economic development. Annals of the American Academy of Political and Social Science(554), 136-149.

Mikkelson, B. (1995). Methods for Development Work and Research: A Guide for Practitioners. London: Sage.

Miles, M. B. (1979). Qualitative data as an attractive nuisance: The problem of analysis. Administrative Science Quarterly, 24(4), 590-601. 
Mincer, J. (1965). Review of the book: The Economic Value of Education by T. W. Schultz. The American Economic Review, 55(3), 637-638.

Mingat, A., \& Tan, J.-P. (1986). Expanding education through user charges: What can be achieved in Malawi and other LDCs? Economics of Education Review, 5(3), 273-286.

Ministry of Education. (2006). Tertiary Education Strategy 2007-12 and Statement of Tertiary Education Priorities Wellington: Ministry of Education.

Ministry of Education. (2013a). ECE Equity Funding Retrieved 11 June, from http://www.minedu.govt.nz/theMinistry/Budget/Budget2012/Factsheets2012/E CEEquityFunding.aspx

Ministry of Education. (2013b). Education Sector Outcomes Retrieved 11June, from http://www.minedu.govt.nz/theMinistry/PublicationsAndResources/StatementOf Intent/SOI2013/NatureAndScopeOfOurFunctions/EducationSectorOutcomes.as $\mathrm{px}$

Ministry of Education. (2013c). The Education System Retrieved 11June from http://www.minedu.govt.nz/theMinistry/PublicationsAndResources/StatementOf Intent/SOI2013/NatureAndScopeOfOurFunctions/TheEducationSystem.aspx

Ministry of Education. (2013d). New Zealand Education Retrieved 11June, from http://www.minedu.govt.nz/

Ministry of Education. (2013e). School decile ratings Retrieved 10 June, 2013, from http://www.minedu.govt.nz/Parents/AllAges/EducationInNZ/SchoolsInNewZe aland/SchoolDecileRatings.aspx

Ministry of Health. (1997). Mental Health in New Zealand from a Public Health Perspective: Public Health Report Number 3. Wellington: Ministry of Health.

Ministry of Social Development. (2007). Social Inclusion and Participation: A Guide for Policy and Planning. Wellington: Ministry of Social Development.

Ministry of Social Development. (2012). Household Incomes in New Zealand: Trends in Indicators of Inequality and Hardship 1982 to 2011. Wellington: Ministry of Social Development.

Ministry of Women's Affairs. Retrieved 13 February 2013, from http://mwa.govt.nz/

Ministry of Women's Affairs. (2010a). Indicators for Change: Tracking the Progress of New Zealand women: 2009. Wellington: Ministry of Women's Affairs. 
Ministry of Women's Affairs. (2010b). The Status of Women in New Zealand: CEDAW Report 2010. Wellington: Ministry of Women's Affairs.

Mishler, E. (1986). Research Interviewing. Cambridge, MA: Harvard University Press.

Moffitt, T. E., Caspi, A., Krueger, R. F., Magdol, L., Margolin, G., Silva, P. A., \& Sydney, R. (1997). Do partners agree about abuse in their relationship?: A psychometric evaluation of interpartner agreement. Psychological Assessment, 9(1), 47-56.

Morse, J. M. (2001). Interviewing the ill. In J. F. Gubrium \& J. A. Holstein (Eds.), Handbook of interview research: Context and Method (pp. 317-332). Thousand Oaks, CA: Sage.

Moser, C. (1993). Gender Planning and Development: Theory, Practice, and Training. London: Routledge.

Nast, H. J. (1994). Women in the field: Critical feminist methodologies and theoretical perspectives. Professional Geographer, 46(1), 54.

New Zealand Government. (1989). Learning for Life Two. Wellington: Government Printer.

Nicholls, M., \& Piesse, D. (1982). The Consequences of Closure: A Study of the Social and Economic Impact of the Southdown Freezing Works Closure. Auckland: Auckland Regional Authority.

Nussbaum, M. (1993). Non-relative virtues: An Aristotelian approach. In M. Nussbaum \& A. Sen (Eds.), The Quality of Life (pp. 242-276). Oxford: Clarendon Press.

Nussbaum, M. (1995). Human capabilities, female human beings. In M. Nussbaum \& J. Glover (Eds.), Women, Culture and Development: A Study of Human Capabilities (pp. 61104). Oxford: Clarendon Press.

Nussbaum, M. (2000). Women and Human Development: The Capabilities Approach. Cambridge: Cambridge University Press.

Nussbaum, M. (2003). "Capabilities as fundamental entitlements: Sen and social justice". Feminist Economics, 9(2-3), 33-59.

Nussbaum, M. (2004). Women's education: A global challenge. Signs, 29(2), 325-355.

Nussbaum, M., \& Sen, A. (1993). Introduction. In M. C. Nussbaum \& A. Sen (Eds.), The Quality of Life (pp. 2). Oxford: Clarendon Press. 
O'Donnell, G. (2004). Why the rule of law matters. Journal of Democracy, 15(4), 32-46.

O'Neill, O. (1993). Justice, gender, and international boundaries. In M. Nussbaum \& A. Sen (Eds.), The Quality of Life (pp. 303-323). Oxford: Clarendon Press.

O'Neill, S. B., \& Spellman, E. K. (1983). Continuing education for women. New Directions for Adult and Continuing Education, 1983(20), 43-52.

O’Brien, M., Bradford, S., Stevens, R., Walters, M., \& Wicks, W. (2010). Welfare Justice for All: Reflection and Recommendations: A Contribution to the Welfare Reform Debate. Wellington: Caritas.

O'Brien, M., \& Wilkes, C. (1993). The Tragedy of the Market: A Social Experiment in New Zealand. Palmerston North: Dunmore Press.

O'Dea, D. (2000). 'The Changes in New Zealand's Income Distribution'. New Zealand Treasury Working Paper 00/13. Wellington: The Treasury.

O’Neill, J. (2011). The privatisation of public schooling in New Zealand. Journal of Education Policy, 26(1), 17-31.

OECD. (2007). PISA 2006 Science Competencies for Tomorrow's World Volume 1: Analysis. In OECD (Ed.). Paris.

Offen, K. (1988). Defining feminism: A comparative historical approach. Signs, 14(1), 119157.

Olssen, M., \& Peters, M. A. (2005). Neoliberalism, higher education and the knowledge economy: from the free market to knowledge capitalism. Journal of Education Policy, 20(3), 313-345.

Onwuegbuzie, A. J. (2000). Positivists, Post-Positivists, Post-Structuralists, and PostModernists: Why can't we all get along? Towards a framework for unifying research paradigms Retrieved 08 August 2013, from http://www.eric.ed.gov/ERICWebPortal/detail?accno=ED452110

Orange, C. (2011). The Treaty of W aitangi: Bridget Williams Books.

Organ, D. W., \& Near, J. P. (1985). Cognition vs affect in measures of job satisfaction. International Journal of Psychology, 20(2), 241. 
Papuni, H. T., \& Bartlett, K. R. (2006a). Maori and Pakeha perspectives of adult learning in Aotearoa/New Zealand workplaces. Advances in Developing Human Resources, 8(3), 400-407.

Papuni, H. T., \& Bartlett, K. R. (2006b). Maori and Pakeha perspectives of adult Llarning in Aotearoa/New Zealand workplaces. Advances in Developing Human Resources, 8(3), 400-407.

Parker, R. (1993). Another Point of View: A Manual on Gender Analysis Training for Grassroots Workers. New York: UNIFEM.

Parliamentary Library. (2000). Welfare benefits trends in New Zealand Retrieved 28 February 2013, from http://www.parliament.nz/NR/rdonlyres/022C2B15-15224140-999C-49CF45B43F46/512/0013Benefits1.pdf

Paxton, P., \& Hughes, M. M. (2007). Women, Politics, and Power: A Global Perspective. Thousand Oaks, CA: Pine Forge.

Paxton, P., Kunovich, S., \& Hughes, M. M. (2007). Gender in politics. Annual Review of Sociology, 33, 263-284.

Pearson, D., \& Thorns, D. (1983). Eclipse of Equality: Social Stratification in New Zealand. Sydney: Allen \& Unwin.

Peet, R., \& Hartwick, E. (1999). Theories of Development. London \& New York: Guilford Press.

Peterson, V. S., \& Runyan Sisson, A. (1999). Gender as a lens on world politics. In V. Peterson \& A. Runyan (Eds.), Global Gender Issues (pp. 21-68). Boulder: Westview Press.

Pinfield, L. T. (1986). A field evaluation of perspectives on organizational decision making. Administrative Science Quarterly, 31(3), 365-388.

Poata-Smith, E. (2008). Closing the gaps? In B. N. Lunt, M. O'Brien \& R. Stephens (Eds.), New Zealand, New Welfare. Melbourne: Cengage.

Pope, C., Ziebland, S., \& Mays, N. (2000). Qualitative research in health care: Analysing qualitative data. BMJ: British Medical Journal, 320(7227), 114-116.

Psacharopoulos, G. (1985). Returns to education: A further international update and implications. The Journal of Human Resources, 20(4), 583-604. 
Psacharopoulos, G., \& Woodhall, M. (1985). Education for Development: An Analysis of Investment Choices. Oxford: Oxford University Press.

Qizilbash, M. (2011). Sugden's critique of Sen's capability approach and the dangers of libertarian paternalism. International Review of Economics, 58(1), 21-42.

Qureshi, M. A. (2008). Challenging trickle-down approach: Modelling and simulation of public expenditure and human development - The case of Pakistan. International Journal of Social Economics, 35(4), 269-282.

Rahnema, M. (Ed.). (1997). The Post-Development Reader/ compiled and introduced by Majid Rahnema with Victoria Bawtree. New Jersey: Zed Books.

Rathgeber, E. M. (1990). WID, WAD, GAD: Trends in research and practice. The Journal of Developing Areas, 24(4), 489-502.

Ravallion, M. (1995). Growth and poverty: Evidence for developing countries in the 1980s. Economics Letters, 48(3-4), 411-417.

Razavi, S., \& Miller, C. (1995). From WID to GAD: Conceptual Shifts in the Women and Development Discourse. Paper presented at the United Nations Research Institute for Social Development, Fourth World Conference on Women, Geneva.

Reay, D. (2004). 'It's all becoming a habitus': Beyond the habitual use of Habitus in educational research. British Journal of Sociology of Education, 25(4), 431-444.

Renzetti, C., \& Lee, R. M. (1993). The problem of researching sensitive topics: An overview and introduction. In C. Renzetti \& R. M. Lee (Eds.), Researching Sensitive Topics (pp. 3-13). Newbury Park, CA: Sage.

Reserve Bank of New Zealand. (2012). Gross Domestic Product (GDP) Retrieved 10 October 2012, from http://www.rbnz.govt.nz/challenge/resources/2970599.html

Robeyns, I. (2005). The capability approach: A theoretical survey. Journal of Human Development, 6(1), 93-114.

Romer, P. M. (1986). Increasing returns and long-run growth. Journal of Political Economy, 94(5), 1002-1037.

Romer, P. M. (1987). Growth based on increasing returns due to specialization. The American Economic Review, 77(2), 56-62. 
Romer, P. M. (1990). Endogenous technological change. Journal of Political Economy, 98(5), S71-S102.

Roper, B. (2005). Prosperity for All? Economic, Social and Political Change in New Zealand Since 1935. Southbank, Victoria, Australia: Thomson.

Roper, B. (2008). The welfare state: Origins, development, crisis and redesign. In B. N. Lunt, M. O’Brien \& R. Stephens (Eds.), New Zealand, New Welfare. Melbourne: Cengage.

Rose, G. (1997). Situating knowledges: positionality, reflexivities and other tactics. Progress in Human Geography, 21(3), 305-320.

Rosenthal, G. (2003). The healing effects of storytelling: On the conditions of curative storytelling in the context of research and counseling. Qualitative Inquiry, 9(6), 915933.

Roulston, K. (2001). Data analysis and 'theorizing as ideology'. Qualitative Research, 1(3), 279-302.

Rudd, C. (1993). The welfare State: Origins, developments and crisis. In B. Roper \& C. Rudd (Eds.), State and Economy in New Zealand. Auckland: Oxford University Press.

Schafer, J., Caetano, R., \& Clark, C. L. (1998). Rates ofiIntimate partner violence in the United States. American Journal of Public Health, 88(11), 1702-1704.

Schultz, T. P. (1993). Returns to women's education. In E. M. King \& M. A. Hill (Eds.), Women's Education in Developing Countries: Barriers, Benefits and Policies (pp. 51-99). Washington: World Bank.

Schultz, T. P. (2002). Why governments should invest more to educate girls. World Development, 30(2), 207-225.

Schultz, T. W. (1961). Education and economic growth. In N. B. Henry (Ed.), Social Forces Influencing American Education. Chicago: University of Chicago Press.

Scott, A., \& Foster, M. (2008). Gender, technology and livelihoods. In V. Desai \& R. Potter (Eds.), The Companion to Development Studies (pp. 369-377). London: Hodder Education.

Scott, J., \& Marshall, G. (2005). Oxford Dictionary of Sociology. New York: Oxford University Press. 
Sen, A. (1979). Equality of What? The Tanner Lecture on Human Values. Delivered at Stanford University, May 221979.

Sen, A. (1997). Editorial: Human capital and human capability. World Development, 25(12), 1959-1961.

Sen, A. (1999). Development as Freedom. New York: Knopf.

Shepherd, A. (1999). Evaluation of DFID Support to Poverty Reduction. Lessons from the Evaluation of a Bi-Lateral Aid Programme. Paper presented at the World Bank Conference on Evaluation and Poverty Reduction, June 14-15, Washington, DC.

Singal, N., Jeffery, R., Jain, A., \& Sood, N. (2009). With Education You Can Do Anything; Without education There's Nothing You Can Do. RECOUP Working Paper Series 24. Research Consortium on Educational Outcomes and Poverty. University of Cambridge. Cambridge. Retrieved from http://recoup.educ.cam.ac.uk/publications/workingpapers.html

Singley, S., \& Callister, P. (2002). Work poor or working poor? A comparative perspective on New Zealand's jobless households. Social Policy Journal of New Zealand, 20, 134155.

Sissel, P. A., Hansman, C. A., \& Kasworm, C. E. (2001). The politics of neglect: Adult learners in higher education. New Directions for Adult and Continuing Education, 2001(91), 17-28.

Slater, G. (2009). The development of adult and community education policy in New Zealand: insights from Popper. Journal of Education Policy, 24(6), 697-716.

Smith, D. M. (2008). Responsibility to distant others. In V. Desai \& R. Potter (Eds.), The Companion to Development Studies (pp. 129-132). London: Hodder Education.

Smulovitz, C., \& Peruzzotti, E. (2000). Societal accountability in Latin America. Journal of Democracy, 11(4), 147-158.

Snively, S. (1994). The New Zealand Economic cost of Family Violence. Wellington, New Zealand: Department of Social Welfare.

St Clair, R., Kintrea, K., \& Houston, M. (2011). The Influence of Parents, Places and Poverty on Educational Attitudes and Aspirations. York, United Kingdom: Joseph Rowntree Foundation.

St John, S. (2008). Working for families: Work, families and poverty. In B. N. Lunt, M. O'Brien \& R. Stephens (Eds.), New Zealand, New Welfare. Melbourne: Cengage. 
Statistics New Zealand. (2005). Focusing on Women 2005. Wellington, New Zealand.

Statistics New Zealand. (2006a). Disability and the Labour Market in New Zealand 2006. Wellington: Statistics New Zealand.

Statistics New Zealand. (2006b). Disability Survey 2006. Wellington: Statistics New Zealand.

Staudt, K. (2008). Women and the state. In V. Desai \& R. Potter (Eds.), The Companion to Development Studies (pp. 343-346). London: Hodder Education.

Steensland, B. (2006). Cultural categories and the American welfare state: The case of guaranteed income policy. American Journal of Sociology, 111(5), 1273-1326.

Stephens, R. (2008). The changing social security system. In B. N. Lunt, M. O’Brien \& R. Stephens (Eds.), New Zealand, New Welfare. Melbourne Cengage.

Stevens, S. (2001). Fieldwork as commitment. Geographical Review, 91(1-2), 66-73.

Stromquist, N. P. (1989). Determinants of educational participation and achievement of women in the Third World: A review of the evidence and a theoretical critique. Review of Educational Research, 59(2), 143-183.

Stromquist, N. P. (1990). Women and illiteracy: The interplay of gender subordination and poverty. Comparative Education Review, 34(1), 95-111.

Sugden, R. (1993). Welfare, resources, and capabilities: A review of inequality reexamined by Amartya Sen. Journal of Economic Literature, 31(4), 1947-1962.

Sultana, F. (2007). Reflexivity, positionality and participatory ethics: Negotiating fieldwork dilemmas in international research. ACME: An International E-Journal for Critical Geographies, 6(3), 374-385.

Sutch, W. B. (1966). The Quest for Security in New Zealand, 1940-1966. Wellington: Oxford University Press.

Sutch, W. B. (1969). Poverty and Progress in New Zealand; A Reassessment. Wellington: Reed.

Sweetland, S. R. (1996). Human capital theory: Foundations of a field of inquiry. Review of Educational Research, 66(3), 341-359. 
Taylor, C. (1993). Explanation and practical reason. In M. Nussbaum \& A. Sen (Eds.), The Quality of Life (pp. 208-231). Oxford: Clarendon Press.

Taylor, P. (1993). The Texts of Paulo Freire Buckingham and Philadelphia: Open University Press.

TEAC. (2001). July, Third Report: Shaping the Strategy. Wellington: TEAC.

TEC. (2005). A Funding Framework for Adult and Community Education: Consultation Document. Wellington: TEC.

Thomas, S. (1991). The impact of women on state legislative policies. Journal of Politics, 53(4), 958-976.

Thorsen, D. E., \& Lie, A. (2006). What is neoliberalism? Department of Political Science: Norway: University of Oslo.

Till, K. E. (2001). Returning home and to the field. Geographical Review, 91(1/2), 46-56.

Tobias, R. (1996). What do adult and community educators share in common? In J. Benseman, B. Findsen \& M. Scott (Eds.), The Fourth Sector: Adult and Community Education in Aotearoa, New Zealand (pp. 38-64). Palmerston North: The Dunmore Press.

Tobias, R. (2002). Reflections on policy in adult education and community learning (ACE), with reference to Koia! Koia! Towards a Learning Society. New Zealand Journal of Adult Learning, 30(1), 7-22.

Toporowski, J. (1993). Housing as a wage and luxury good: absolute poverty and the distribution of income in supply-side economics. International Review of Applied Economics, 7(3), 330-344.

Toulmin, C., \& Quan, J. (2000). Introduction. In C. Toulmin \& J. Quan (Eds.), Evolving Land Rights, Policy and Tenure in Africa (pp. 1-30). London: IIED.

Tout, D. (2007). ALLS survey update : initial messages regarding. Literary Link, 27(4), 1112.

True, J. (1996). “Fit citizens for the British Empire?”: Class-ifying racial and gendered subjects in "Godzone" (New Zealand)'. In B. Williams (Ed.), Women out of place: The gender of agency and the race of nationality. London: Routledge. 
UNESCO. (1960). Convention against Discrimination in Education. Paris, France: UNESCO.

UNESCO. (1997). The Hamburg Declaration on Adult Learning, Fifth International Conference on Adult Education. Hamburg: UNESCO.

UNESCO. (2000). The Dakar Framework for Action 2000, World Education Forum. Paris: UNESCO.

UNESCO. (2011). UNESCO and Education Retrieved 01 October 2012, from http://www.unesco.org/new/en/education/

UNESCO. (2012). EFA Global Monitoring Report 2012: Youth and Skills - Putting Education to Work. Paris: UNESCO.

United Nations. (1948). The Universal Declaration of Human Rights: adopted and proclaimed by General Assembly resolution 217 A (III) of 10 December 1948.

United Nations. (1966). International Covenant on Economic, Social and Cultural Rights, . New York: United Nations.

United Nations. (2012). The Millennium Development Goals Report 2012. New York: United Nations.

United Nations Development Programme. (1990). Human Development Report. New York: UNDP.

United Nations Development Programme. (2011). "Sustainability and Equity: A Better Future for All". New York: UNDP.

United Nations Development Programme. (2012). Goal 3, Promote gender equality and empower women. The Millennium Development Goals Eight Goals for 2015, Retrieved 08 October 2012, from http://www.undp.org/content/undp/en/home/mdgoverview/mdg_goals/mdg3/

United Nations Girls' Education Initiative. (2012). Gender Analysis in Education: A Conceptual Overview. New York: UNICEF.

United Nations Population Fund. (2012). Empowering Women through Education, Retrieved 03 October, 2012, from http://www.unfpa.org/gender/empowerment2.htm 
United Nations Statistics Division. (2011). Composition of Macro Geographical (Continental) Regions, Geographical Sub-Regions, and Selected Economic and Other Groupings. New York: United Nations.

Waring, M. (1988). Counting for Nothing: What Men V alue and What Women are Worth. Wellington: Allen \& Unwin.

Waring, M. (1997). The Invisibility of women's work: The economics of local and global "bullshit". Canadian Woman Studies, 17(2), 1-8.

Waring, M. (2010). Women's Political Participation Retrieved 03 October 2012, from http://www.marilynwaring.co.nz/130393 1 .pdf

Weiler, K. (1996). Myths of Paulo Freire. Educational Theory, 46(3), 353-371.

Whitty, G., Power, S., \& Halpin, D. (1998). Devolution and Choice in Education. Buckingham: Open University Press.

Willmore, L. (2004). Basic education as a human right. Economic Affairs, 24(4), 17-21.

World Bank. (1990). World Development Report 1990: Poverty. Washington: World Bank.

World Bank. (2008). The Growth Report: Strategies for Sustained Growth and Inclusive Development. Washington: World Bank on behalf of Commision on Growth and Development.

Yin, R. K. (1981a). The case study as a serious research strategy. Science Communication, 3(1), 97-114.

Yin, R. K. (1981b). The case study crisis: Some answers. Administrative Science Quarterly, 26(1), 58-65.

Yngstrom, I. (2002). Women, wives and land rights in Africa: Situating gender beyond the household in the debate over land policy and changing tenure systems. Oxford Development Studies, 30(1), 21-39.

Yodanis, C. L., Godenzi, A., \& Stanko, E. A. (2000). The benefits of studying costs: A review and agenda for studies on the economic costs of violence against women. Policy Studies, 21(3), 263-276.

Young, K. (2008). WID, GAD and WAD. In V. Desai \& R. Potter (Eds.), The Companion to Development Studies (2nd ed., pp. 321-324). London: Hodder Education. 
Zajda, J. (2006). Introduction: Decentralisation and privatisation in education: The role of the state. In J. Zajda (Ed.), Decentralisation and Privatisation in Education (pp. 3-27): Springer Netherlands.

Zepke, N. (2009). A future for adult lifelong education in Aotearoa New Zealand: neoliberal or cosmopolitan? International Journal of Lifelong Education, 28(6), 751-761. 


\section{Appendices}

\section{Appendix A: Participant Interview: Information Sheet}

Participation Information Sheet for research into barriers to adult education amongst lower socioeconomic Pākehā women in Wellington, New Zealand

\section{Researcher:}

Lynette Cochrane: School of Geography, Environment and Earth Sciences, Development Studies Programme, Victoria University of Wellington.

I am a masters student in the Department of Development Studies at the Victoria University of Wellington. As part of the fulfilment of this degree, I am undertaking a research thesis. The thesis that I am undertaking will examine what are the barriers to adult education within a New Zealand context; investigation to include government education policies, societal, family and personal influences.

The University requires that ethics consent be obtained for research involving human participants. In this study I am inviting Pākehā women who reside in Wellington of lower socioeconomic means to participate. All participants will be interviewed through semistructured interviews.

Interviews will be taped and transcribed for use as both attributable and non-attributable comments in the research. Participants will have the opportunity to review their transcript if they wish and such revision should take place within a month of receiving the transcript. A reply paid envelope will be supplied for the edited version to be sent back. No person other than my supervisor Professor John Overton and myself will see the fully transcribed material. If you do not wish to be personally identified in the final report please indicate so on the consent form.

If you would like to withdraw from the project, you may do so at any time prior to the 31 st January 2013 when data collection is due to be completed. Please email me at lynette.cochrane@vuw.ac.nz and any related material will be destroyed.

The responses collected will form the basis of my research project and will be put into a written report. The report will be submitted to the School of Earth Sciences for marking and deposited in the University Library. The collected, collated, and analysed data may be published in case studies, academic journals, and/or presented at conferences. All material collected will be kept confidential, only myself and my supervisor, Professor John Overton will see this material. The material will be stored securely and destroyed 5 years after the completion of this project. This project has ethics approval from the Victoria University Human Ethics Committee.

If you have any questions or require further information on the project, please feel free to contact me at lynette.cochrane@vuw.ac.nz or my supervisor, Professor John Overton at the School of School of Geography, Environment and Earth Sciences, Victoria University, PO Box 600, Wellington, email john.overton@vuw.ac.nz. My contact phone number is (04) 463 5233 extension 8403.

The consent form is attached, please return it to me. Thank you for your time.

Yours sincerely,

Lynette Cochrane

School of Geography, Environment and Earth Sciences, Development Studies Programme

Victoria University of Wellington 


\section{Appendix B:}

\section{Consent for Participation in Research}

Project Title: Barriers to adult education amongst lower socioeconomic Pākehā women in Wellington, New Zealand

I have been given an explanation and have understood this research project. I have had the opportunity to ask questions and have them answered to my satisfaction. I understand that I may withdraw myself (or any information I have provided) from this project (before data collection is completed by 31 January 2013) without having to give any reason.

I agree to have the interview recorded and understand that the recording will be held for a period of up to 5 years, after which it will be destroyed or electronically wiped. I understand that full interview transcripts will be kept confidential to the researcher and supervisor.

I understand that I will have the opportunity to check the transcripts and any attribution quotes before publication.

I would like to receive a copy of the transcript when it is completed.

Please circle Yes / No.

I would like to receive a summary of the results of this research when it is completed.

Please circle Yes / No.

Please select how you would like to receive information about the research if you have chosen to have the transcript and/or the summary results of the research sent to you:

$\square$ Hard copy: Please complete address details if you prefer a hard copy of the transcript and/or summary results

Name:

Address:

Electronic copy: Please complete email details if you prefer an electronic copy of the transcript and/or summary results

Email:

Please indicate if you do not wish to be personally identified in the final report by ticking one of the boxes below;

No, please do not personally identify me in the final report

Yes, I agree to the research personally identifying me in the final report

I agree to take part in this research.

Signed:

Name of Participant:

(Please print clearly)

Date: 
Appendix C:

\section{Informal complaint procedure: Information Sheet}

Information Sheet for interview participants taking part in the research into barriers to adult education amongst lower socioeconomic Pākehā women in Wellington, New Zealand

\section{Researcher:}

Lynette Cochrane: School of Geography, Environment and Earth Sciences, Development Studies Programme, Victoria University of Wellington.

\section{Participants:}

Pākehā women who identify themselves as low income with no formal education qualifications.

\section{Procedure to voice concerns arising from the interview:}

If you have any concerns about the interviewer or the interview, please raise your concerns in the first instance to a member of staff at the organisation where you saw the flyer asking for interview participants. They will in turn pass on to either my supervisor or myself any concerns, they feel should be brought to the interviewer's attention.

Thank you for your time.

Yours sincerely,

Lynette Cochrane

School of Geography, Environment and Earth Sciences, Development Studies Programme Victoria University of Wellington 


\section{Appendix D:}

\section{Information Sheet:}

\section{Research into barriers to adult education amongst lower socioeconomic Pākehā women in Wellington, Aotearoa/New Zealand}

\section{Introduction}

This briefing sheet is to provide you with information about my research project.

My name is Lynette Cochrane and I am a masters student in the Department of Development Studies at the Victoria University of Wellington. As part of the fulfilment of this degree, I am undertaking a research thesis. The thesis that I am undertaking will examine what are the barriers to adult education within a New Zealand context. To ascertain this information I will be conducting a small number of confidential interviews. This research project has ethics approval from the Victoria University Human Ethics Committee (approval number 19454, date 03.09.2012).

\section{Purpose of the research}

For this project I wish to examine and understand the issues of lower socioeconomic Pākehā women in relation to adult education and to give them a voice in regards to this issue.

A further and important benefit to New Zealand society will be to invite further debate on poverty in this country.

\section{Participant Selection}

In this study I am inviting adult Pākehā women who reside in Wellington of lower socioeconomic means with few or no formal education qualifications to participate. All participants will be interviewed through semi-structured interviews.

\section{Voluntary Participation}

Participation in this research is entirely voluntary and participants can withdraw at any time.

\section{Procedures}

Confidential interviews will be taped and transcribed for use in the research. Interviews will be held at time and place that is suitable to the participant. Participants will be required to sign a consent form prior to be interviewed.

\section{Contact details}

My supervisor for this research project is Professor John Overton. Professor Overton may be contacted on email john.overton@vuw.ac.nz or at the School of Geography, Environment and Earth Sciences, Victoria University of Wellington, PO Box 600, Wellington.

My contact phone numbers are (04) 4635233 extension 8403 or 0221668727.

If you have any further questions at any time please contact me at lynette.cochrane@vuw.ac.nz

Yours sincerely,

Lynette Cochrane

School of Geography, Environment and Earth Sciences, Development Studies Programme Victoria University of Wellington 
Appendix E:

\section{Pākehā Women - An invitation to have your voice heard!!!}

Hi, I am Lynette. I am a Master's student at Victoria University and I am seeking participants to take part in a research project.

This project is interested in the education experiences of low income Pākehā Women.

The research will take the form of one confidential interview approximately 45-60 minutes long.

If you identify yourself as a low income adult Pākehā woman with few or no formal education qualifications, your participation would be greatly appreciated.

If you are interested in volunteering I would like to talk to you and for your time you will receive a \$15 Pak 'n' Save voucher!!!

Please register your interest at the email address or via one of the phone numbers listed on the tear-off in order for me to arrange a time and place to meet that suits you.
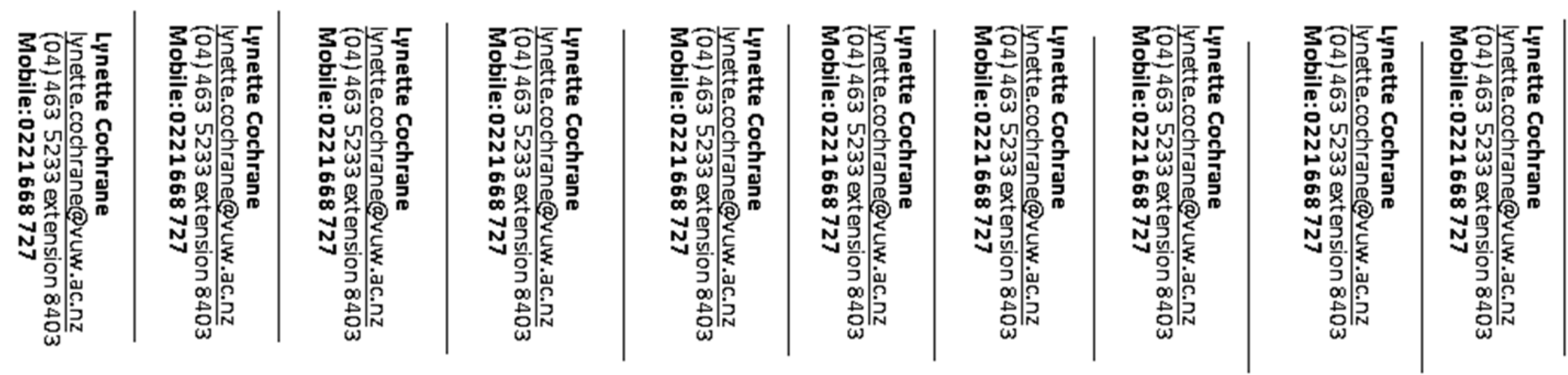


\section{Appendix F}

\section{$\underline{\text { Interview Questions }}$}

Tell me about yourself, where were you born, how old are you, do you have family and/or children?

1. What level of formal education do your parents have?

2. How does your family view education?

3. How old were you when you left school?

4. Can you tell me about your own experiences at school?

5. What were the reasons why you left school?

6. How did you make the choice to leave school?

7. If you could turn back time, would you have stayed longer at school? If so why?

8. In your mind what does educated look like?

9. In your mind what does uneducated look like or mean?

My next question is about society perceptions

10. How do you think society views (perceives) people without formal educational qualifications?

a. Have you felt any of these perceptions?

My next questions are about adult education

11. Have you tried to seek out adult education classes?

a. Can you tell me about the positive and negative aspects of that experience?

12. Why would you take up or not take up adult education? 